NUREG/CR-6774

ANL-01/34

\title{
Validation of Failure and Leak Rate Correlations for Stress Corrosion Cracks in Steam Generator Tubes
}

Manuscript Completed: December 2001

Date Published:

Prepared by

Saurin Majumdar, Sasan Bakhtiari, Ken Kasza, and Jang Yul Park

Energy Technology Division

Argonne National Laboratory

9700 South Cass Avenue

Argonne, IL 60439

J. Muscara, NRC Project Manager

Prepared for

Division of Engineering

Office of Nuclear Reactor Research

U. S. Nuclear Regulatory Commission

Washington, DC 20555 
NRC JCN W6487 



\begin{abstract}
This report summarizes models for the prediction of failure pressures and leak rates under normal operation and design-basis accident conditions in steam generator tubes with axial and circumferential cracks. These models were first validated through failure and leak rate tests at room temperature and at $282^{\circ} \mathrm{C}$ on tubes with rectangular, triangular, and trapezoidal notches fabricated by electrodischarge machining. They were then compared with failure and leak rate tests conducted on tubes with laboratory-generated outer-diameter stress corrosion cracks and steam generator tubes with fieldinduced stress corrosion cracks, which have highly complex morphology. Complex crack profiles are addressed using a model based on the concept of equivalent rectangular cracks. The predictions of the models are in reasonable agreement with test results, the time-dependent initiation and increase of leak rates observed in some tests cannot be predicted by the model.
\end{abstract}




\section{Contents}

Abstract ....

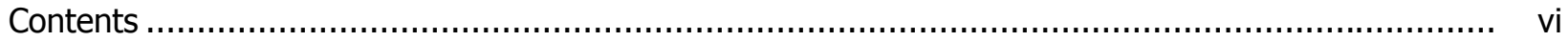

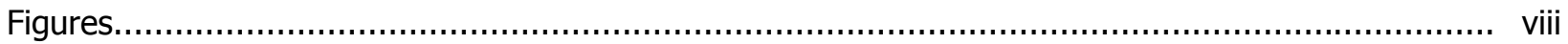

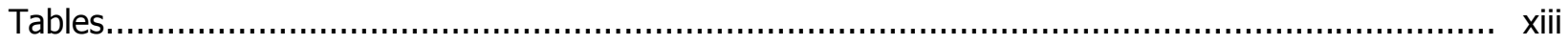

Executive Summary

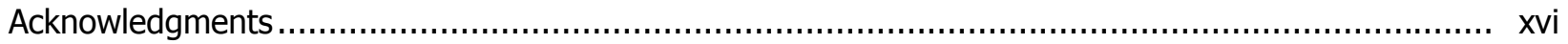

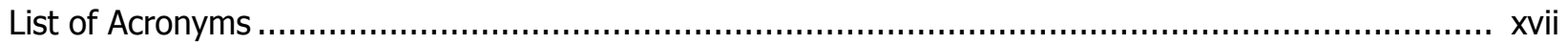

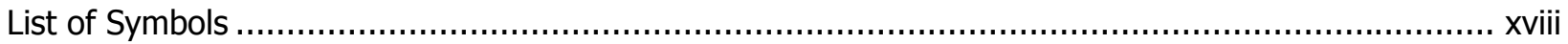

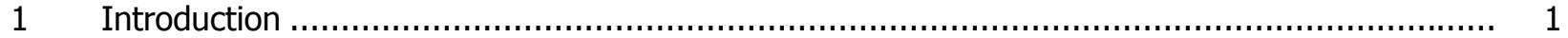

2 Failure and Leak Rate Models Applicable to Normal Operation and Design-Basis Accident

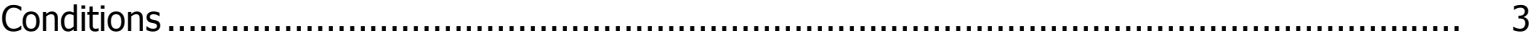

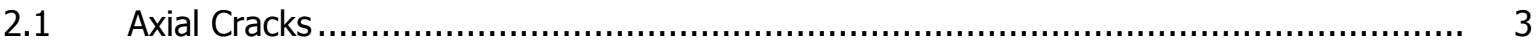

2.1.1 Throughwall Rectangular Axial Cracks ................................................... 3

2.1.2 Part-Throughwall Rectangular Axial Cracks............................................. 7

2.1.3 Equivalent Rectangular Crack .......................................................... 10

$2.2 \quad$ Circumferential Cracks ........................................................................... 18

2.2.1 Throughwall Circumferential Cracks ................................................... 18

2.2.2 Part-Throughwall Circumferential Cracks.............................................. 19

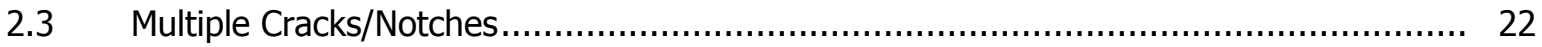

2.3.1 Two Throughwall Axial Cracks/Notches ............................................ 22

2.3.2 Two Part-Throughwall Axial Cracks/Notches........................................ 27

2.3.3 Multiple Part-Throughwall Notches ……………................................. 29

$2.4 \quad$ Leak Rate Model ........................................................................................ 33

$2.5 \quad$ Leak Rate Tests on EDM Notches ................................................................ 33

2.5.1 Rectangular Notches.................................................................... 33

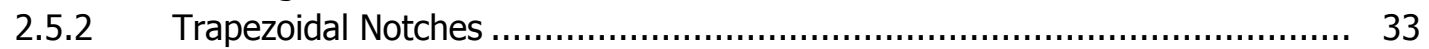

$3 \quad$ Pressure and Leak Rate Tests on Stress Corrosion Cracks.................................................. 34

3.1 Analysis of Tests on Laboratory-Generated SCC ................................................ 35

3.1.1 Specimens with High Temperature Annealing ........................................ 35

3.1.2 Specimens without High Temperature Annealing................................... 40

3.2 Analysis of Tests on McGuire Steam Generator Tubes ........................................... 43

$4 \quad$ Jet Erosion under Design Basis Accident Conditions .................................................... 49

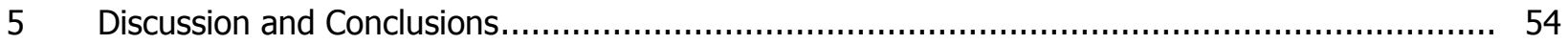


References. 


\section{Figures}

1. Observed vs. predicted unstable burst pressures for tubes with throughwall EDM and laser-cut notches using (a) $k=0.55$ and (b) $k=0.595$.

2. Predicted vs. observed variation of unstable burst pressure with notch length of Heat M90 tubes with TW axial EDM notches.

3. Measured vs. calculated COD as a function of pressure for a 38-mm (1.5-in.)-long TW notch with $2.4-\mathrm{mm}(3 / 32-$ in. $)$-thick bladder and $0.15-\mathrm{mm}$ (6-mils)-thick brass foil..

4. Calculated and experimental variation of COD with pressure for various notch lengths in a Type 316 stainless steel tube at room temperature.

5. (a) Variation of observed failure pressures divided by predicted failure pressures and (b) variation of the mean and standard deviation of the observed failure pressure divided by predicted failure pressure.

6. Observed vs. predicted ligament rupture pressures for tubes with EDM notches using (a) $\mathrm{k}=0.55$ and $\beta=1$ and $(\mathrm{b}) \mathrm{k}=0.595$ and $\beta=0.83$.

7. Predicted vs. observed unstable burst pressures of M100 tubes with PTW and TW rectangular notches.

8. Determination of equivalent rectangular crack

9. Predicted versus observed (a) ligament rupture pressures and (b) unstable burst pressures for ANL tests on specimens with trapezoidal notches.

10. Typical geometries of (a) symmetrical triangular and trapezoidal notches and (b) asymmetrical triangular notch tested by Woods.

11. Predicted vs. observed burst pressures for triangular and trapezoidal notch specimens.

12. (a) Predicted vs. observed COD and (b) fitted TW crack length needed to match the measured COD vs. predicted TW crack length for specimen E.

13. (a) Predicted vs. observed COD and (b) fitted TW crack length needed to match the measured COD vs. predicted TW crack length for specimen F.

14. (a) Predicted vs. observed COD and (b) fitted TW crack length needed to match the measured COD vs. predicted TW crack length for specimen $\mathrm{G}$ 
15. (a) Predicted vs. observed COD and (b) fitted TW crack length needed to match the measured COD vs. predicted TW crack length for specimen $\mathrm{H}$.

16. (a) Predicted vs. observed COD and (b) fitted TW crack length needed to match the measured COD vs. predicted TW crack length for specimen J.

17. (a) Predicted vs. observed COD for specimens with rectangular and triangular notches with average depth 50\% and with OD lengths (a) $6 \mathrm{~mm}$ [0.25 in.] and (b) $38 \mathrm{~mm}$ [1.5 in.].

18. Engineering and true stress-strain curves of Alloy 600 used for finite element analysis.

19. Calculated variations of average hoop stress, average von Mises effective stress, and average hoop plastic strain in the axial ligament with pressure using (a) infinitesimal deformation and (b) finite deformation analyses.

20. Calculated variation of average inter-notch axial ligament thickness with pressure using finite deformation analyses by ANSYS and ABAQUS

21. Variation of average hoop stress, average von Mises effective stress, average thickness plastic strain, and average effective plastic strain in the circumferential ligament with pressure using infinitesimal and finite deformation analyses.

22. Deformed shape of type 4 specimen.

23. Calculated variation of average circumferential ligament thickness with pressure using finite deformation analyses by ANSYS and ABAQUS for two 6-mm (0.25-in.) long axial cracks separated by a $1.3-$ and $2.5-\mathrm{mm}(0.05-$ and $0.1-$ in.) circumferential ligament.

24. Predicted ligament rupture pressures of type 2 and type 4 specimens with two TW axial cracks.

25. Predicted vs. observed variation of ligament rupture pressure with ligament width for type 4 specimens having two $6-$ and $13-\mathrm{mm}$ long TW notches.

26. Variation of COA with pressure and ligament width for (a) two 6-mm and (b) two 13-mm type 2 (colinear) cracks.

27. Variation of COA with pressure and ligament width for (a) two 6-mm and (b) two-13 mm type 4 (staggered) cracks. 
28. Variation of the COA for a crack with ligament normalized by the COA for a crack without ligament for type 2 (colinear) and type 4 (staggered) cracks at two values of pressure.

29. Equivalent rectangular crack for two $13-\mathrm{mm}$ long and $80 \%$ deep PTW notches separated by a $1.27-\mathrm{mm}$ wide ligament.

30. Predicted and observed through-thickness ligament rupture pressures vs. axial or circumferential ligament widths for two PTW EDM notches.

31. Geometries of multiple axial notch specimens.

32. Ligament rupture pressure vs. predicted ligament rupture pressure for multiple laser-cut notches.

33. Specimen with multiple circumferential laser-cut notches

34. Specimens with axial/circumferential laser-cut notches

35. (a) Lgament rupture pressures of $\mathrm{T}-$ and $\mathrm{L}-$ notches with predicted and experimental ligament rupture pressures of a single $13-\mathrm{mm}(0.5-$ in.) long axial notch of various depths, and (b) predicted vs. observed unstable burst pressures for EDM and laser-cut notches of various lengths.

36. Calculated and measured pressure vs. leak rate plots of tests (a) OM-169 and (b) OM171 , both conducted on as-received tubes with rectangular notches at $20^{\circ} \mathrm{C}$.

37. Calculated and measured pressure vs. leak rate plots of tests (a) OM-T32 and (b) OM$\mathrm{T} 34$, both conducted on as-received tubes with trapezoidal notches at $20^{\circ} \mathrm{C}$.

38. (a) Crack depth profiles for specimen SGL-480 measured by pretest EC/NDE and posttest fractography and (b) variation of TW crack length with pressure calculated from crack depth profiles measured by EC/NDE and fractography....

39. (a) Measured (and predicted pressure vs. leak rate plots for Test SGL-480.and (b) posttest view of the OD surface of specimen SGL -480 .

40. (a) Crack depth profiles for specimen SGL-494 measured by pretest EC/NDE and posttest fractography and (b) variation of TW crack length with pressure calculated from crack depth profiles measured by EC/NDE and fractography.

41. (a) Measured (symbols) and predicted (based on EC/NDE and fractography depth data) pressure vs. leak rate plots for Test SGL-494 and (b) posttest view of the OD surface of specimen SGL-494. 
42. (a)Crack depth profiles for specimen SGL-493 measured by pretest EC/NDE and posttest fractography and (b) variation of TW crack length with pressure calculated from crack depth profiles measured by EC/NDE and fractography.

43. (a) Measured and predicted (based on EC/NDE and fractography depth data) pressure vs. leak rate plots for Test SGL-493 and (b) posttest view of the OD surface of specimen SGL-493.

44. Crack depth profiles for specimen SGL-413 measured by pretest EC/NDE and posttest fractography and (b) variation of TW crack length with pressure calculated from crack depth profiles measured by EC/NDE and fractography.

45. (a) Measured and predicted (based on NDE and fractography depth data) pressure vs. leak rate plots for Test SGL-413 and (b) post-test view of the OD surface of specimen SGL-413.

46. (a) Crack depth profiles by EC/NDE and fractography of test SGL-731 and (b) variation of TW crack length with pressure calculated from crack depth profiles measured by EC and fractography

47. Predicted and measured pressure vs. leak rate plots for SGL-731

48. Crack depth profiles by EC/NDE and fractography of test SGL-822.

49. (a) Predicted and measured pressure vs. leak rate plots for specimen SGL-822 conducted at $282^{\circ} \mathrm{C}$ and (b) pressure and leak rate variation observed during test SGL-822.

50. (a) Pretest and posttest (after room-temperature testing) EC/NDE profile of SCC flaw in specimen SGL-876 and (b) observed vs. predicted leak rate curve based on EC/NDE depth profile.

51. Fishmouth burst of specimen SGL-876 during pressurization at $282^{\circ} \mathrm{C}$.

52. Crack depth profiles by EC/NDE and fractography of McGuire tube (a) 7-24-3 and (b) 5$51-2$

53. Crack depth profiles by EC/NDE and fractography of McGuire tube (a) 4-43-2 and (b) 14$55-3$.

54. Crack depth profiles by EC/NDE and fractography of McGuire tube (a) $14-55-5$ and (b) 39-57-3. 
55. Reported (a) yield and (b) ultimate tensile strengths of tubes in McGuire Unit 1 SGs A, B, and $\mathrm{C}$

56. Observed vs. predicted rupture pressures for McGuire SG tubes using reported value of flow stress.

57. Observed and predicted pressure vs. leak rates for McGuire test 4-43.

58. Jet-impact erosion test setup showing circular EDM hole in Alloy 600 tube and Alloy 600 impact specimen fastened by spot-welded straps to the tube with a $6.35-\mathrm{mm}(0.25-\mathrm{in}$.) gap between the jet exit and the impact specimen.

59. Close-up view of $0.79-\mathrm{mm}\left(1 / 32^{-i n}\right.$.) hole from jet-impact specimen after $265 \mathrm{~min}$ of testing at $282^{\circ} \mathrm{C}\left(540^{\circ} \mathrm{F}\right)$ and $17.2 \mathrm{MPa}(2500 \mathrm{psig})$ with $3.7 \mathrm{MPa}$ (530 psig) back pressure.

60. Depth of the erosion zone shown in Fig. 59, as determined using interferometric techniques.

61. Jet erosion penetration depth as a function of water temperature for circular EDM holes.

62. Test results from the literature on flashing as a function of stagnation pressure and subcooling. 


\section{Tables}

1 Room temperature mechanical properties of alloy 600 tubes used for tests on rectangular, triangular, and trapezoidal EDM notches.........................................................

2 Results from pressure and leak rate tests on tubes from McGuire SG.............................

3 Erosion data from jet-impact erosion tests utilizing jets from 1.59-, 0.79-, and 0.40-mm $\left(1 / 16^{-}, 1 / 32-\right.$, and $1 / 64-$ in. $)$-diameter circular EDM holes.

4 Erosion data from jet-impact erosion tests utilizing jets from 0.40-mm (1/64-in.)-diameter circular EDM holes for various water temperatures.

5 Erosion data from jet-impact erosion tests utilizing jets from $0.79 \mathrm{~mm}(1 / 32 \mathrm{in}$.)-diameter circular EDM holes for various water temperatures. 


\section{Executive Summary}

This report summarizes and validates the models used for predicting failure pressures and leak rates in unrepaired steam generator (SG) tubes with axial and circumferential cracks that developed under normal operation and design-basis accident conditions. Failure and leak rate tests have been conducted on SG tubes with outer diameter (OD), part-throughwall, electrodischarge machined (EDM) notches both at room temperature and at $282^{\circ} \mathrm{C}$. Notch length in these tests ranged from $6 \mathrm{~mm}$ ( 0.25 in.) to $38 \mathrm{~mm}$ (1.5 in.), and notch depths of 60,80 , and $90 \%$ (in addition to $100 \%$ throughwall) were tested.

Extensive tests on rectangular as well as trapezoidal and triangular part-throughwall flaws were conducted to derive a correlation for predicting ligament rupture pressure of tubes with axial notches, either shallow or deep.

A procedure for defining an equivalent rectangular crack for an arbitrarily shaped notch or crack (e.g., ODSCC), based on multiparameter analysis of eddy current data from a rotating pancake coil, has been developed. Structural and leak rate analyses of the flaws and comparison with experimental data have shown that the ligament failure pressure in nonrectangular notches or SCCs can be predicted reasonably well. These predictions were made with a flow stress model that is strictly applicable to rectangular part-throughwall cracks, in which the actual crack profile was replaced by an equivalent rectangular crack.

Interaction effects between two or more throughwall notches as influenced by ligaments separating the notches were analyzed by finite element analyses. It was found that for type 4 (staggered) axial notches with two 6- or 13- $\mathrm{mm}$ cracks, the ligament width has to be $\geq 0.8$ to $1.1 \mathrm{~mm}$ in order for their strength (i.e., unstable burst pressure) to exceed that of notches without the ligament. For type 2 (colinear) notches of similar size, the ligament width has to be greater than 1.8 to $2.5 \mathrm{~mm}$ to strengthen the notches in comparison to the strength without the ligament.

Interaction effects between two or more part-throughwall notches were estimated by the equivalent rectangular crack approach. The inter-notch ligament width beyond which the two notches do not interact (from the viewpoint of pressure for through-thickness ligament rupture) depends on the notch depth as well as notch length. A 3-mm wide ligament increases the through-thickness ligament rupture pressure by $\approx 30 \%$, with the axial ligament (type 2 ) having a slightly higher strengthening effect than the circumferential ligament (type 4). For smaller ligament widths, both types of ligaments have a comparable strengthening effect.

An empirical approach for calculating crack growth by stable ligament rupture has been developed by an extension of the equivalent rectangular crack method. The approach has been used to calculate the incremental ligament rupture of nonrectangular notches as well as stress corrosion cracks.

Leak rates for tests on specimens with EDM notches were predicted reasonably well by using the well-known formula for single-phase flow through smooth circular orifices by replacing the orifice area by the crack opening area. The calculated crack opening displacements (areas) for rectangular and trapezoidal throughwall notches were in reasonable agreement with measured values. In tests conducted to date, the equations have predicted the ligament rupture pressures and leak rates for rectangular and trapezoidal EDM notches at both room temperature and $282^{\circ} \mathrm{C}$ when the appropriate 
densities of water were used. The limit of applicability for the leak rate equation at $282^{\circ} \mathrm{C}$ has not been established yet.

Tests have been performed on laboratory-degraded tubes containing axial ODSCCs that are 10$15 \mathrm{~mm}$ (0.39-0.55 in.) long in 22-mm (7/8-in.)-diameter Alloy 600 tubing. Some of the tubes had lower flow stress because they had been subjected to high temperature annealing. The predicted ligament rupture pressures and leak rates for these specimens, based on the depth profile determined by fractography, were in reasonable agreement with test results. Predictions based on eddy current (EC) nondestructive evaluation (NDE) profiles were less accurate than those based on fractography. Prediction of rupture pressure and leak rate on specimens without the high temperature annealing was less successful for the tests at $282^{\circ} \mathrm{C}$, because they start leaking at very low pressures and experience a time-dependent increase of leak rate under constant pressure hold. Currently, we do not have analytical or empirical methods for predicting time-dependent crack growth at such a low temperature.

Six pressure tests have been conducted on tubes with field-induced ODSCCs from a retired McGuire SG in the high pressure test facility at room temperature. Due to the shallow depth of these flaws, four of them did not show any leakage up to a pressure of $52 \mathrm{MPa}(7.5 \mathrm{ksi})$. The predicted rupture pressures (based on heat-specific flow stresses from the mill certifications) for these tubes are consistent with the observed behavior.

Overall, the success in predicting ligament rupture pressures and leak rates of SCCs has been somewhat uneven. Generally, the predictions calculated on the basis of depth profiles measured by fractography are in better agreement with test results than the predictions based on crack profiles obtained by analysis of EC/NDE data. Nonetheless, the predictions based on multiparameter analysis of EC rotating-pancake-coil data are encouraging.

During normal operation or under design basis accident conditions, fluid jets from flawed SG tubes could produce damage in adjacent tubes through two basic erosion damage mechanisms, droplet impact and cavitation. In the case of jets comprised of water droplets, the impacts of the droplets give rise to fluctuating stresses in the target, which produce fatigue damage. In the case of cavitation, bubbles form in the liquid stream and then collapse on impact, again producing fluctuating stresses and fatigue in the target. Tests has been conduced to determine the susceptibility of steam generator tubes to erosive damage from impacting jets of superheated water or steam leaking from adjacent tubes.

The tests show that impact erosion depth varies with water temperature. The peak erosion rates occur for subcooling typical of the cold leg, where, however, cracking is much less likely to occur. Erosion rates are much lower for conditions more typical of the hot leg. However, even in the case of the cold leg where the erosion rates are the highest, the likelihood of failure propagation by jet erosion appears to be very low. 


\section{Acknowledgments}

Helpful discussions with Dr W. J. Shack of Argonne National Laboratory are acknowledged. Thanks are also due to J. Franklin and L. Knoblich of Argonne National Laboratory for their help in conducting the tests. This work is sponsored by the Office of Nuclear Regulatory research, U.S. Nuclear Regulatory Commission, under Job Code W6487; Project Manager Dr. J. Muscara. 


\section{List of Acronyms}

ANL

ASME

COA

COD

EC

EDM

FEA

ID

MSLB

NDE

NO

NRC

OD

ODSCC

PNNL

PSI

PTW

PWR

RPC

RT

SCC

SG

TSP

TW

UTS
Argonne National Laboratory

American Society of Mechanical Engineers

Crack opening area

Crack opening displacement

Eddy current

Electrodischarge machining

Finite-element analysis

Inner diameter

Main steam line break

Nondestructive evaluation

Normal operation

(U.S.) Nuclear Regulatory Commission

Outer diameter

Outer diameter (secondary water) stress corrosion cracking

Pacific Northwest National Laboratory

Paul Scherrer Institute

Part-throughwall

Pressurized water reactor

Rotating pancake coil

Room temperature

Stress corrosion cracking

Steam generator

Tube support plate

Throughwall

Ultimate tensile strength 


\section{List of Symbols}

\begin{tabular}{ll} 
A & crack opening area \\
$\mathrm{a}$ & crack depth \\
$\mathrm{B}, \mathrm{C}$ & constants \\
$\mathrm{C}, \mathrm{C}_{\mathrm{e}}$ & half crack length and half effective crack length \\
$\mathrm{D}$ & hydraulic diameter \\
$\mathrm{d}$ & notch depth \\
$\mathrm{E}$ & Young's modulus \\
$\mathrm{F}_{,} \mathrm{F}_{\mathrm{m}}$ & constants \\
$\mathrm{h}$ & wall thickness \\
$\mathrm{k}$ & constant for defining flow stress \\
$\mathrm{L}$ & flow path length \\
$\mathrm{m}$ & bulging factor (or exponent for defining stress-strain curve) \\
$\mathrm{m}_{\mathrm{p}}$ & ligament stress magnification factor \\
$\mathrm{n}$ & number of cracks \\
$\mathrm{p}$ & pressure \\
$\mathrm{P}_{\mathrm{b}}, \mathrm{p}_{\mathrm{cr}}$ & unstable burst pressures for unflawed and flawed tubes \\
$\mathrm{P}_{\mathrm{sc}}$ & pressure to cause ligament rupture \\
$\mathrm{Q}$ & leak rate \\
$\mathrm{R}, \mathrm{R}_{\mathrm{O}}, \mathrm{R}_{\mathrm{i}}$ & mean radius (or radius of curvature), outer radius, and inner radius of tube \\
$\mathrm{S}_{\mathrm{y}}, \mathrm{S}_{\mathrm{u}}$ & yield and ultimate tensile strengths \\
$\mathrm{T}$ & temperature \\
$\mathrm{t}$ & time \\
$\mathrm{V}_{\mathrm{O}}$ & constant \\
$\beta$ & constant and angle defining location of neutral axis \\
$\Delta \mathrm{p}$ & pressure differential \\
$\Delta \mathrm{p}_{\mathrm{no}}$ & pressure differential during normal operation \\
$\Delta \mathrm{p}_{\mathrm{MSLB}}$ & pressure differential during main steam line break \\
$\lambda$ & constant \\
$v$ & Poisson's ratio \\
$\rho$ & density of water \\
$\sigma$ & stress, hoop stress \\
$\sigma$ & flow stress \\
$\sigma_{\mathrm{A}}$ & axial stress \\
$\sigma_{\mathrm{lig}}$ & ligament stress \\
$\sigma_{\mathrm{y}}, \sigma_{\mathrm{u}}$ & yield and ultimate tensile strengths \\
$\theta$ & half circumferential crack angle \\
& \\
\hline &
\end{tabular}




\section{Introduction}

For typical unflawed steam generator (SG) tubes made of Alloy 600 , the burst pressure, $\mathrm{p}_{\mathrm{b}}$, at room temperature is $\approx 9.4 \mathrm{ksi}(65 \mathrm{MPa})$. However, operating experience with PWR steam generators in both the U.S. and abroad has shown that cracks of various morphologies can and do occur in steam generator tubes, starting early in life. These may be single cracks that are axial or circumferential, inside or outside diameter (ID or OD) initiated, and part or complete throughwall (TW); they may also be multiple cracks that are parallel or form a network. Tests have shown that, depending on the location and morphology of these cracks, the tubes can be weakened relative to unflawed tubes to various extents.

Detection of cracks and assessment of leak rate and structural integrity of cracked SG tubing during normal operation and design-basis accident conditions are of interest because failure of the tubes could lead to bypass of the reactor containment.

The primary-to-secondary differential pressure during normal operation of PWR SGs, $\Delta \mathrm{p}_{\mathrm{no}}$, is in the range of $8.6 \mathrm{MPa}(1.25 \mathrm{ksi})$ to $11 \mathrm{MPa}(1.6 \mathrm{ksi})$. Degraded tubes must actually be capable of withstanding $3 \Delta \mathrm{p}_{\mathrm{no}}=26-33 \mathrm{MPa}(3.75-4.8 \mathrm{ksi})$ to meet requirements for continued operation. The hot leg temperature can range from about 305 to $330^{\circ} \mathrm{C}$, although most fall in the range of 312 to $320^{\circ} \mathrm{C}$. In this temperature range, creep effects are negligible in Alloy 600.

The severest design-basis accident depends on the license of the plant. Typically, main steam line break (MSLB) leads to a long-term differential pressure of $17.7 \mathrm{MPa}(2.56 \mathrm{ksi})$ at $315^{\circ} \mathrm{C}$. For other plants there is a feed-line break event that leads to a pressure spike of $18.3 \mathrm{MPa}$ ( $2.65 \mathrm{ksi})$. Hence, the pressure difference across a SG tube wall in a design-basis accident, $\triangle \mathrm{p}_{\mathrm{MSLB}}$, can range from 17.7 to $18.3 \mathrm{MPa}$ (2.56 to $2.65 \mathrm{ksi}$ ). Degraded tubes must actually be capable of withstanding $1.4 \Delta \mathrm{p}_{\mathrm{MSLB}}=24.7-$ $25.6 \mathrm{MPa}(3.58-3.71 \mathrm{ksi})$ to meet requirements for continued operation. Creep effects are also negligible in Alloy 600 at the MSLB temperature.

Failure pressures, leak rates, etc., depend on the mechanical properties (primarily the flow stress) of the tubing. The minimum ASME code requirements for yield and ultimate tensile strengths of Alloy 600 steam generator tube are $240 \mathrm{MPa}(35 \mathrm{ksi})$ and $550 \mathrm{MPa}(80 \mathrm{ksi})$, respectively, which correspond to a minimum flow stress of $400 \mathrm{MPa}(58 \mathrm{ksi}$ ). Some of the older steam generators may have tubes with properties close to the code minimum. The actual flow stress of steam generator tubes in most current plants can vary widely depending on the age and heat of material used. To compare results on one material with results on a different material, the effect of variations in the mechanical properties must be accounted for, i.e., the results must be normalized in terms of the flow stress. The correlations that have been developed for predicting failure pressure and leak rate account for flow stress effects.

Correlations for predicting ligament rupture pressure and leak rate of axial and circumferential part-throughwall (PTW) rectangular cracks under normal operation and design-basis accident conditions have been presented in the past. ${ }^{1-2}$ As is emphasized in Ref. 2, failure data on SG tubing are relatively sparse for short and deep flaws. Limited failure data on tubes with notched axial flaws, including those that are short and deep, are presented in Ref. 2. In this report we present additional failure data, which are used to update the ANL ligament rupture model presented in Ref. 2. 
Multiple stress corrosion cracks (SCCs) or SCCs separated by narrow ligaments are often observed in SG tubes. In this report we present failure prediction models and test results validating the models for tubes with multiple axial cracks and notches.

In this report we will consider an additional mode of failure of steam generator tubes during MSLBs. In the event of a tube failure during accidents, it is possible that the escaping jet of superheated steam could impinge on a neighboring tube. The steam jet could then erode through the neighboring tube, leading to another escaping jet and the possibility of a cascading failure event in the steam generator. Results from an experimental study investigating the erosive effect of steam jet on a neighboring tube are also included in this report.

In contrast to rectangular machined notches, SCCs in operating SG tubes are irregularly shaped, have variable depths along their lengths, and may have one or more through-thickness penetrations in localized regions. Instead of being a single planar crack, each is composed of a family of crack segments in different planes. Currently, it is not clear as to how much detail must be available on the complex morphology of the cracks before the structural integrity of the tubes can be assessed by mechanistic models. A method for handling such complex-shaped cracks, based on the concept of an equivalent rectangular crack determined from multiparameter analysis of eddy current data from a rotating pancake coil, was proposed in Ref. 2. We continue to use this approach for predicting ligament rupture pressures of SCCs and have extended it to predict the stable ligament rupture that is often observed during testing of tubes with SCCs. 


\section{Failure and Leak Rate Models Applicable to Normal Operation and Design-Basis Accident Conditions}

Because temperatures under normal operating and design-basis accident conditions are too low for creep effects to occur, the failure of flawed tubes in these cases can be adequately described using flowstress-based models. In the following sections, we summarize the available models and back-up test data for calculating ligament rupture pressures, crack opening areas, and leak rates of SG tubes with axial and circumferential, TW and PTW, cracks.

\subsection{Axial Cracks}

\subsubsection{Throughwall Rectangular Axial Cracks}

The critical pressures and crack sizes for the unstable failure (rupture) of a thin-wall internally pressurized cylindrical shell with a single TW axial crack can be estimated with an equation originally proposed by Hahn et al. ${ }^{3}$ and later modified by Erdogan 4 :

$$
\mathrm{p}_{\mathrm{cr}}=\frac{\bar{\sigma} \mathrm{h}}{\mathrm{mR}}=\frac{\mathrm{p}_{\mathrm{b}}}{\mathrm{m}}
$$

where:

$\bar{\sigma}=$ flow stress $=\mathrm{k}\left(\mathrm{S}_{\mathrm{y}}+\mathrm{S}_{\mathrm{u}}\right)($ with $\mathrm{k}=0.5-0.6)$,

$\mathrm{S}_{\mathrm{y}}$ and $\mathrm{S}_{\mathrm{u}}$ are the yield and ultimate tensile strengths, respectively,

$\mathrm{m}=0.614+0.481 \lambda+0.386 \exp (-1.25 \lambda)$,

$\lambda=\left[12\left(1-v^{2}\right)\right]^{\frac{1}{4}} \frac{\mathrm{c}}{\sqrt{\mathrm{Rh}}}=\frac{1.82 \mathrm{c}}{\sqrt{\mathrm{Rh}}}$,

$\mathrm{p}_{\mathrm{b}}=\frac{\overline{\mathrm{\sigma}} \mathrm{h}}{\mathrm{R}}=$ burst pressure of an unflawed virgin tubing

$\mathrm{R}$ and $\mathrm{h}$ are the mean radius and wall thickness of tube, respectively,

$v$ is the Poisson's ratio, and

$2 \mathrm{c}$ is the axial crack length.

\subsubsection{Database for Unstable Burst of Throughwall Axial EDM Notch}

A database for the unstable burst pressure of tubes with single, TW, EDM and laser-cut notches has been generated at Argonne National Laboratory (ANL). A critical factor for predicting unstable burst 
pressure is $k$, the flow stress factor. R. Keating from Westinghouse ${ }^{*}$ has determined that based on data on the burst pressure of unflawed tubes, $k=0.595$. On the other hand, the best fit to ANL data on unstable burst of tubes with TW axial notches gives $k=0.55$. Comparisons of the observed and predicted unstable burst pressures using $k=0.55$ and $k=0.595$ are shown in Figs. $1 a$ and $1 b$, respectively. For PTW laser-cut notches, the notch lengths were obtained from fractography. In the cases where multiple tests were performed for a given EDM notch length, Figure 1a shows that the unstable burst pressures of the shorter (6- and 9- $\mathrm{mm}$ [0.25- and 0.35-in.]) laser-cut notches tend to be at the lower end of the range of burst pressures observed for the EDM notches. However, the burst pressures for the larger number of specimens with 13-mm (0.5-in.) laser-cut notches were distributed equally above and below those of the EDM notches. Thus, overall, the unstable burst pressures of the EDM and laser-cut notches of equal length are comparable. Figures $1 a-b$ show that unstable burst pressures are better predicted by $\mathrm{k}=0.55$ than $\mathrm{k}=0.595$. Ultimately, to reconcile the predicted burst pressures of unnotched and notched specimens into a single value of $k$, the definition of the bulging factor $\mathrm{m}$ (Eq. 1d) will have to be changed.

A series of tests was performed by J. P. Woods ${ }^{* *}$ to measure failure pressures and crack-opening displacements of Alloy 600 tubes with rectangular as well as triangular and trapezoidal EDM notches. Woods conducted pressure tests with internal bladders and foils on two heats of alloy 600 tubes at room temperature. Nominal dimensions of both heats of tubes were the same - outer diameter $=19 \mathrm{~mm}$ ( $0.75 \mathrm{in}$.) and wall thickness $=1.1 \mathrm{~mm}(0.043 \mathrm{in}$.). The mechanical properties of the two heats are given in Table 1. It is evident that Heat M100 has a significantly higher flow stress than Heat M90. The test program was conducted in two phases. In phase 1, duplicate specimens made from Heat M90 tubes with TW axial EDM notches of 13 to $64 \mathrm{~mm}$ ( 0.5 to $2.5 \mathrm{in}$.) were tested. Figure 2 shows that the observed unstable burst pressures of M90 tubes with TW axial notches are close to those predicted with $\mathrm{k}=0.55$. Interestingly, a reduction of bladder thickness from 3.2 to $2.4 \mathrm{~mm}$ (1/8 to $3 / 32 \mathrm{in}$.) decreased the burst pressures of tubes with 13 and $19 \mathrm{~mm}$ ( 0.5 and $0.75 \mathrm{in}$.) notches by $20 \%$. In agreement with our prior experience, the burst pressure of the unflawed tube is underestimated with $\mathrm{k}=0.55$ and is much closer to the predicted burst pressure with $\mathrm{k}=0.595$.

\subsubsection{Crack Opening Area and Displacement of Throughwall Axial Rectangular Cracks}

The crack opening area (COA) in the Zahoor model ${ }^{5}$ for an axial TW crack in a thin-walled tube is given by

$$
\mathrm{A}=2 \pi \mathrm{c}_{\mathrm{e}}^{2} \mathrm{~V}_{\mathrm{o}} \sigma / \mathrm{E},
$$

where

$$
\begin{aligned}
& \sigma=\text { hoop stress }=\Delta p R / h, \\
& \Delta p=\text { differential pressure across tube wall, }
\end{aligned}
$$

\footnotetext{
* Private Communication, R. Keating, Westinghouse Electric Company, to W. J. Shack, Argonne National Laboratory, February 15, 2000.

** J. P. Woods, "The Effect of Ligament Size on the Burst Pressure of Alloy 600 Tubing Containing Axial Cracks," Master's Thesis, Illinois Institute of Technology, 1995.
} 
Test Unstable Burst Pressure (MPa)

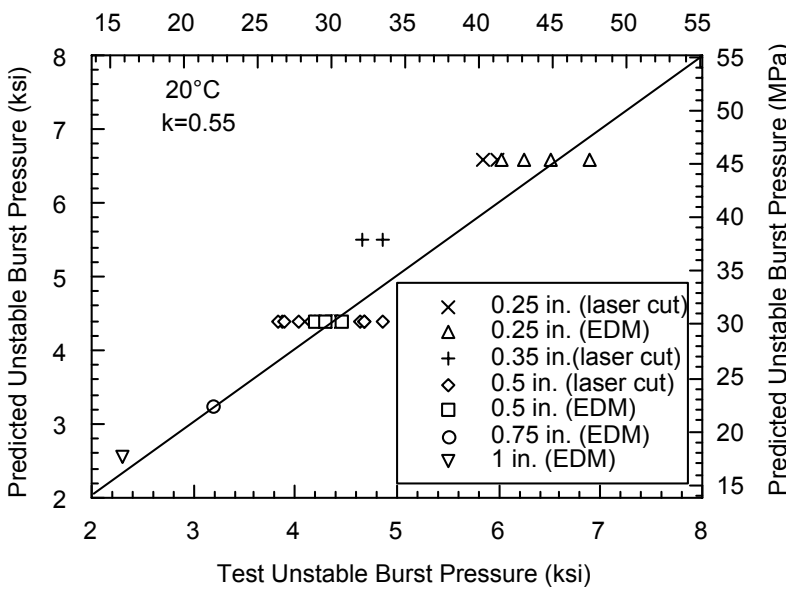

(a)

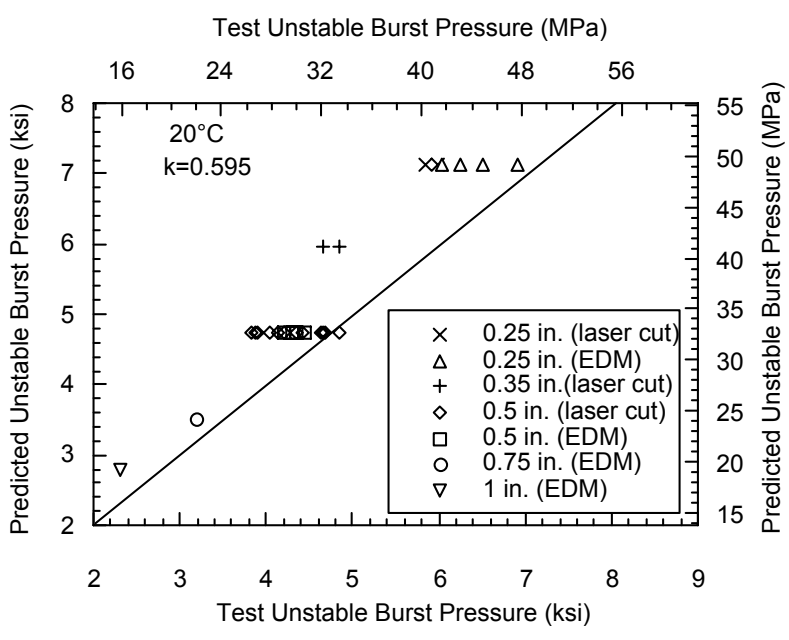

(b)

Figure 1. Observed vs. predicted unstable burst pressures for tubes with throughwall EDM and lasercut notches using (a) $\mathrm{k}=0.55$ and $(\mathrm{b}) \mathrm{k}=0.595$.

Table 1. Room temperature mechanical properties of alloy 600 tubes used for tests by Woods on rectangular, triangular, and trapezoidal EDM notches.

\begin{tabular}{cccc}
\hline Heat Number & $\begin{array}{c}\text { Ultimate Tensile } \\
\text { Strength (MPa/ksi) }\end{array}$ & $\begin{array}{c}\text { Yield Strength } \\
(\mathrm{MPa} / \mathrm{ksi})\end{array}$ & Elongation (\%) \\
\hline M90 & $660 / 95.6$ & $275 / 39.8$ & 50 \\
M100 & $738 / 107.1$ & $400 / 58.1$ & 40 \\
\hline
\end{tabular}

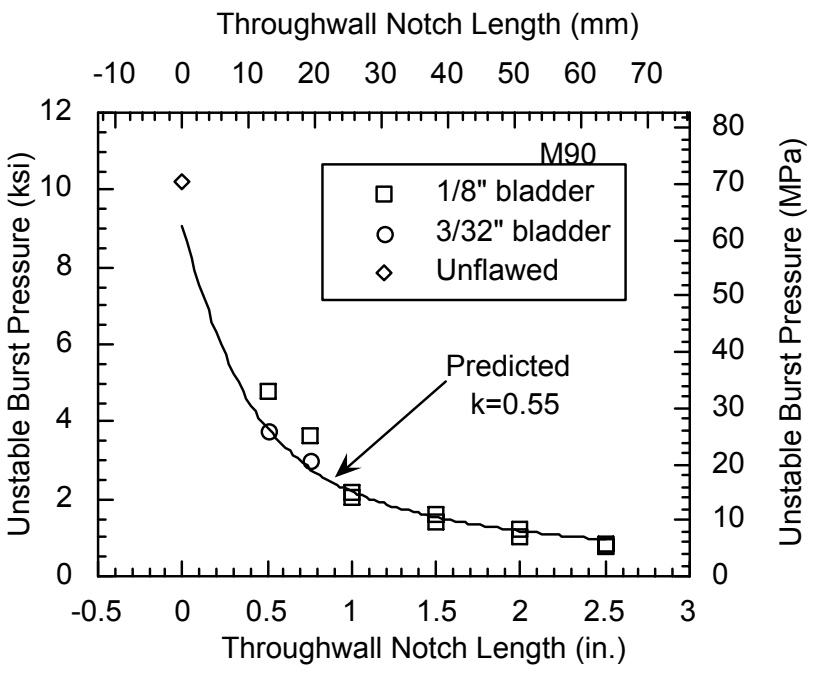

Figure 2.

Predicted vs. observed variation of unstable burst pressure with notch length of Heat M90 tubes with TW axial EDM notches. 


$$
\begin{aligned}
& \mathrm{E}=\text { Young's modulus, } \\
& \mathrm{R} \text { and } \mathrm{h}=\text { mean radius and thickness of tube, respectively, } \\
& \mathrm{V}_{\mathrm{o}}=1+0.64935 \lambda_{\mathrm{e}}^{2}-8.9683 \times 10^{-3} \lambda_{\mathrm{e}}^{4}+1.33873 \times 10^{-4} \lambda_{\mathrm{e}}^{6}, \\
& \lambda_{\mathrm{e}}^{2}=\mathrm{c}_{\mathrm{e}}^{2} / \mathrm{Rh}, \mathrm{c}_{\mathrm{e}}=\mathrm{c}\left[1+\frac{\mathrm{F}}{2}\left(\frac{\sigma}{\mathrm{S}_{\mathrm{y}}}\right)^{2}\right], \mathrm{F}=1+1.2987 \lambda^{2}-2.6905 \times 10^{-2} \lambda^{4}+5.3549 \times 10^{-4} \lambda^{6}, \\
& \lambda^{2}=\mathrm{c}^{2} / \mathrm{Rh}, \\
& \mathrm{S}_{\mathrm{y}}=\text { yield strength, and } \\
& \mathrm{C}=\text { crack half length. }
\end{aligned}
$$

The flaw opening area for an EDM notch can be estimated by adding the initial flaw area (=flaw length $x$ flaw width) to the crack opening area given by Eq. 2. Crack opening areas calculated by Eq. 2 agree well with finite element analysis (FEA). ${ }^{2}$ The crack opening displacement (COD) can be determined from the crack opening area by assuming an elliptical geometry for the opened flaw.

\subsubsection{COD Data for Throughwall Axial EDM Notches (bladder and foil effect)}

Woods ${ }^{*}$ measured the COD as a function of pressure in a specimen with a 38-mm (1.5-in.) TW rectangular notch. A $24-\mathrm{mm}$ ( $3 / 32$ in.)-thick bladder and a $0.15-\mathrm{mm}$ ( 6 mils)-thick brass foil were used to protect the COD gauge in this test. Figure 3 shows that the COD is significantly overestimated if we ignore the stiffening effect of the bladder and foil. A good correlation is obtained for an effective wall thickness of $1.3 \mathrm{~mm}$ ( $0.05 \mathrm{in}$.). However, the observed burst pressure of $11.7 \mathrm{MPa}(1.7 \mathrm{ksi})$ is close to the burst pressure of $12.8 \mathrm{MPa}(1.86 \mathrm{ksi})$ calculated by ignoring the presence of the bladder or the foil.

A similar phenomenon was observed during testing performed for the Paul Scherrer Institute (PSI) in which flawed Type 316L stainless steel tubes were stably pressurized to prescribed final aspect ratios of the notches. The COD of long notches was consistently overestimated at low pressures where the reinforcing effects of the bladder and foil can not be ignored (Fig. 4). As a result, when the prescribed final notch aspect ratio was low (which typically meant a relatively long notch at low pressure), it was achieved at a significantly lower pressure than predicted. On the other hand, the predicted pressure was much closer to the actual pressure when the final notch aspect ratio was higher (i.e., shorter notch at higher pressure), except when the final pressure was close to the burst pressure. In the few cases where the specimens were inadvertently pressurized to unstable burst, the burst pressures were close to the predicted values as long as the bladder and foil failed prior to burst. Thus, both the PSI and Woods data suggest that the observed COD of long notches at low pressures in the presence of bladder and foil may very likely be overestimated by analytical means unless the stiffening effects of the bladder and foil are taken into account. It should be pointed out, however, that we have previously successfully predicted the CODs of rectangular EDM notches that were tested in the blow-down facility without bladder or foil. ${ }^{2}$

\footnotetext{
* J. P. Woods, "The Effect of Ligament Size on the Burst Pressure of Alloy 600 Tubing Containing Axial Cracks," Master's Thesis, Illinois Institute of Technology, 1995.
} 

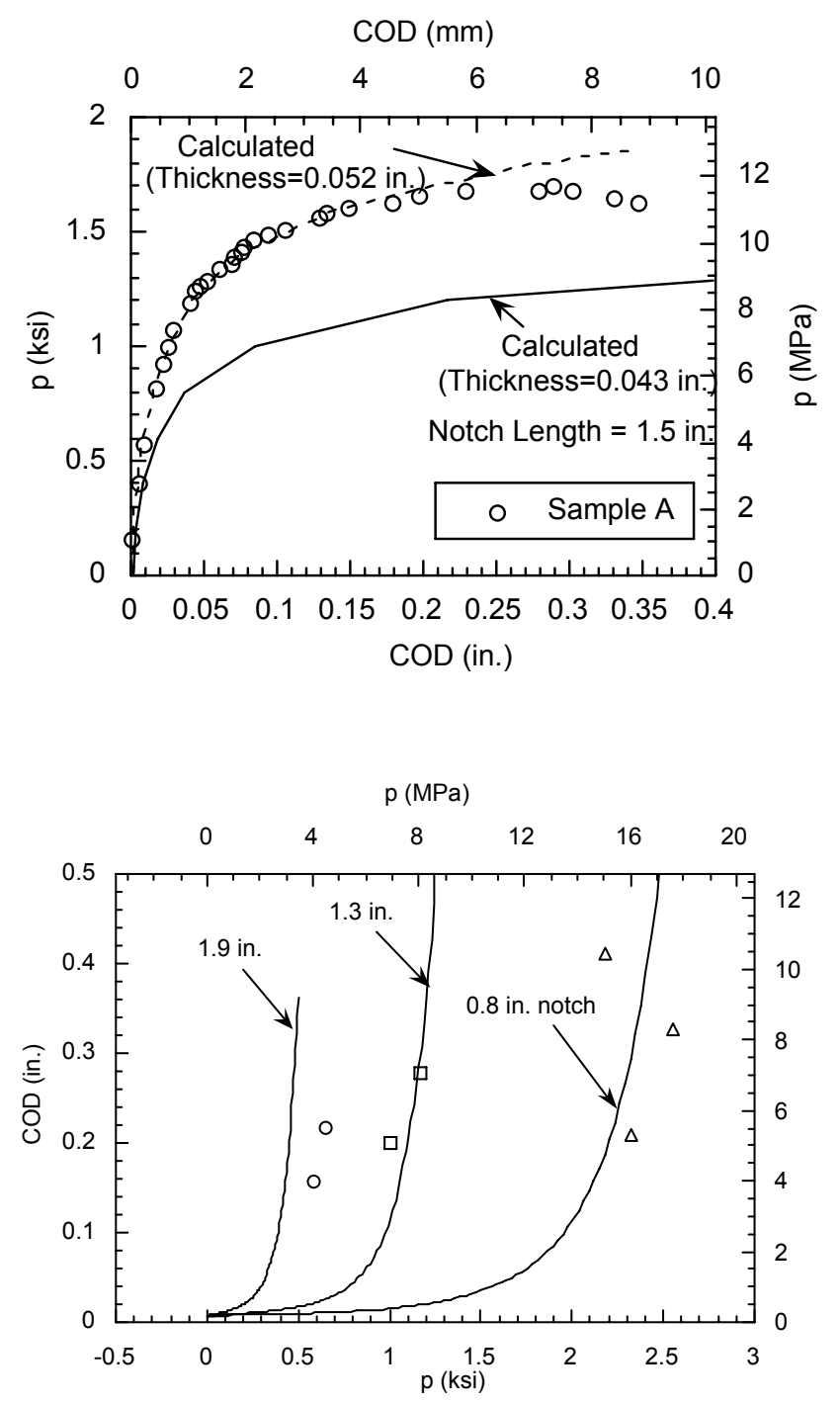

Figure 3.

Measured vs. calculated COD as a function of pressure for sample A with a 38-mm (1.5-in.)-long TW notch with 2.4-mm (3/32-in.)-thick bladder and 0.15 -mm (6-mils)-thick brass foil. Calculations given for two effective thicknesses of tube wall.
Figure 4.

Calculated and experimental variation of COD with pressure for various notch lengths in a Type $316 \mathrm{~L}$ stainless steel tube at room temperature.

\subsubsection{Part-Throughwall Rectangular Axial Cracks}

A general failure criterion for predicting rupture of the crack tip ligament in a tube with a PTW crack can be expressed as follows:

$$
\sigma_{\text {lig }}=\bar{\sigma},
$$

where $\sigma_{\text {lig }}$ is the average ligament stress, which for the axial crack is given by

$$
\sigma_{\text {lig }}=\mathrm{m}_{\mathrm{p}} \sigma
$$

where $m_{p}$ is the ligament stress magnification factor (which depends on the axial crack length and depth), and $\sigma$ is the nominal hoop stress (calculated using the mean radius and thickness of the tube, including the sleeve, if any). 
An expressions for $m_{p}$ of rectangular PTW axial cracks was presented in Ref. 2 and is reproduced below:

$$
\begin{aligned}
& \mathrm{m}_{\mathrm{p}}=\frac{1-\alpha \frac{\mathrm{a}}{\mathrm{mh}}}{1-\frac{\mathrm{a}}{\mathrm{h}}}, \\
& \alpha=1+\beta\left(\frac{\mathrm{a}}{\mathrm{h}}\right)^{2}\left(1-\frac{1}{\mathrm{~m}}\right),
\end{aligned}
$$

where $\beta=0.9$, and $a$ is crack depth.

\subsubsection{Updated Values of $\beta$ and $\mathrm{k}$}

The value of $\beta$ was originally determined from failure tests conducted at Pacific Northwest National Laboratory (PNNL). These tests did not involve many tubes having short deep flaws. ${ }^{6}$ In the original analysis the value of the flow stress factor was chosen as $k=0.55$, and $\beta$ was determined to be $0.9 .^{2}$ ANL has conducted a number of tests on tubes with short and deep $(6.35-, 8.9-$, and 12.7-mm [0.25-, 0.35-, and 0.5-in.]-long and 60, 80, and 90\% TW) EDM notches. A plot of the normalized test failure pressures (i.e., test failure pressures divided by predicted failure pressures) is shown in Fig. 5a for various values of $\beta$. The mean and standard deviation, plotted in Fig. $5 b$, show that $\beta=1$ is the best-fit value for these tests. Re-analysis of the PNNL data together with the new ANL data on short and deep notches also shows that with $\mathrm{k}=0.55$ the best-fit value is $\beta=1$. As noted earlier, R. Keating from Westinghouse* has observed that based on data for the burst pressure of unflawed tubes, $k=0.595$. The value of $k=0.595$ also gives a slightly better fit for the PNNL data on unflawed tubes. For this value of $k$, the best fit to the failure data for the flawed tubes gives $\beta=0.83$.

Equations $3 a-b$ and $4 a-b$ were used to predict the ligament rupture pressures of the tests recently conducted at ANL on specimens with EDM notches. Both sets of $k$ and $\beta$ values were used. A comparison of the observed and predicted ligament rupture pressures for $\beta=1$ and $k=0.55$ is shown in Fig. 6a. A similar comparison for $\beta=0.83$ and $k=0.595$ are shown in Fig. $6 \mathrm{~b}$. Both sets of $\beta$ and $k$ provide comparable predictions. However, in this report $\beta=1$ and $k=0.55$ have been used.

\footnotetext{
* Private Communication, R. Keating, Westinghouse Electric Company, to W. J. Shack, Argonne National Laboratory, February 15, 2000.
} 


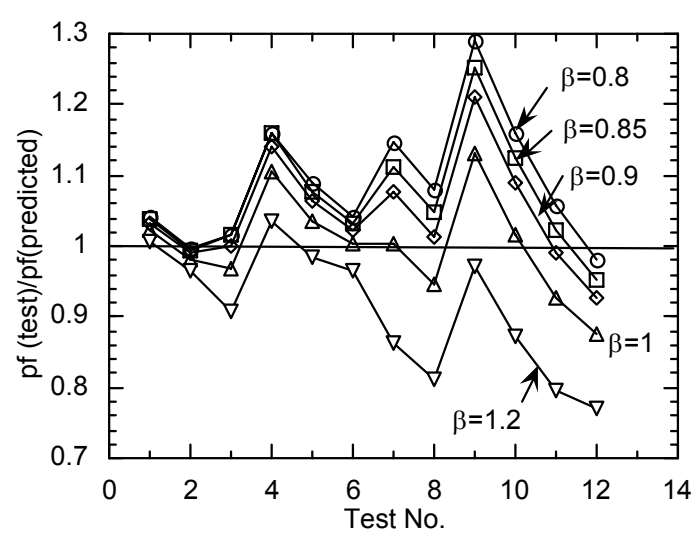

(a)

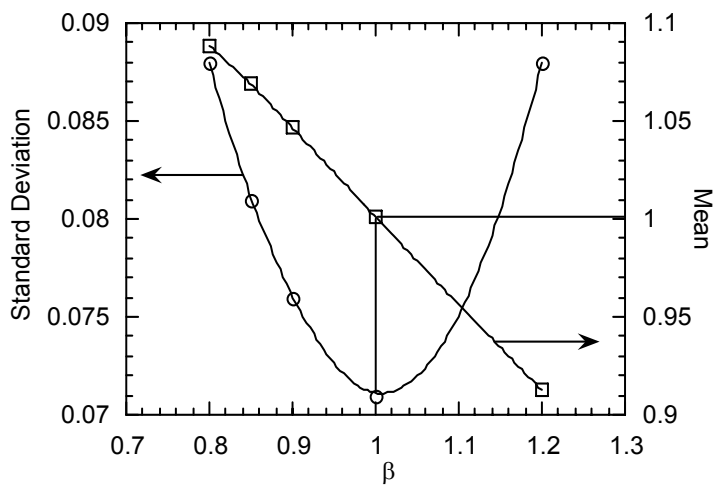

(b)

Figure 5. (a) Variation of observed failure pressures divided by predicted failure pressures corresponding to various values of $\beta$ for the ANL tests and (b) variation of the mean and standard deviation of the observed failure pressure divided by predicted failure pressure with $\beta$.

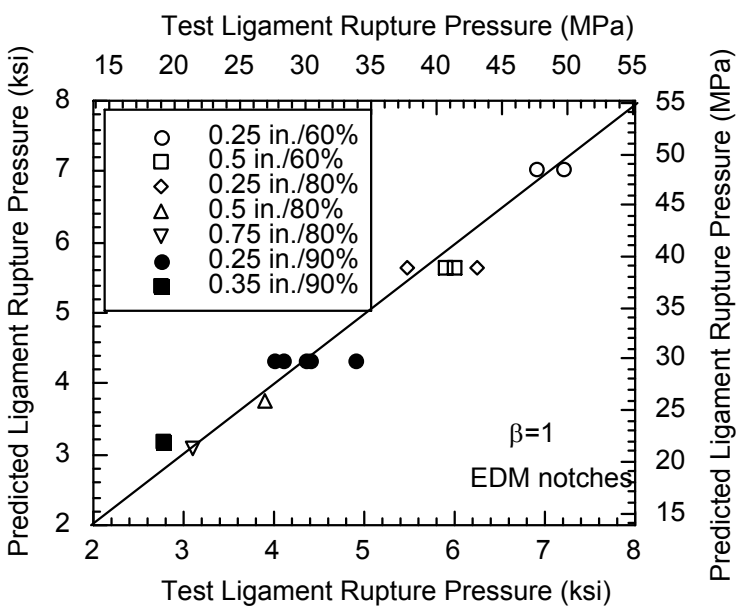

(a)

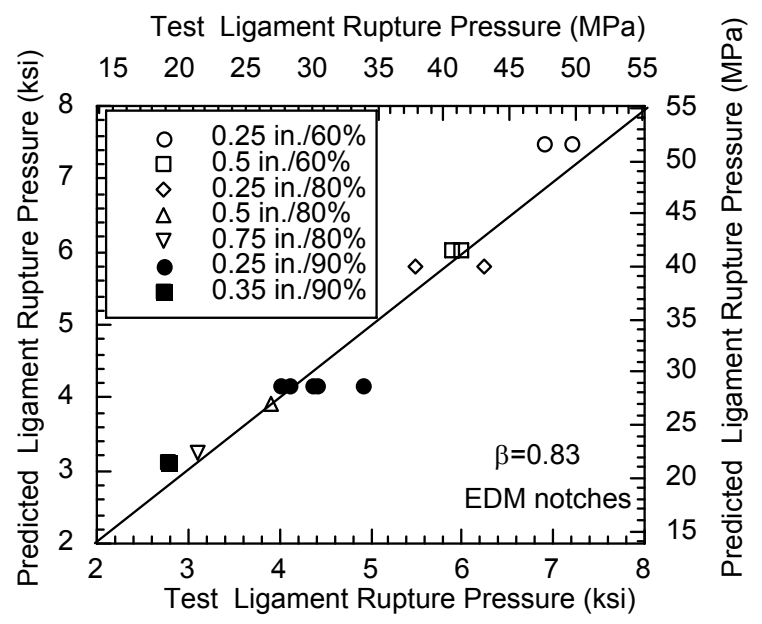

(b)

Figure 6. Observed vs. predicted ligament rupture pressures for tubes with EDM notches using (a) $\mathrm{k}=0.55$ and $\beta=1$ and $(\mathrm{b}) \mathrm{k}=0.595$ and $\beta=0.83$. 


\subsubsection{Additional Failure Data for Part-throughwall Rectangular Axial Notches}

During phase 2 of his program, Woods ${ }^{*}$ tested the stronger Heat M100 tubes with PTW (50 to $90 \%$ deep) rectangular, trapezoidal, and triangular EDM notches using 2.4-mm (3/32 in.) thick bladder and $0.15-\mathrm{mm}(0.006-$ in.) thick brass foil (only for depths $\geq 90 \%$ ). Although the thesis reports a machining tolerance in notch depths of $\pm 0.06 \mathrm{~mm}$ ( $\pm 0.0025 \mathrm{in}$.) $( \pm 6 \%)$, it is not clear whether any destructive or posttest measurements were done to verify that these tolerances were actually met. Also, note that, for deep notches $(80-90 \%), \pm 6 \%$ variations in depths can lead to significant variations in ligament rupture pressures. The unstable burst pressures of tubes with PTW rectangular notches are underestimated by 0 to $25 \%$ (Fig. 7).

\subsubsection{Equivalent Rectangular Crack}

Although Eqs. 3a-b and $4 a-b$ can be used to estimate the ligament rupture pressure of the tip for rectangular PTW cracks, they are not directly applicable to triangular or trapezoidal notches or to laboratory-grown and service-induced SCC cracks, which are irregular in shape and have variable depths along their length. Such cracks, instead of being considered a single plane, are composed of a family of crack segments in different planes. Local variations in crack depth and geometry are smoothed out in the EC measurements because the EC signals are necessarily averaged over a finite volume, and hence the EC data tend to show a relatively smooth variation of crack depth along the crack length (for example, see Fig. 8). This is evidenced by the fact that, although all the SCC specimens tested to date have shown leakage under low gas pressure before testing, the EC NDE using the +Point probe has failed to detect or identify the locations of these small pinholes. However, no leakage of water was detected through these cracks until much higher pressures were applied.

Currently, no widely accepted models are available for predicting the ligament failure pressure of cracks with such complex geometries. From a limit analysis viewpoint, it can be argued that the collapse behavior of a crack tip ligament with an irregular point-by-point variation of crack depth should be similar to that of a crack with a smoothed-out, "average" crack depth profile. For the present, we assume that the average profile measured by multiparameter analysis of eddy current (EC) data from a rotating pancake coil (RPC) is relevant for limit analysis. With this assumption, although the real crack may have short TW segments at a number of locations, from the viewpoint of plastic collapse of the ligament, the tube behaves as if it has a smoothly varying average ligament thickness (or crack depth) profile.

Since the measured crack depth profile by multiparameter analysis of EC RPC data is generally not rectangular (e.g., see Fig. 8), the procedure described below was used to establish the length and depth of an equivalent rectangular $\operatorname{crack}^{* *}$ :

\footnotetext{
* J. P. Woods, "The Effect of Ligament Size on the Burst Pressure of Alloy 600 Tubing Containing Axial Cracks," Master's Thesis, Illinois Institute of Technology, 1995.

** Similar equivalent rectangular crack approaches have been used by others, e.g., see the report by Aptech Engineering Services, Inc., in Docket No. 50-361, "Steam Generator Run Time Analysis for Cycle 9, San Onofre Nuclear Generating Station, Unit 2, September 25, 1997."
} 

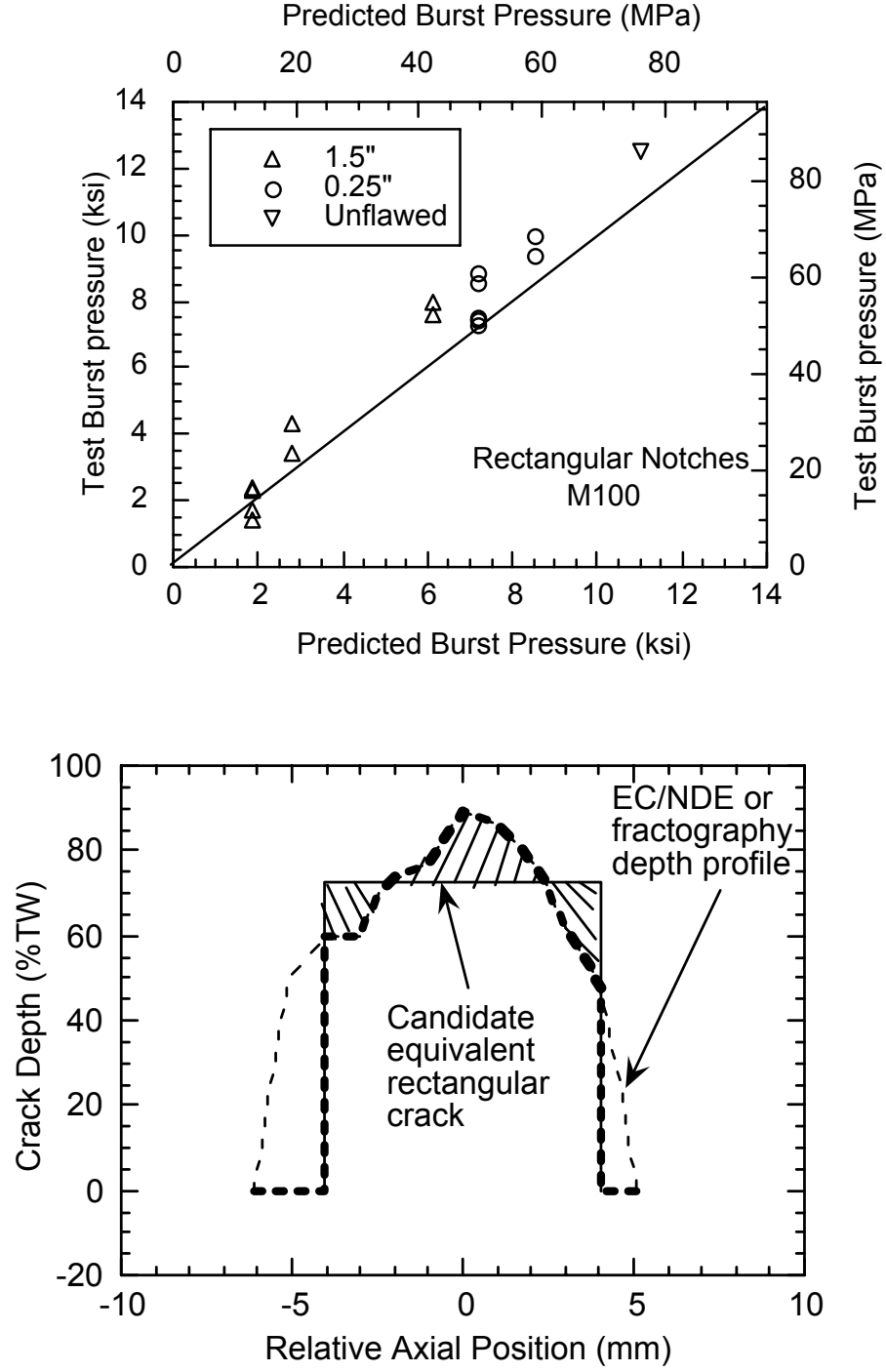

Figure 7.

Predicted vs. observed unstable burst pressures of M100 tubes with PTW and TW rectangular notches.
Figure 8.

Determination of equivalent rectangular crack.

1. Select a candidate equivalent rectangular crack of given length (e.g., Fig. 8, solid line). Replace the original crack depth profile (plain dashed line) by a new crack depth profile (bold dashed line), in which any crack segment lying outside the selected crack length is replaced by depth $=0$ (Fig. 8 ) .

2. Determine the depth of the candidate equivalent rectangular crack by equating its area to the area under the newly defined crack depth profile (bold dashed line) in step 1, i.e., equating the cross hatched areas in Fig. 8.

3. Generate a series of candidate equivalent rectangular cracks of various lengths and depths, and use the ANL correlation (Eqs. $3 a-b$ and $4 a-b$ ) for calculating the ligament rupture pressures for all the candidates.

4. The equivalent rectangular crack corresponds to the crack with the lowest ligament rupture pressure, i.e., highest $m_{p}$. 
The procedure has been automated in an Excel spreadsheet. It is assumed that the length of the $100 \%$ TW segment of the crack after ligament rupture is equal to the length of the equivalent rectangular crack. Also, it is assumed that the COD and COA of the stress corrosion crack after ligament rupture are the same as those of the equivalent rectangular crack.

\subsubsection{Extension of Equivalent Rectangular Crack Method to Stable Crack Growth}

Although we have used the equivalent rectangular crack length and depth to predict the ligament rupture pressure and leak rate, the full ligaments of SCCS rarely rupture during the initial ligament rupture, and specimens generally undergo incremental stable ligament rupture with increasing pressure before the cracks become unstable. Ideally, such stable crack growth could be calculated by an elasticplastic fracture mechanics R-curve method. However, for complex-shaped SCCs, it is not easy to implement such a method. We have tentatively generalized the equivalent rectangular crack approach to the following empirical procedure for predicting incremental ligament rupture after the initial ligament rupture event:

1. As usual, in the first step, determine the ligament rupture pressure by maximizing $\mathrm{m}_{\mathrm{p}}$ corresponding to an equivalent rectangular crack length and depth, and assume that the initial TW crack length is the same as the equivalent rectangular crack length.

2. Increase the equivalent rectangular crack length by a small increment. The increment should be from a crack tip of the equivalent rectangular crack that is not already at the end of the ligament. Calculate the equivalent crack depth and $m_{p}$ corresponding to the increased equivalent crack length (using the original crack depth profile and ignoring the fact that part of the crack is currently TW).

3. Repeat step 2 by incrementing the equivalent rectangular crack length at the other crack tip (unless the crack tip is already at the end of the ligament) instead of the first crack tip.

4. Select the increased equivalent crack length and ligament rupture pressure that correspond to the higher $m_{p}$ from steps 2 and 3.

5. Assume that the new equivalent crack length and the corresponding ligament rupture pressure are the same as the pressure needed to propagate the TW portion of the SCC to the new length. Also, the COD and COA of the SCC are the same as those of the new equivalent rectangular crack.

6. Calculate the unstable burst pressure corresponding to the new equivalent rectangular crack length and verify that the applied pressure is less than the unstable burst pressure.

7. Repeat steps 2-7 until either both ends of the TW crack reach the ends of the ligament, i.e., the full ligament is ruptured and the crack remains stable, or the crack fails unstably.

The above procedure assumes that the TW crack remains contiguous and will have to be further generalized in the future for cases where there are several such TW segments. 


\subsubsection{Application of Equivalent Rectangular Crack Method to Rupture of Triangular and Trapezoidal Notches}

A number of specimens with trapezoidal notches were tested at ANL. All the specimens had an OD notch length of $25 \mathrm{~mm}$ ( $1 \mathrm{in}$.). In specimens T-29, T-32, and T-33, the notch depth at both axial tips of the notch was $80 \%$, while the notch depth at the center was $90 \%$. In specimens $\mathrm{T}-30, \mathrm{~T}-31, \mathrm{~T}-35$, and $\mathrm{T}-36$, the notch depth at the tips of the notch was $50 \%$, while the notch depth at the center was $90 \%$. In addition, to simulate the effect of local TW penetrations often observed in SCCs, specimen T-31 had a 0-13 mm (0.005-in.) diameter TW hole drilled at the center. The tests were run in two stages. First, they were pressurized without a bladder until ligament rupture and until the pump ran out of pressure and flow capability. In the second stage, a bladder and foil were inserted, and the specimen was pressurized until unstable burst. Predicted vs. observed ligament rupture pressures during loading (stage 1) and during unstable burst (stage 2 ) are shown in Figs. 9a and 9b, respectively. In all cases, the ligament rupture pressure is overestimated by about $20-30 \%$. The equivalent rectangular approach predicts an equivalent rectangular crack of $25 \mathrm{~mm}$ ( 1 in.) by $85 \%$ for the deeper notches and $18 \mathrm{~mm}$ ( 0.7 in.) by $76 \%$ for the shallower notches. Actual observations after phase 1 testing showed that the TW crack lengths of specimens T29, T30, and T31 were 21,14 , and $18 \mathrm{~mm}(0.84,0.54$, and $0.72 \mathrm{in}$.), respectively, and the maximum $O D$ widths of the notches were $0.3,0.6$, and $1.3 \mathrm{~mm}(0.012,0.023$, and 0.05 in.), respectively. Note that the specimen with the drilled hole (T-31) failed at a higher pressure, had a longer TW crack length, and had a larger opening at the OD surface than its sister specimen T-30 without the drilled hole. During stage 2, the notches are predicted to become $100 \%$ TW throughout their length by the process of incremental ligament rupture. However, in all cases the unstable burst pressures were about $10-15 \%$ less than the observed burst pressures (18 MPa [2.6 ksi]) of rectangular notches that are initially $100 \%$ TW and $25-\mathrm{mm}$ (1-in.) long. This finding may be due to the fact that the axial crack tips created by the incremental ligament rupture are much sharper than those of the blunt TW EDM notches.

Woods* also conducted burst tests with trapezoidal and triangular notches for which the maximum notch opening displacements at the OD surface were also measured as functions of pressure. Some of these tests indicated ligament tearing with increasing pressure. The symmetrical triangular and trapezoidal notch geometries tested by Woods are depicted in Fig. 10a, and the asymmetrical triangular notch geometry is shown in Fig. 10b. The equivalent rectangular crack method was used to calculate the ligament rupture pressure and the equivalent crack length (i.e., TW crack length). If the ligament rupture pressure was less than the unstable burst pressure corresponding to the equivalent crack length, we calculated TW crack length extension by stable ligament tearing until unstable burst, using the method discussed in Section 2.1.3.1. Predicted vs. observed unstable burst pressures are shown in Fig. 11 .

\footnotetext{
* J. P. Woods, Master's Thesis, Illinois Institute of Technology, 1995.
} 
Predicted Ligament Rupture Pressure (MPa)

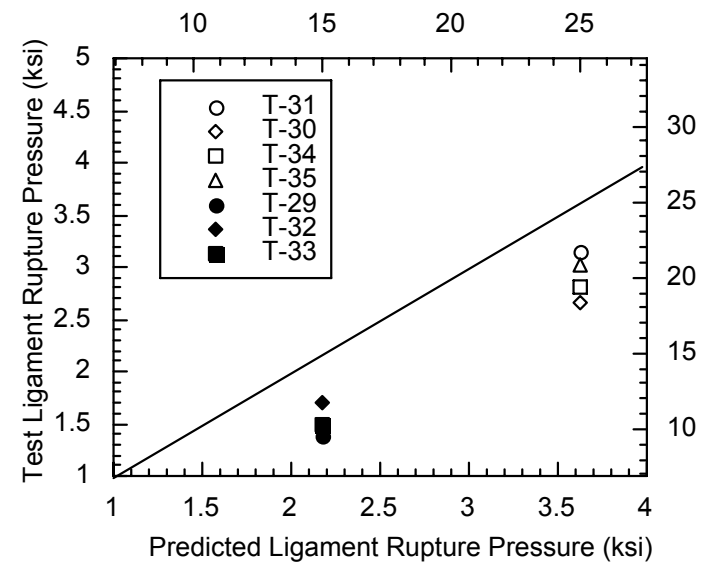

(a)
Predicted Unstable Burst Pressure (MPa)

$14.415 .2 \quad 16 \quad 16.817 .618 .4 \quad 19.2 \quad 20$

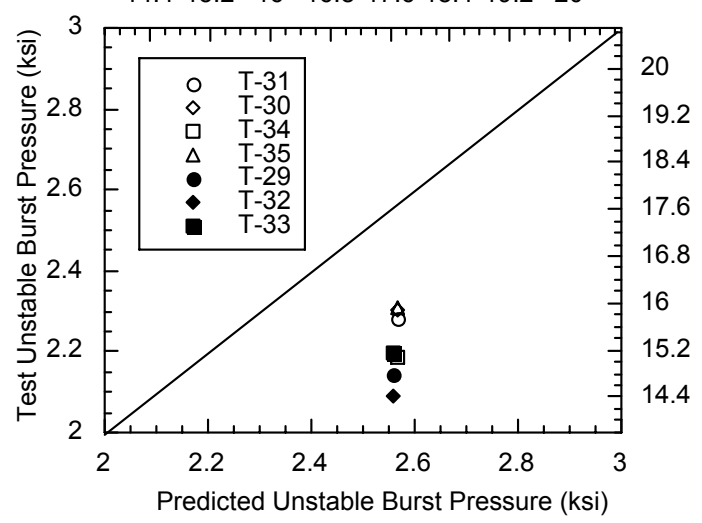

(b)

Figure 9. Predicted versus observed (a) ligament rupture pressures and (b) unstable burst pressures for ANL tests on specimens with trapezoidal notches.

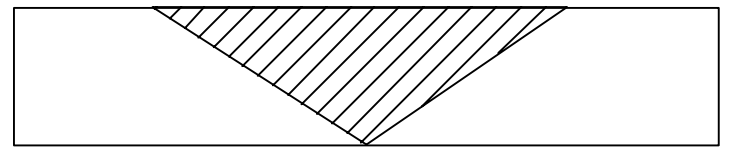

Specimen E

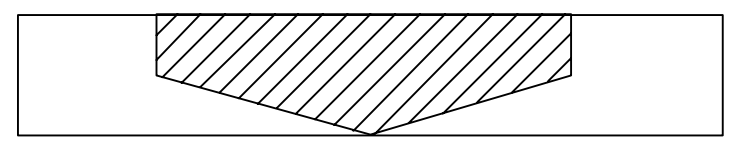

Specimen $\mathrm{F}$

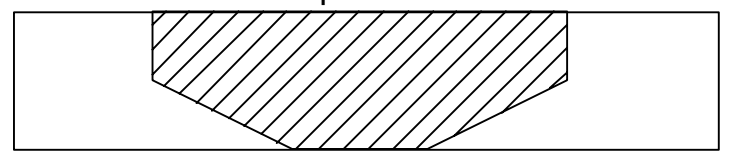

Specimens G, H, I, J

(a)

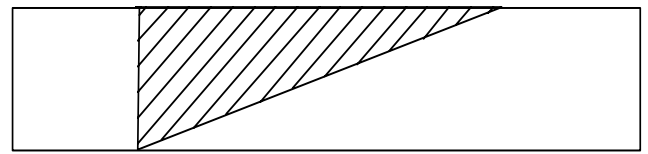

Specimens K, L, M, N, O

(b)

Figure 10. Typical geometries of (a) symmetrical triangular and trapezoidal notches and (b) asymmetrical triangular notch tested by Woods. 


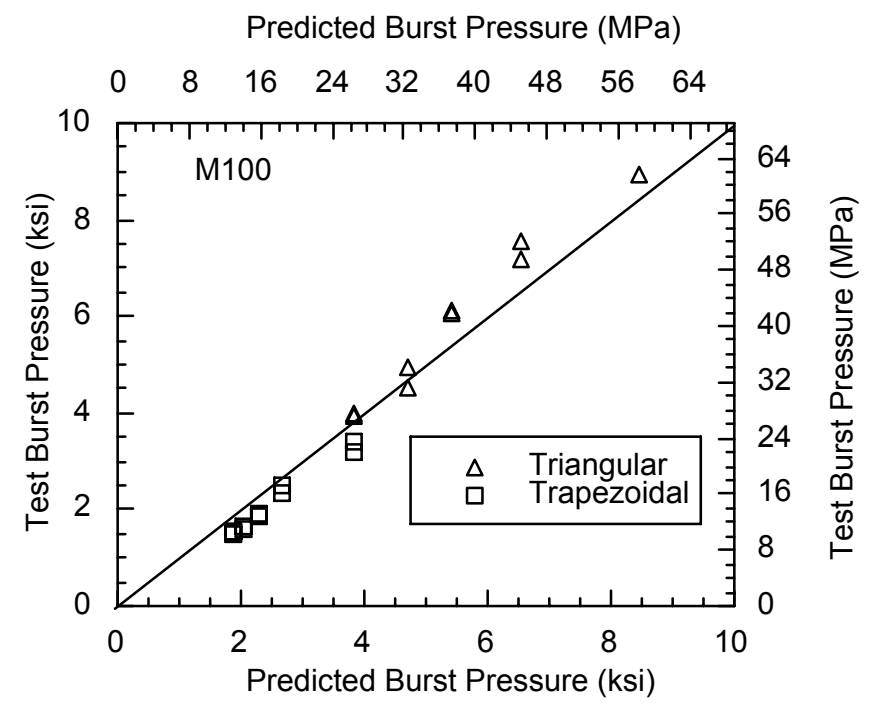

Figure 11.

Predicted vs. observed burst pressures for triangular and trapezoidal notch specimens.

\subsubsection{Application of Equivalent Rectangular Crack Method to COD of Triangular and Trapezoidal Notches}

Figure 12a compares the predicted vs. observed variation of COD with pressure for specimen $\mathrm{E}$, which had a symmetrical triangular notch with an OD length of $38 \mathrm{~mm}(1.5 \mathrm{in}$.$) , ID length of 0$, and minimum depth of $0 \%$ and maximum depth $100 \%$ at a point at the center. Figure $12 \mathrm{~b}$ shows the predicted TW crack lengths and the TW crack lengths that fit the measured CODs as a function of pressure.

Next, we consider a series of symmetrical trapezoidal notches, all with OD length $38 \mathrm{~mm}(1.5 \mathrm{in}$.$) ,$ minimum depth of $50 \%$ at the notch tips, and maximum depth of $100 \%$ at the center, but different TW ID lengths. Figure 13a compares the predicted vs. observed variation of COD with pressure for specimen $\mathrm{F}$, which had a TW ID length of $0 \mathrm{~mm}$. Figure 13b shows the predicted TW crack lengths and the TW crack lengths that fit the measured CODs as a function of pressure. Similar comparisons for specimens $G$ (TW ID length $=6 \mathrm{~mm}[0.25 \mathrm{in}$.$] ) and specimen H (TW ID length =13 \mathrm{~mm}[0.5 \mathrm{in}$.$] ) are shown in Figs.$ $14 a-b$ and $15 a-b$, respectively. Figures $16 a-b$ show the same comparisons for specimen $\mathrm{J}$, which was similar to specimen $\mathrm{H}$ in all respects except that it had a minimum depth of $75 \%$. Note that the variations of TW crack length with pressure, calculated from experimentally measured COD data, suggest that crack growth tends to occur more discontinuously than predicted. However, on the average, predicted crack growth tends to follow the experimental crack growth approximately.

Next we consider the effect of notch shape on the crack opening displacements for rectangular and triangular notches with average depth $50 \%$. Predicted and observed variations of COD with pressure for specimens with notches of various shapes are shown in Figs. 17a-b for OD lengths 6 and $38 \mathrm{~mm}(0.25$ and 1.5 in.), respectively. Note that notch shape has less effect on CODs for the short notches than the long notches. The 38-mm (1.5-in.) long rectangular notch has significantly greater COD than either the symmetrical or the asymmetrical triangular notch of the same OD length and average depth. On the other hand, symmetrical and asymmetrical triangular notches have comparable CODs. Note that the dependence of COD on notch shape is predicted reasonably well by the equivalent rectangular crack method. 


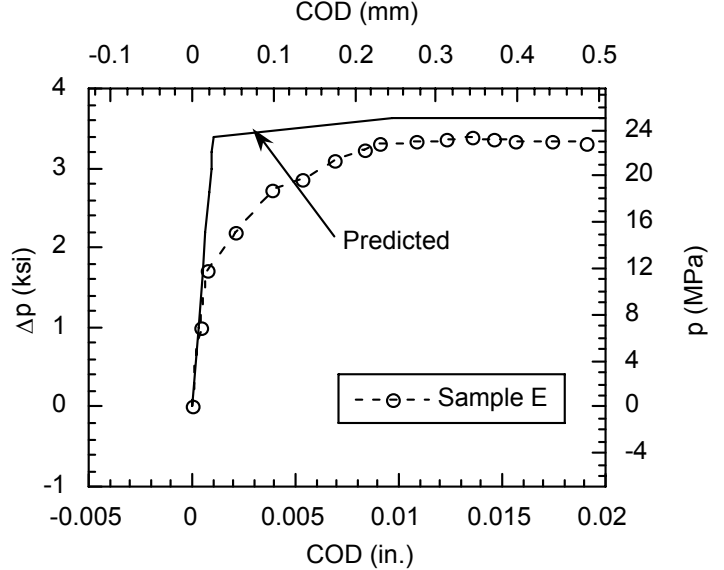

(a)

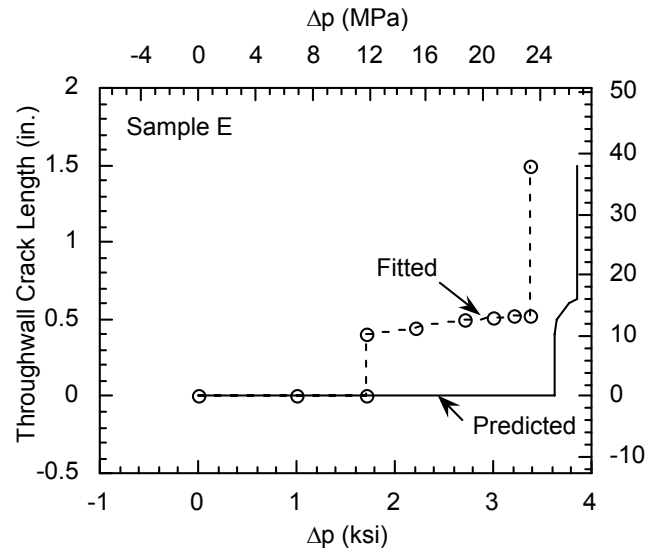

(b)

Figure 12. (a) Predicted vs. observed COD and (b) fitted TW crack length needed to match the measured COD vs. predicted TW crack length for specimen E.

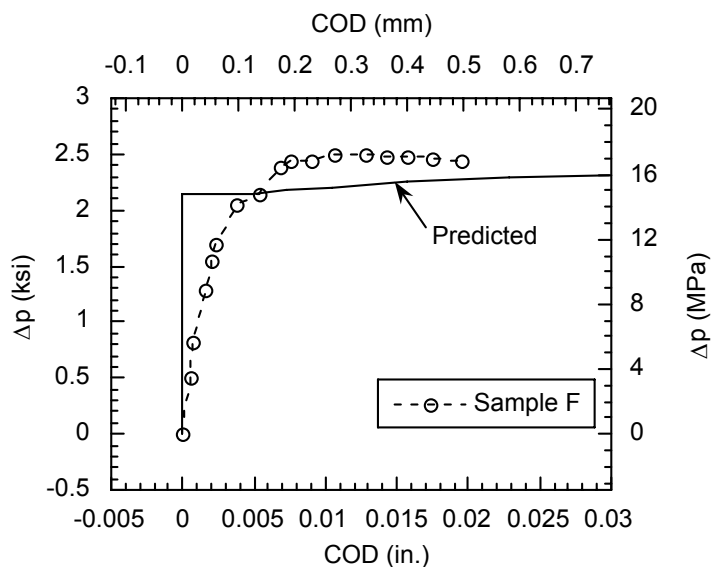

(a)

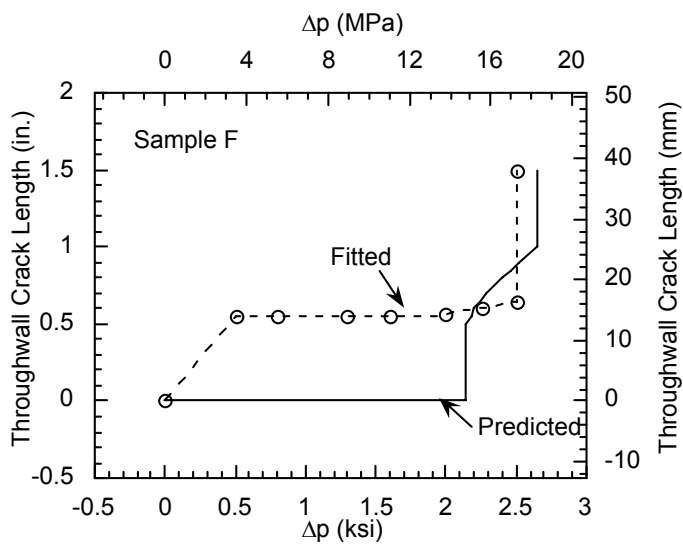

(b)

Figure 13. (a) Predicted vs. observed COD and (b) fitted TW crack length needed to match the measured COD vs. predicted TW crack length for specimen $F$.

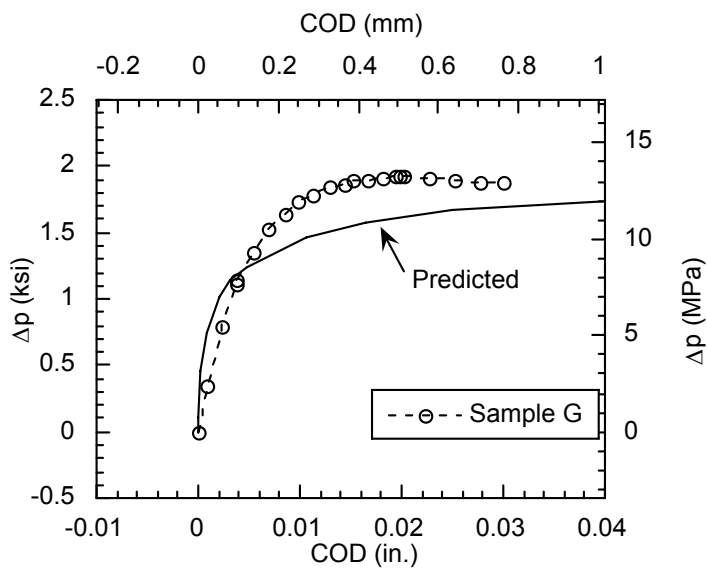

(a)

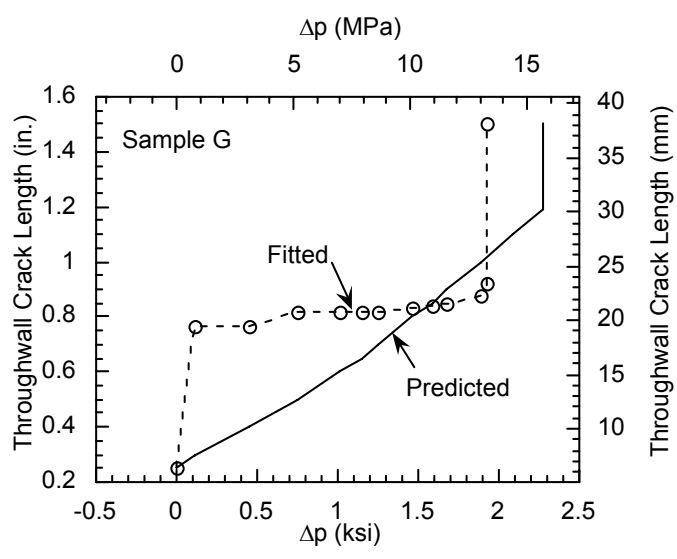

(b)

Figure 14. (a) Predicted vs. observed COD and (b) fitted TW crack length needed to match the measured COD vs. predicted TW crack length for specimen G. 


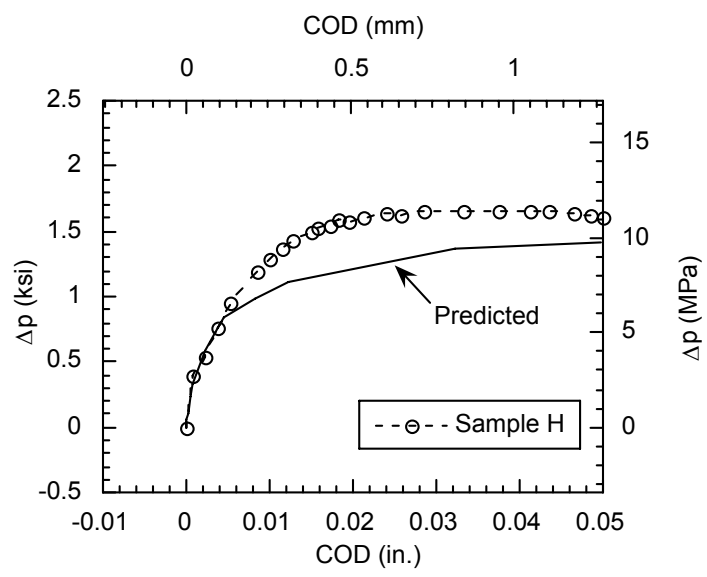

(a)

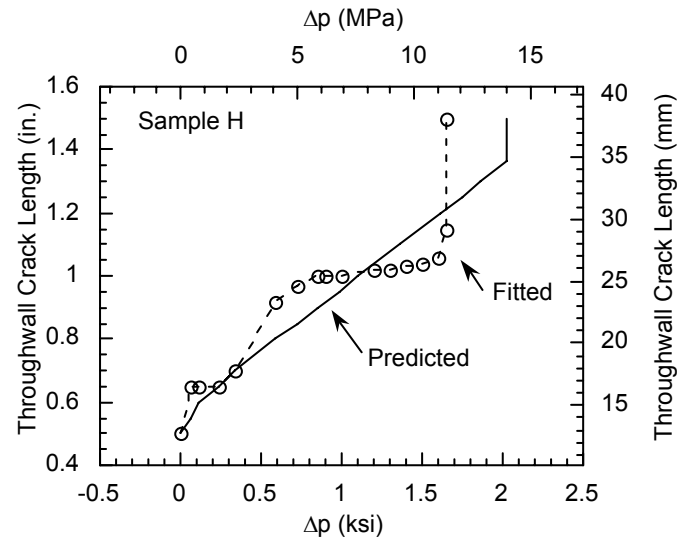

(b)

Figure 15. (a) Predicted vs. observed COD and (b) fitted TW crack length needed to match the measured COD vs. predicted TW crack length for specimen $\mathrm{H}$.

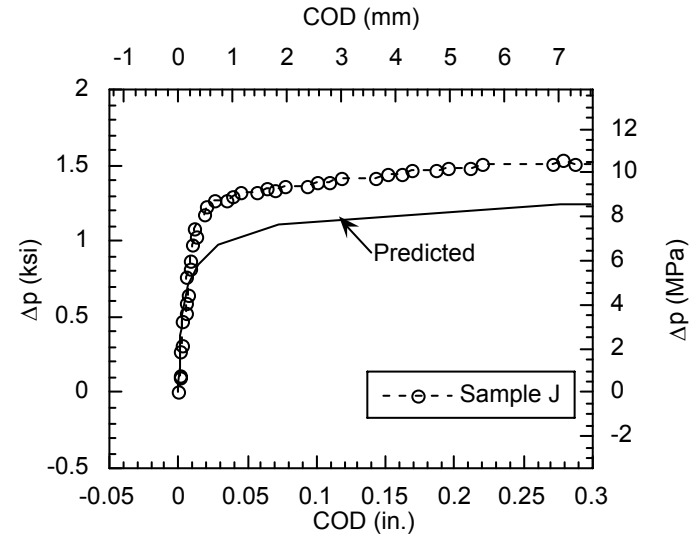

(a)

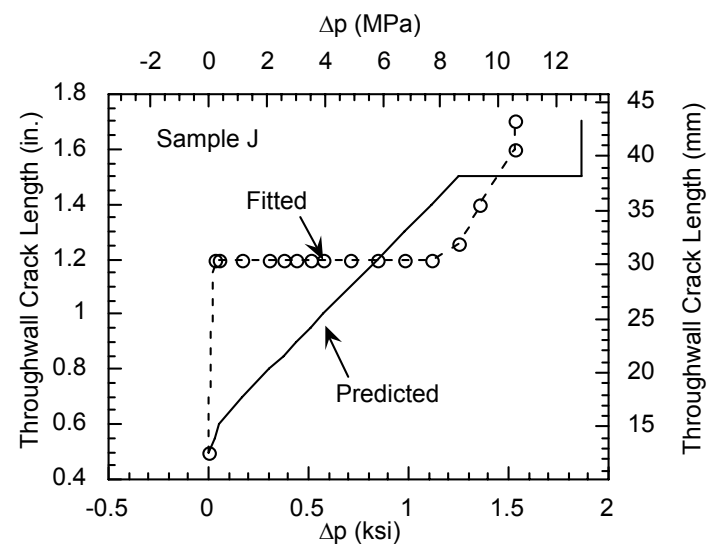

(b)

Figure 16. (a) Predicted vs. observed COD and (b) fitted TW crack length needed to match the measured COD vs. predicted TW crack length for specimen $\mathrm{J}$.

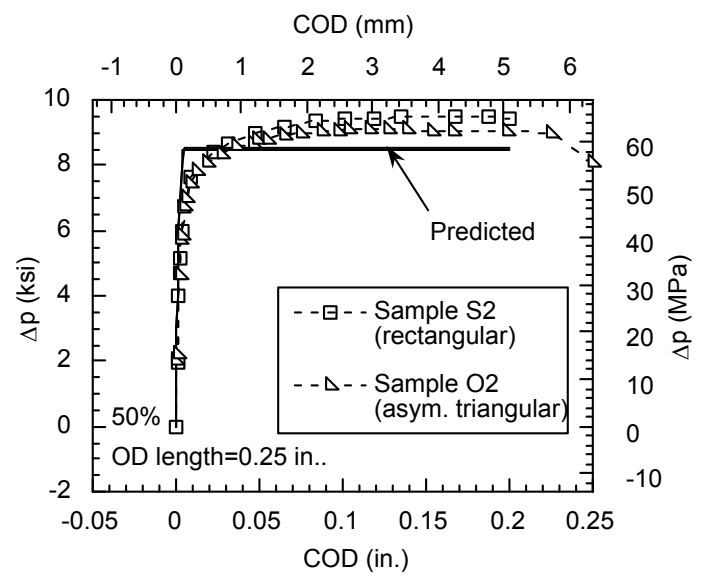

(a)

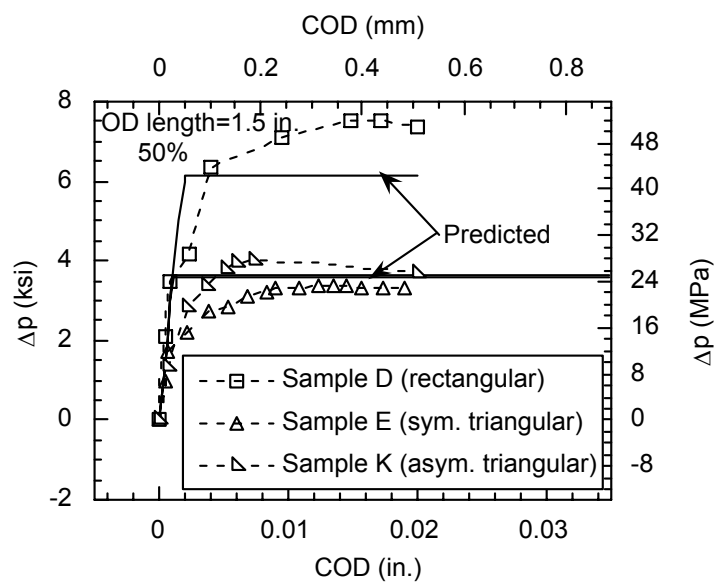

(b)

Figure 17. (a) Predicted vs. observed COD for specimens with rectangular and triangular notches with average depth $50 \%$ and with OD lengths (a) $6 \mathrm{~mm}$ [0.25 in.] and (b) $38 \mathrm{~mm}$ [1.5 in.]. 


\subsection{Circumferential Cracks}

\subsubsection{Throughwall Circumferential Cracks}

Failure loads of tubes with a single circumferential crack critically depend on the bending constraint imposed externally on the tubes. The two extreme cases are the free-bending case and the fully constrained case. In reality, steam generator tubes are partially constrained against bending by tube support plates.

\subsubsection{Free Bending Case}

Failure loads for tubing with through-wall circumferential cracks can be calculated by plastic limit load (collapse) analyses, which are based on earlier work by Kanninen et al. ${ }^{7}$ and are described by Ranganath and Mehta. ${ }^{8}$ For an unconstrained (free-to-bend) tube with a throughwall crack of angular length $2 \theta$ and no applied primary bending stress, the critical failure pressure is

$$
\mathrm{p}_{\mathrm{cr}}=\frac{2 \bar{\sigma} \mathrm{h}}{\mathrm{R}}\left(1-\frac{\theta}{\pi}-\frac{2 \beta}{\pi}\right) \text {, }
$$

where the angular location of the neutral axis is given by

$$
\beta=\sin ^{-1}\left(\frac{\sin \theta}{2}\right)
$$

\subsubsection{Fully Constrained Case}

Equation 5a is applicable to one extreme case, where the tube is completely free to bend. In the opposite extreme case of total constraint against bending, a criterion based on maximum shear stress in the net section, as proposed by Cochet et al., ${ }^{9}$ can be used to calculate the instability limit pressure:

$$
\mathrm{p}_{\mathrm{cr}}=\frac{2\left(\gamma^{2}-1\right)(\pi-\theta) \bar{\sigma}}{2 \pi+(\pi-\theta)\left(\gamma^{2}-1\right)}
$$

where

$$
\gamma=\frac{\mathrm{R}_{0}}{\mathrm{R}_{\mathrm{i}}}
$$

where $R_{0}$ and $R_{i}$ are the outer and inner radius, respectively. Equation $6 c$, which is a thin-shell uniaxial approximation to Eq. $6 \mathrm{a}$, is often used to predict failure of steam generator tubes that are fully constrained against bending:

$$
\mathrm{p}_{\mathrm{cr}}=\frac{2 \bar{\sigma} \mathrm{h}}{\mathrm{R}}\left(1-\frac{\theta}{\pi}\right) \text {. }
$$

In reality, the tube support plates offer significant but not total restraint against bending, a circumstance that tends to increase the failure pressure to somewhere between those predicted by Eq. $5 \mathrm{a}$ and those of 
Eq. $6 a($ or $6 c) \cdot 10$

\subsubsection{Crack Opening Area and Displacement of Throughwall Circumferential Cracks}

To obtain the COA, we used the Paris/Tada model. ${ }^{11}$ Being restricted to small-scale yielding, this model does not depend on the bending constraint on the tube. The COA before the onset of large-scale plasticity in the cracked section is given by the following:

$$
\mathrm{A}=\frac{\pi \mathrm{pR}^{2}}{\mathrm{E}} \mathrm{B},
$$

where

$$
\begin{aligned}
& \mathrm{B}=\left\{\begin{array}{c}
\lambda_{\mathrm{e}}{ }^{2}+0.16 \lambda_{\mathrm{e}}^{4} \text { for } 0 \leq \lambda_{\mathrm{e}} \leq 1 \\
0.02+0.81 \lambda_{\mathrm{e}}^{2}+0.30 \lambda_{\mathrm{e}}{ }^{3}+0.03 \lambda_{\mathrm{e}}^{4} \text { for } 1 \leq \lambda_{\mathrm{e}} \leq 5
\end{array}\right. \\
& \lambda_{\mathrm{e}}=\theta_{\mathrm{e}}\left(\frac{\mathrm{R}}{\mathrm{h}}\right)^{0.5} \\
& \theta_{\mathrm{e}}=\theta\left[\mathrm{l}+\mathrm{F}_{\mathrm{m}}^{2} \mathrm{p}^{2} \mathrm{R}^{2} /\left(8 \mathrm{~h}^{2} \sigma_{\mathrm{y}}^{2}\right)\right] \\
& \mathrm{F}_{\mathrm{m}}=\left\{\begin{array}{c}
1+0.1501 \lambda^{1.5} \text { for } \lambda \leq 2 \\
0.8875+0.2625 \lambda \text { for } 2 \leq \lambda \leq 5
\end{array}\right. \\
& \lambda=\theta\left(\frac{\mathrm{R}}{\mathrm{h}}\right)^{0.5} .
\end{aligned}
$$

It should be noted that the Paris/Tada model ${ }^{11}$ is restricted to small-scale yielding $(\lambda \leq 5)$ and does not account for the bending effects that become important at pressures that induce large-scale plasticity in the crack plane. As a result, the COA calculated by this model is independent of the span of the tube or the support conditions. The COA for cases where large-scale plasticity occurs in the cracked section is discussed in Ref. 10.

\subsubsection{Part-Throughwall Circumferential Cracks}

Consider a tube with mean radius $R$ and wall thickness $h$ and with either two symmetrical partthroughwall circumferential cracks or a single PTW circumferential crack of angular length $2 \theta$ and depth a. At low temperatures, where creep effects are negligible, the ligament failure pressure ( $p_{s c}$ ) is generally expressed in terms of a stress magnification factor $\left(m_{p}\right)$ by equating the magnified axial stress in the ligament to the flow stress,

$$
\sigma_{\text {lig }}=\mathrm{m}_{\mathrm{p}} \frac{\mathrm{p}_{\mathrm{sc}} \mathrm{R}}{2 \mathrm{~h}}=\bar{\sigma} .
$$

The failure pressure for circumferentially cracked tubes, i.e., the value of the magnification factor $\mathrm{m}_{\mathrm{p}}$, depends strongly on the degree of restraint that the tubes are subjected to against bending. The 
two extreme cases, i.e., the free-bending case and the completely constrained case, are relatively easy to analyze. Generally, steam generator tubes are sufficiently constrained laterally that failure loads are expected to be much closer to the completely constrained case than the free-bending case. The discussion here assumes that the tubes are either completely constrained or are completely free to bend.

\subsubsection{Fully Constrained Case}

The fully constrained case also includes the case for an unconstrained tube that contains two symmetrical cracks. In this situation, the whole section that contains the crack (or cracks) is subjected to axial tensile stress, with the ligament (or ligaments) subjected to stress intensification. If the average stress in the ligament (or ligaments) is expressed as $1 / \mathrm{m}$ times the average stress in the rest of the section that contains the crack (or cracks), the average ligament axial stress ( $\sigma$ lig) can be calculated from a simple equilibrium of axial forces,

$$
\sigma_{\text {lig }}=\frac{\mathrm{pR}}{2 \mathrm{~h}} \frac{1}{\left[\mathrm{~m}+\left(\frac{\mathrm{n} \theta}{\pi}\right)\left(1-\frac{\mathrm{a}}{\mathrm{h}}-\mathrm{m}\right)\right]^{\prime}}
$$

where

$$
\mathrm{n}=\left\{\begin{array}{c}
1 \text { for a single crack } \\
2 \text { for two symmetrical cracks. }
\end{array}\right.
$$

We define $m_{p}$ as the ratio of the average ligament axial stress and the average axial stress in the unflawed tube,

$$
\mathrm{m}_{\mathrm{p}}=\frac{1}{\left[\mathrm{~m}+\left(\frac{\mathrm{n} \theta}{\pi}\right)\left(1-\frac{\mathrm{a}}{\mathrm{h}}-\mathrm{m}\right)\right]} .
$$

Originally, Kurihara et al. ${ }^{12}$ used the empirically obtained expression

$$
\mathrm{m}=1-\left(\frac{\mathrm{a}}{\mathrm{h}}\right)^{\kappa}\left(\frac{\mathrm{n} \theta}{\pi}\right)^{\mu}
$$

(with $n=1$ ). Although Kurihara et al. ${ }^{12}$ recommended values of $\kappa=2$ and $\mu=0.2$ for the exponents, the results are almost indistinguishable from those obtained by using $\kappa=3$ and $\mu=0.3$. Because the value of $\mathrm{m}$ in Eq. 10 does not tend to 0 when a/h tends to 1 for all $\theta$. This equation was modified to have the same form as in the case of axial cracks, i.e.,

$$
\mathrm{m}=\frac{1-\frac{\mathrm{a}}{\mathrm{h}}}{1-\frac{\mathrm{a}}{\mathrm{Nh}}},
$$

where 


$$
\mathrm{N}=1+\lambda\left(\frac{\mathrm{n} \theta}{\pi}\right)^{\gamma}
$$

and $\lambda$ and $\gamma$ are fitting parameters.

Both the failure modes and moments of the original set of test data from four-point bending failure tests on pressurized, PTW circumferentially cracked, Type 304 stainless steel pipes at room temperature (used by Kurihara et al. ${ }^{12}$ ) can be predicted somewhat better by the current model with $\lambda=0.2$ and $\gamma=0.2$ than by the Kurihara model. ${ }^{2}$ This approach led to reasonable predictions of failure temperatures of tubes with two symmetrical PTW circumferential notches subjected to high temperature ramps. ${ }^{1}$

\subsubsection{Free-Bending Case}

In the free-bending case, part of the section that contains the crack will generally be subjected to compressive stress. As a result, Eq. 9a must be replaced by

$$
\sigma_{\text {lig }}=\frac{\mathrm{pR}}{2 \mathrm{~h}} \frac{1}{\left[\mathrm{~m}\left(1-\frac{2 \beta}{\pi}\right)+\left(\frac{\mathrm{n} \theta}{\pi}\right)\left(1-\frac{\mathrm{a}}{\mathrm{h}}-\mathrm{m}\right)\right]^{\prime}}
$$

where the angle $\beta$ that defines the location of the neutral axis is given by

$$
\beta=\sin ^{-1}\left\{\frac{\sin \theta}{2}\left[1-\frac{1}{m}\left(1-\frac{a}{h}\right)\right]\right\} \text { for } \beta \leq \pi-\theta,
$$

and Eq. 9b must be replaced by

$$
\mathrm{m}_{\mathrm{p}}=\frac{1}{\left[\mathrm{~m}\left(1-\frac{2 \beta}{\pi}\right)+\left(\frac{\mathrm{n} \theta}{\pi}\right)\left(1-\frac{\mathrm{a}}{\mathrm{h}}-\mathrm{m}\right)\right]^{\prime}}
$$

with $\mathrm{m}$ and $\mathrm{N}$ are defined by Eqs. $11 \mathrm{a}$ and $11 \mathrm{~b}$, respectively. This approach led to reasonable predictions of failure temperatures of free-to-bend tubes with a PTW circumferential notches subjected to high temperature ramps. ${ }^{1}$

Although a detailed analysis comparable to that presented in Ref. 2 for TW cracks has not been carried out, it is expected that tubes with PTW circumferential cracks at the top of the tube sheet will behave as though they were fully constrained against bending. 


\subsection{Multiple Cracks/Notches}

\subsubsection{Two Throughwall Axial Cracks/Notches}

\subsubsection{Finite Element Analysis}

Two types of TW notches were analyzed. First, in type 2 specimens, two notches, $0.19-\mathrm{mm}$ (0.0075-in.) wide, were colinear with an axial ligament separating the two. Second, in type 4 specimens, the two axial notches were offset in the circumferential direction with the right tip of the first notch aligning with the left tip of the second notch (i.e., the ligament separating the two notches was circumferential). Finite element analyses were conducted for a type 2 specimen with two 6-mm (0.25in.) long TW notches separated by a $0.25-\mathrm{mm}(0.01-i n$.) wide axial ligament at room temperature. The engineering and true stress-strain curves of the as-received material are shown in Fig. 18. Initially, an analysis using infinitesimal deformation theory (engineering stress-strain curve) was conducted using the ANSYS code. The analysis showed that much of the ligament is under the plane strain condition (i.e., axial plastic strain $=0$ ). Variations of the volume-averaged hoop stress, von Mises effective stress, and hoop plastic strain with pressure in the ligament are shown in Fig. 19a. A flow stress criterion would predict a ligament rupture pressure of either $6 \mathrm{MPa}(0.9 \mathrm{ksi})$ or $8 \mathrm{MPa}(1.2 \mathrm{ksi})$, depending on whether hoop stress or von Mises effective stress is used. Both of these values are much less than the maximum pressure of $17 \mathrm{MPa}(2.5 \mathrm{ksi})$ employed in the test without ligament rupture. The analysis was discontinued at a pressure of $15.5 \mathrm{MPa}(2.25 \mathrm{ksi})$, after which numerical problems were encountered. Extrapolation implies that the average effective stress in the ligament would equal the ultimate tensile strength (UTS), or the average hoop stress would equal the plane strain UTS at a pressure of $17 \mathrm{MPa}$ (2.5 ksi).

The same problem was reanalyzed by ANSYS as well as ABAQUS using finite deformation theory (true stress-strain curve). Graphs of the average true hoop stress, true effective stress and hoop true plastic strain as a function of the pressure are shown in Fig. 19b. Plots of the average thickness vs. pressure (Fig. 20) shows that onset of necking in the ligament is predicted to occur at a pressure of $17 \mathrm{MPa}(2.5 \mathrm{ksi})$ by ANSYS and $19.5 \mathrm{MPa}(2.8 \mathrm{ksi})$ by ABAQUS, in reasonable agreement with the test result.

Finite element analysis was also conducted for a specimen with two 6-mm (0.25-in.) long type 4 TW notches separated by a $1.27 \mathrm{~mm}$ (0.05 in.) wide circumferential ligament. The variation of the ligament-averaged hoop stress, von Mises effective stress, hoop plastic strain, and effective plastic strain with pressure is shown in Fig. 21a. If we use the failure criterion that is used in the infinitesimal analysis, i.e., failure occurs when the average effective stress in the ligament equals the ultimate tensile strength, the failure pressure is predicted to be $23 \mathrm{MPa}(3.3 \mathrm{ksi})$, which is significantly less than the experimentally observed burst pressure of $32.5 \mathrm{MPa}(4.71 \mathrm{ksi})$. The same problem was reanalyzed using finite deformation FEA, and the calculated values are plotted in Fig. 21b. An examination of the FEA results shows that the ligament is subjected to high shearing strain and rotation (Fig. 22) but relatively low hoop and axial stresses (Fig. 21b). Average thickness vs. pressure plots for this specimen, together with one in which the ligament width is $2.5 \mathrm{~mm}(0.1 \mathrm{in}$.), are shown in Fig. 23 . The finite deformation analyses are much more in agreement with test results than infinitesimal analyses, because they properly account for the large rotations of the ligament (Fig. 22). 


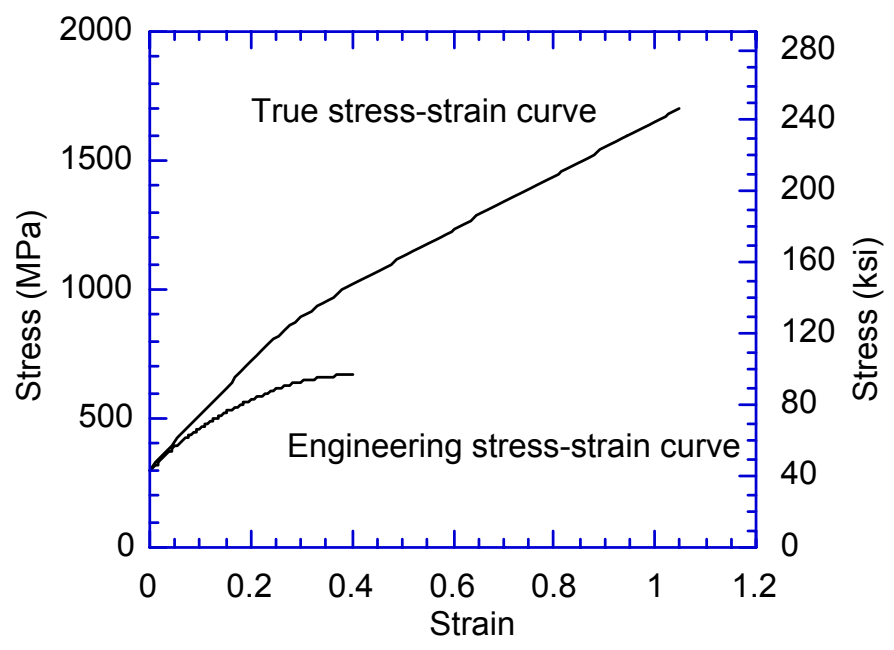

Figure 18.

Engineering and true stress-strain curves of Alloy 600 used for finite element analysis.

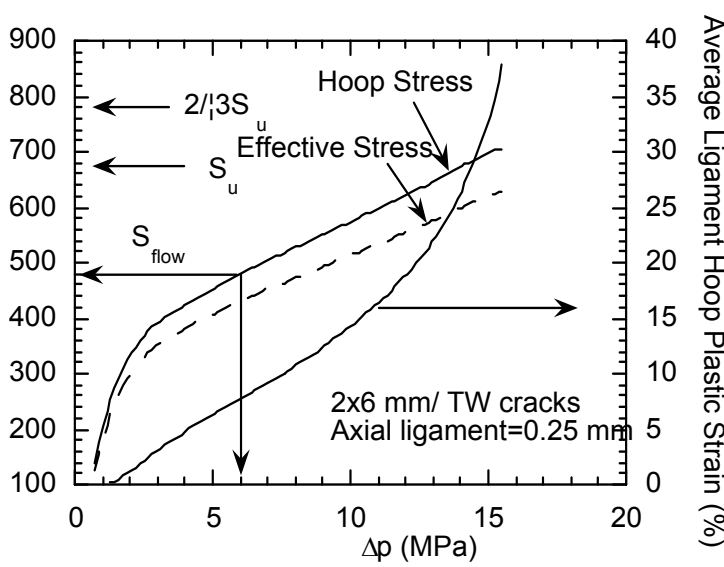

(a)

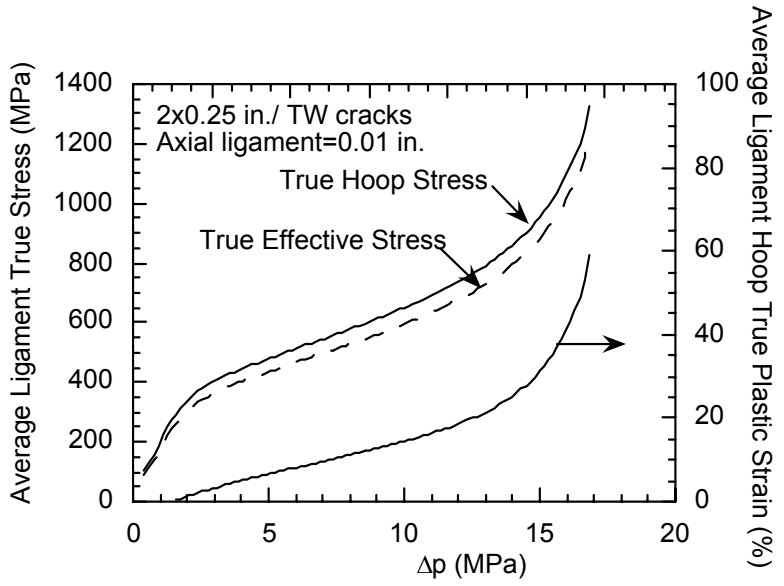

(b)

Figure 19. Calculated variations of average hoop stress, average von Mises effective stress, and average hoop plastic strain in the axial ligament with pressure using (a) infinitesimal deformation and (b) finite deformation analyses for two 6-mm (0.25-in.) long axial cracks separated by a $0.25-\mathrm{mm}(0.01-\mathrm{in}$.) wide axial ligament. 


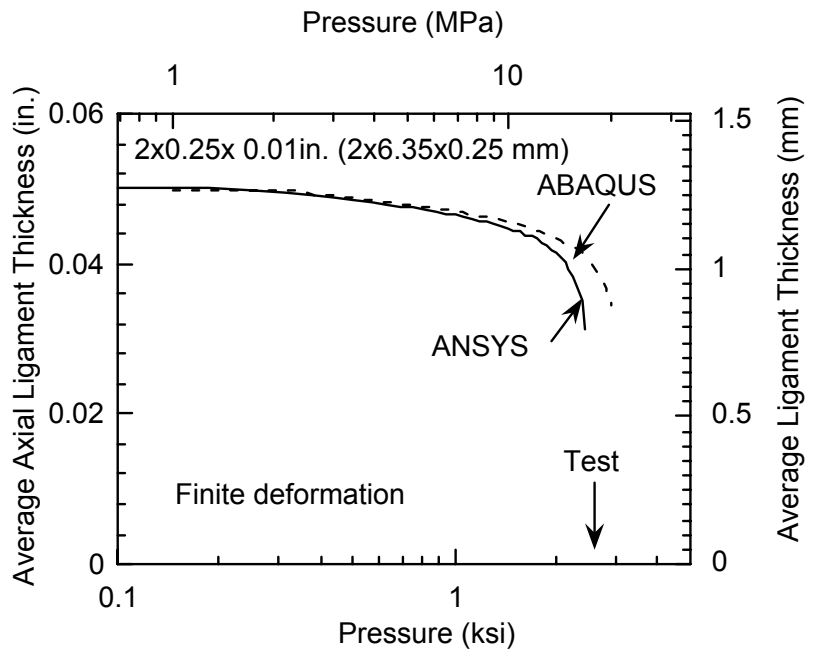

Figure 20.

Calculated variation of average internotch axial ligament thickness with pressure using finite deformation analyse by ANSYS and ABAQUS for two 6-mm (0.25-in.) long axial cracks separated by a $0.25-\mathrm{mm}(0.01-$ in. $)$ wide axial ligament.

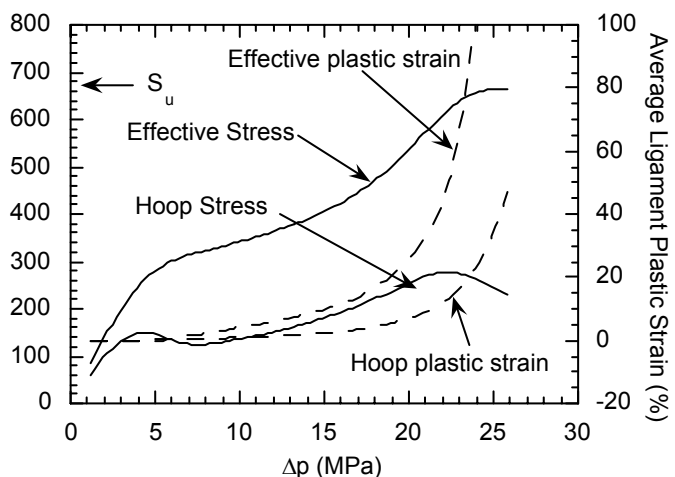

(a)

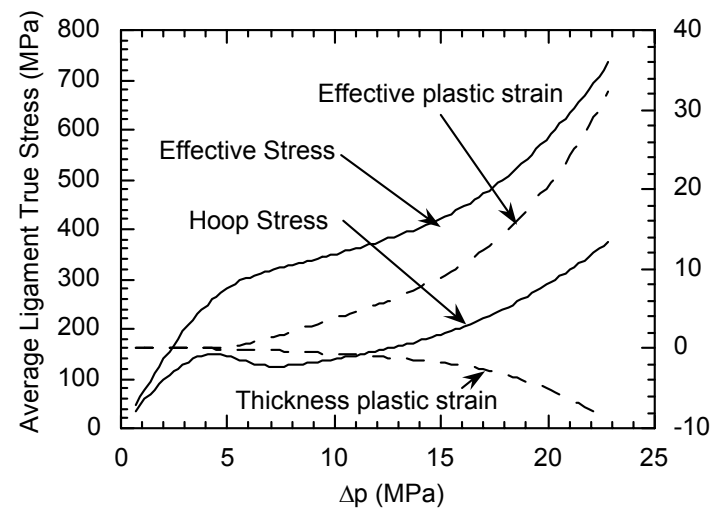

(b)

Figure 21. Variation of average hoop stress, average von Mises effective stress, average thickness plastic strain, and average effective plastic strain in the circumferential ligament with pressure for two 6-mm (0.25-in.) long axial cracks separated by a $1.27-\mathrm{mm}(0.05-i n$.$) circumferential$ ligament calculated using (a) infinitesimal deformation analyses, and (b) finite deformation analyses.

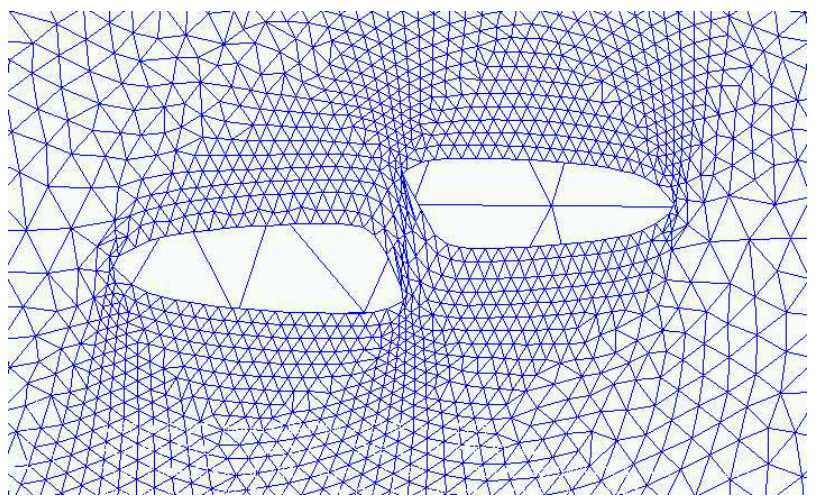

Figure 22.

Deformed shape of type 4 specimen. 


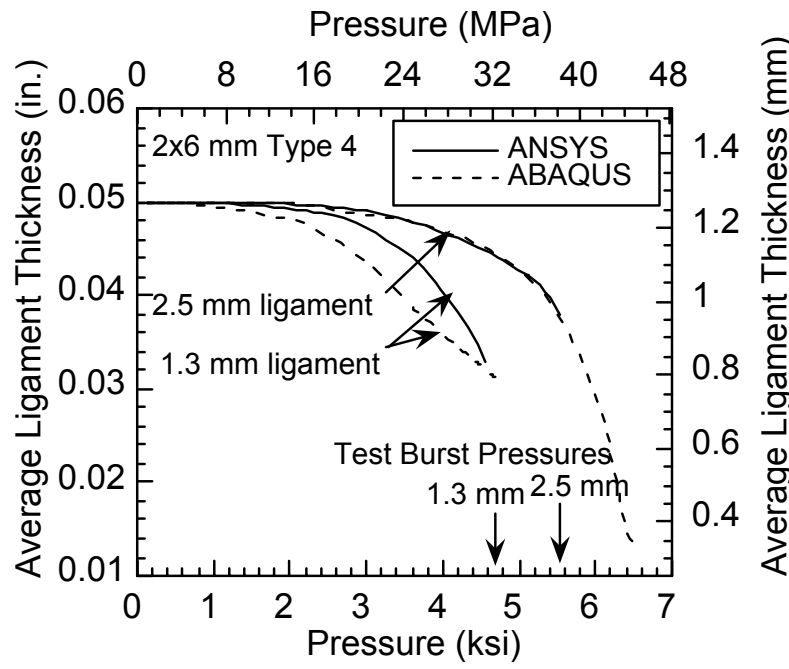

Figure 23.

Calculated variation of average

circumferential ligament thickness with pressure using finite deformation analyse by ANSYS and ABAQUS for two 6-mm (0.25-in.) long axial cracks separated by a $1.3-$ and $2.5-\mathrm{mm}(0.05-$ and 0.1 -in.) circumferential ligament.

The predicted ligament ruptures for type 2 and type 4 specimens with two TW axial cracks are shown in Fig. 24. Note that although for small ligament widths the failure pressures of both types of ligaments are comparable, the type 4 ligaments fail at higher pressures than type 2 ligaments with increasing ligament size.

\subsubsection{Test Results for Specimens with Two Throughwall Notches}

A pressure test at room temperature was conducted in the ANL Pressure and Leak Rate Facility on a specimen with two type 2 (colinear) axial TW notches that were $6 \mathrm{~mm}(0.25 \mathrm{in}$.) long and had a $0.25-$ $\mathrm{mm}(0.01-\mathrm{in}$.) wide axial ligament in-between. This specimen experienced a leak rate of $18.6 \mathrm{~L} / \mathrm{min}$ $(4.9 \mathrm{gpm})$ at $17 \mathrm{MPa}(2.5 \mathrm{ksi})$ but without ligament rupture. In a subsequent test at $282^{\circ} \mathrm{C}$, a specimen of similar geometry experienced ligament rupture at $15.5 \mathrm{MPa}(2.25 \mathrm{ksi})$. The flow stress of Alloy 600 at $282^{\circ} \mathrm{C}$ is about $10 \%$ less than that at room temperature. It is likely that the room temperature test was close to ligament rupture at $17 \mathrm{MPa}(2.5 \mathrm{ksi})$.

Tests were conducted on specimens with two TW axial notches in the type 4 configuration. Predicted vs. observed ligament rupture pressures are shown in Fig. 25. Note that for type 4 cracks with two 6- or 13-mm cracks, the ligament width has to be $\geq 0.8$ to $1.1 \mathrm{~mm}$ in order to strengthen the cracks without the ligament. Figure 24 shows that for type 2 cracks of similar size, the ligament width has to be greater than 1.8 to $2.5 \mathrm{~mm}$ to strengthen the cracks without the ligament.

\subsubsection{Calculation of Crack Opening Areas}

Crack opening areas for type 2 and type 4 configurations of two cracks were computed by FEA. Variations of COA with pressure for two type 2 (colinear) cracks, each 6- and 13-mm long, are shown in Figs. 26a and 26b, respectively. Similar plots for two type 4 (staggered) cracks are shown in Figs. 27ab. To determine the effect of ligament width on COA, the COAs 


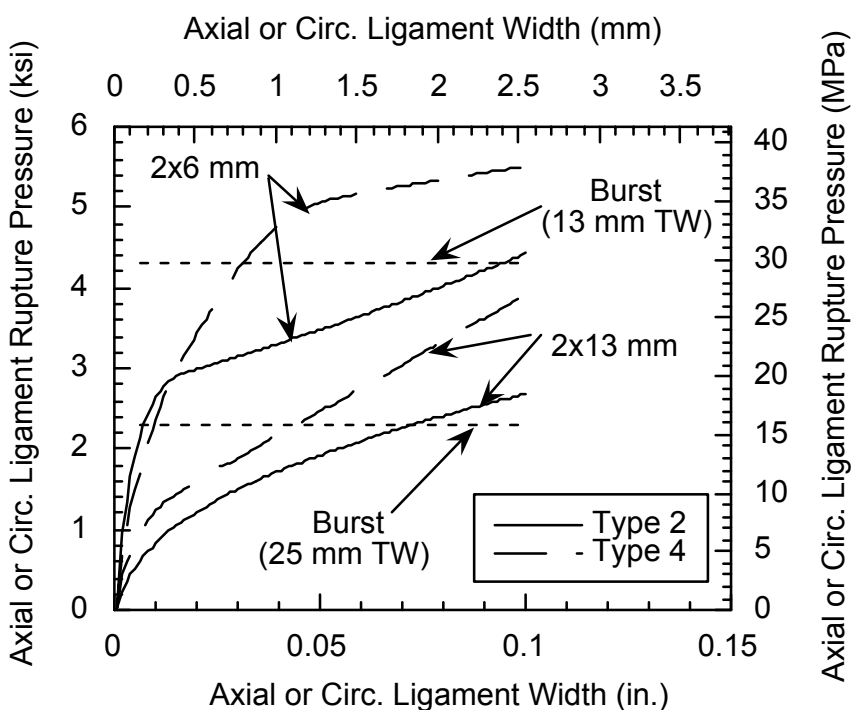

Circ. Ligament Width (mm)

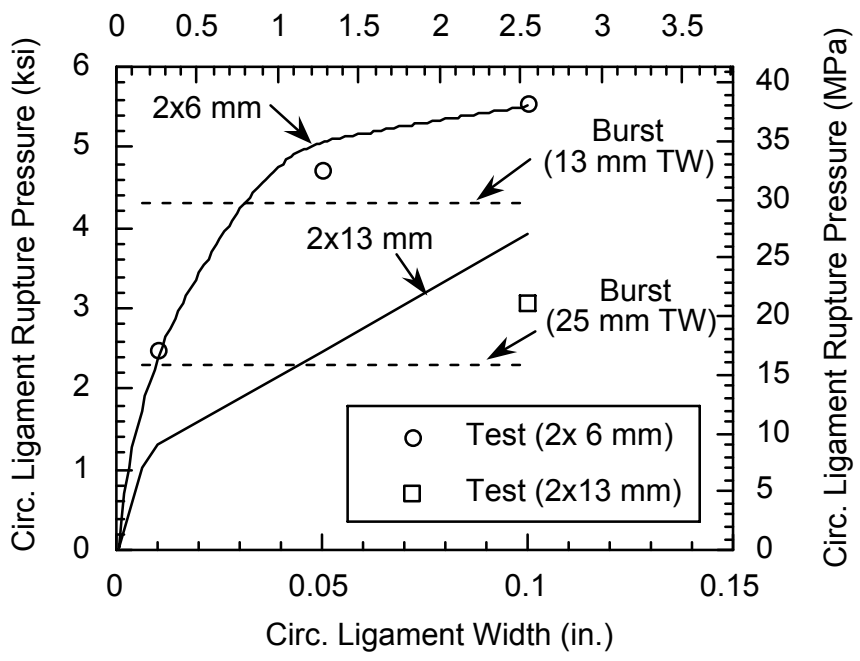

Figure 24.

Predicted ligament rupture pressures of type 2 and type 4 specimens with two TW axial cracks.
Figure 25.

Predicted vs. observed variation of ligament rupture pressure with ligament width for type 4 specimens having two 6- and 13-mm long TW notches. 


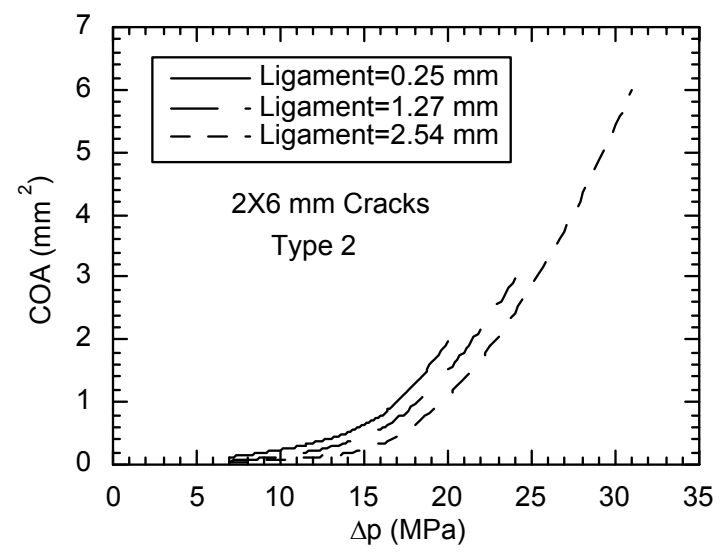

(a)

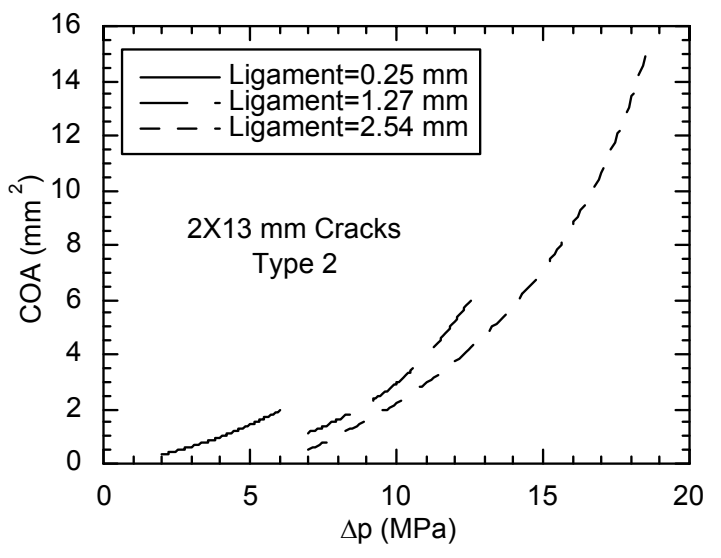

(b)

Figure 26. Variation of COA with pressure and ligament width for (a) two 6-mm and (b) two 13-mm type 2 (colinear) cracks.

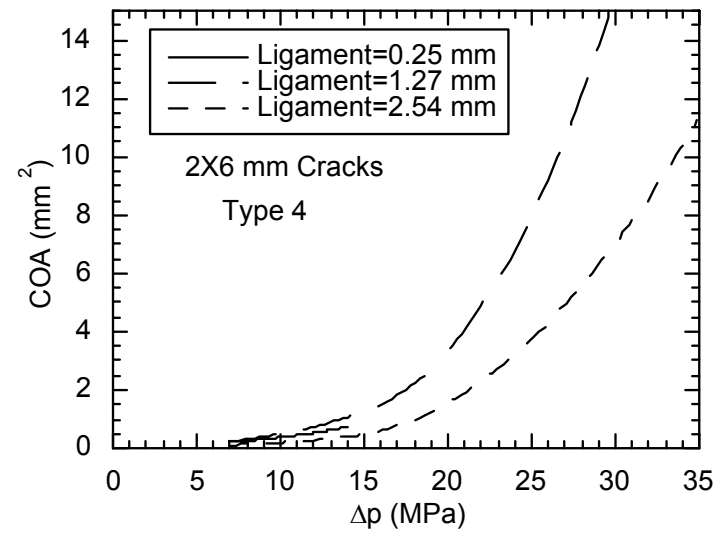

(a)

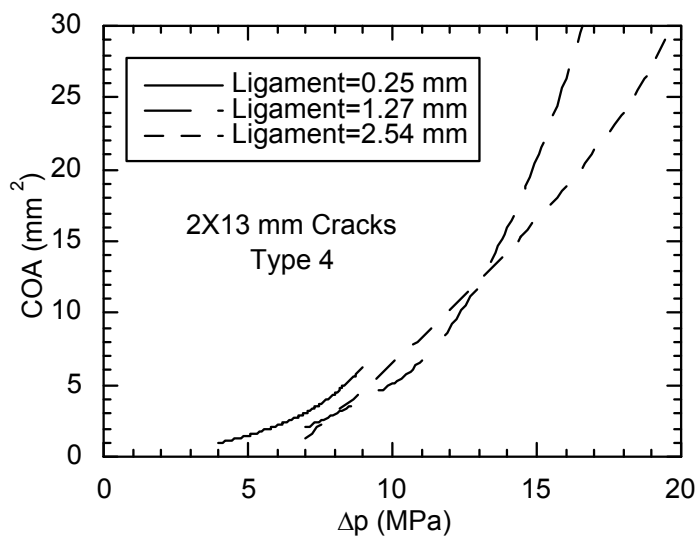

(b)

Figure 27. Variation of COA with pressure and ligament width for (a) two 6-mm and (b) two-13 mm type 4 (staggered) cracks.

presented in Figs. $26 a-b$ and $27 a-b$ are plotted after normalizing them with the COAs of a crack without any ligament in Figs. 28a-b. As expected, the normalized COAs are always less than one. As shown in Figs. $28 a-b$, the normalized COA for type 2 cracks is less than that for type 4 cracks at the same pressure.

\subsubsection{Two Part-Throughwall Axial Cracks/Notches}

We used the equivalent rectangular crack method to predict the through-thickness (radial) ligament rupture for two PTW cracks separated by either an axial (type 2) or circumferential (type 4) full-thickness ligament. The procedure is depicted in Fig. 29 for two 13-mm long, 80\% deep PTW notches in a type 2 configuration. The dashed line in Fig. 29 represents the equivalent rectangular crack, which has an effective depth of $76 \%$ and effective length of $26.7 \mathrm{~mm}$. In this case the predicted pressure for ligament rupture, $21.7 \mathrm{MPa}$, is equal to that of the test ligament rupture. 


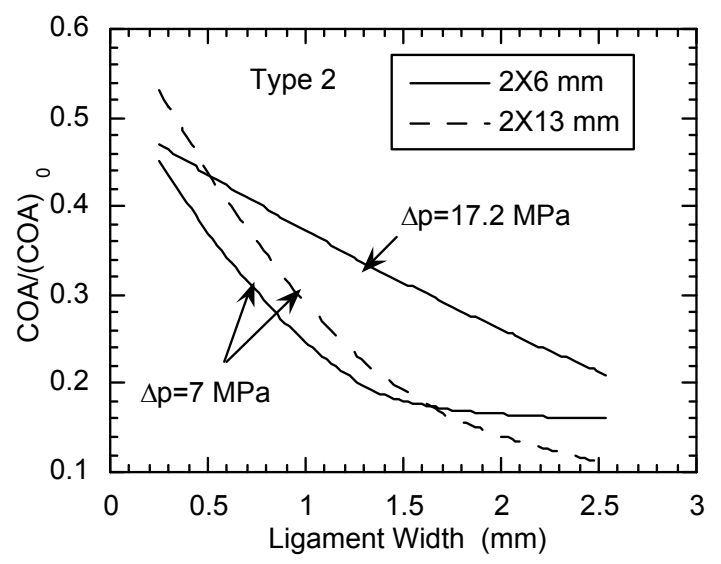

(a)

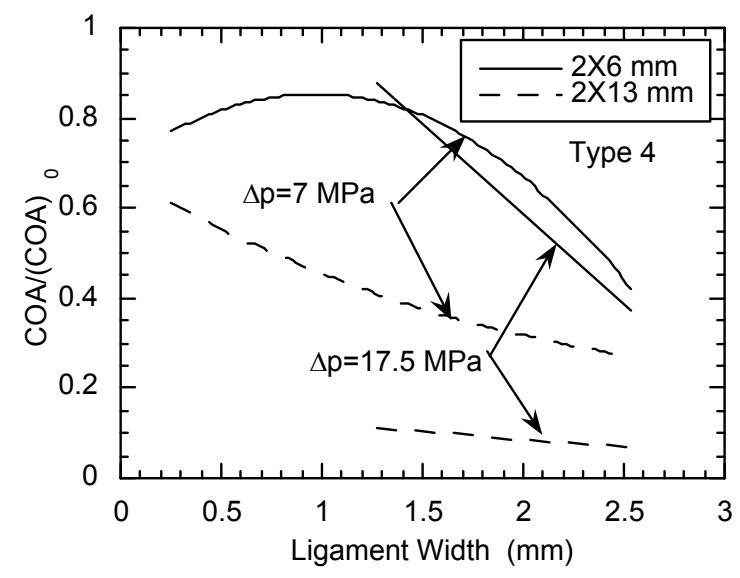

(b)

Figure 28. Variation of the COA for a crack with ligament normalized by the COA for a crack without ligament for (a) two type 2 (colinear) and (b) two type 4 (staggered) cracks at two values of pressure.

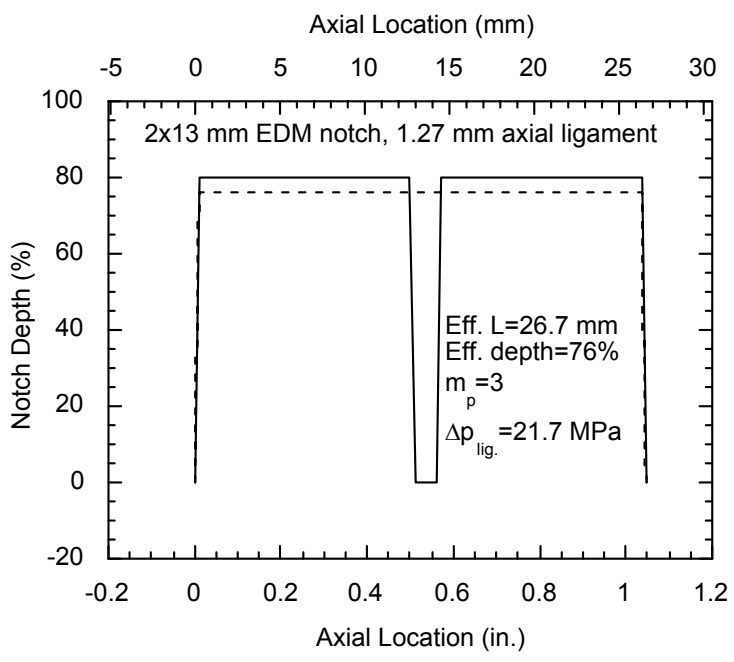

Figure 29.

Equivalent rectangular crack for two 13-mm long and $80 \%$ deep PTW notches separated by a $1.27-\mathrm{mm}$ wide ligament.

The through-thickness ligament rupture pressures for tubes with two axial notches, type 2 (axial ligament) and type 4 (circumferential ligament), were calculated by the equivalent rectangular approach for various notch lengths and inter-notch ligament widths. Tests were conducted in the ANL High Pressure Test Facility on specimens without bladders and were interrupted after the through-thickness ligament ruptured, as evidenced by onset of leakage (Stage 1). The predicted vs. experimental ligament rupture pressures given in Figs. 30a-b for two 6- and 13-mm long notches, respectively, indicate that the equivalent rectangular crack approach can predict the pressures for through-thickness ligament rupture reasonably well. Except for the cases identified in Figs. 30a-b, the through-thickness ligament and the inter-notch ligament ruptured simultaneously. Note that the inter-notch ligament width beyond which the two notches do not interact (from the viewpoint of the pressure for through-thickness ligament rupture)) depends on the notch depth as well as notch length. A 3-mm (0.1-in.) wide ligament increases the pressure for through-thickness ligament rupture by $\approx 30 \%$, with the axial ligament having a slightly higher strengthening effect than the circumferential ligament. For smaller ligament widths, both types of ligaments have a comparable strengthening effect. 


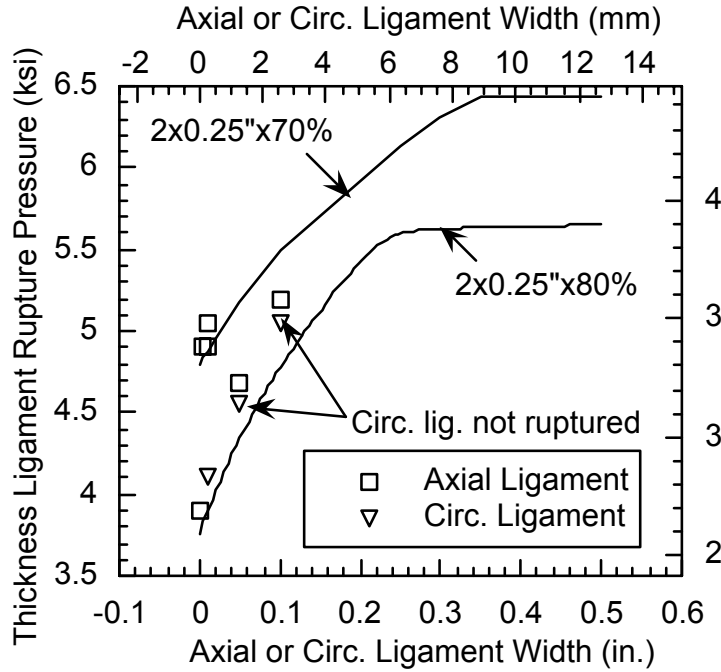

(a)

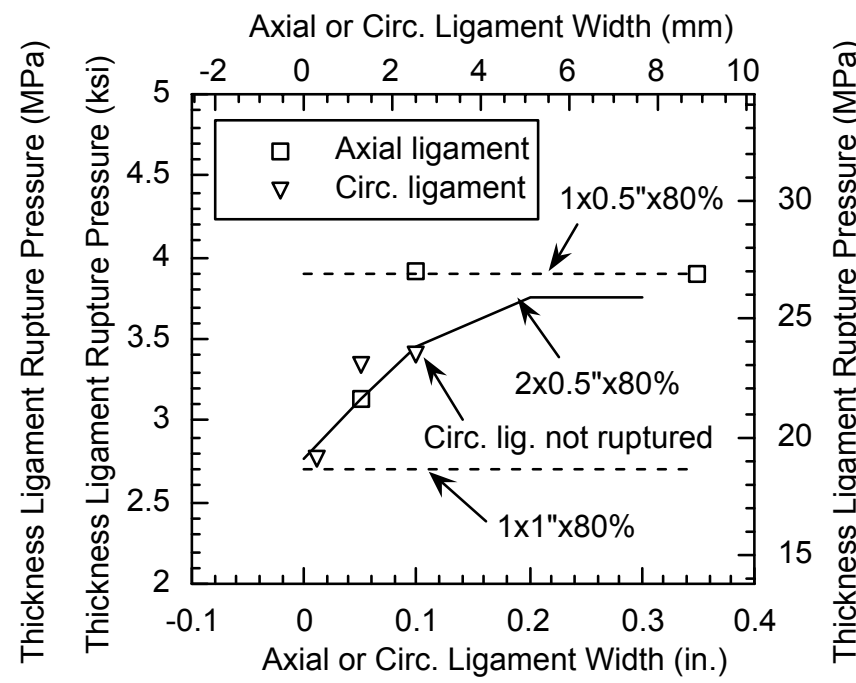

(b)

Figure 30. Predicted and observed through-thickness ligament rupture pressures vs. axial or circumferential ligament widths for two PTW EDM notches (a) 6-mm (0.25-in.) and (b) 13$\mathrm{mm}(0.5-\mathrm{in}$.$) long.$

\subsubsection{Multiple Part-Throughwall Notches}

\subsubsection{Specimens with Multiple Axial Notches}

A series of tests was conducted on Alloy 600 tubes with 2 to 6 PTW axial laser-cut notches in various configurations (Fig. 31 . The ligament widths were $0.13-0.25 \mathrm{~mm}(0.005-0.010 \mathrm{in}$.). The equivalent rectangular crack method was used to predict the pressures for through-thickness notch tip ligament rupture. Predicted vs. observed pressures for through-thickness ligament rupture are shown in Fig. 32. Although the rupture pressures are reasonably predicted by the equivalent rectangular crack method for the case of two notches, they are overestimated by $\approx 30 \%$ for the case of six notches.

\subsubsection{Specimens with Multiple Circumferential Notches}

Two types of circumferential, PTW, laser-cut notches were tested (Fig. 33). The type 7 specimens were $360^{\circ}$ circumferential notches whose depths were nominally $80 \%$. In one specimen, the circumferential notches were axially separated by $0.127 \mathrm{~mm}(0.005 \mathrm{in}$.$) , and it first leaked at 50 \mathrm{MPa}$ $(7.3 \mathrm{ksi})$ and ruptured at $51 \mathrm{MPa}(7.45 \mathrm{ksi})$. In the second specimen, the circumferential notches were axially separated by $0.254 \mathrm{~mm}(0.010 \mathrm{in}$.$) , and it first leaked at 50 \mathrm{MPa}(7.3 \mathrm{ksi})$ and ruptured at $53 \mathrm{MPa}$ (7.7 ksi).

In the type 8 specimens, the axial ligaments separating the two sets of three circumferential notches (nominally $80 \%$ deep) were $0.127 \mathrm{~mm}(0.005 \mathrm{in}$.) and $0.254 \mathrm{~mm}(0.010 \mathrm{in}$.). The specimen with the narrower ligament first leaked at $36 \mathrm{MPa}(5.2 \mathrm{ksi})$ and ruptured at $38 \mathrm{ksi}(5.55 \mathrm{ksi})$. The specimen with the wider ligament first leaked at $38 \mathrm{MPa}(5.5 \mathrm{ksi})$ and ruptured at $39 \mathrm{MPa}(5.68 \mathrm{ksi})$. 


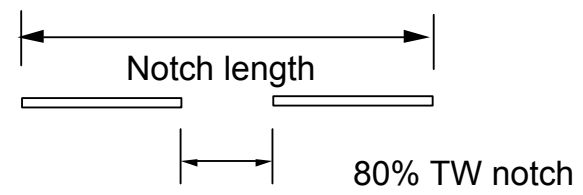

Ligament width

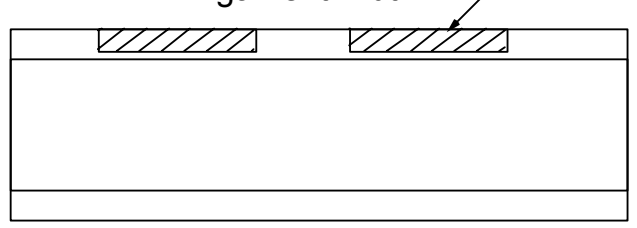

Type 2 specimen

(a)

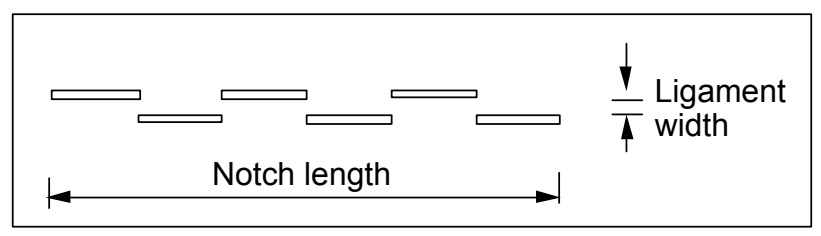

Type 4 specimen

(c)

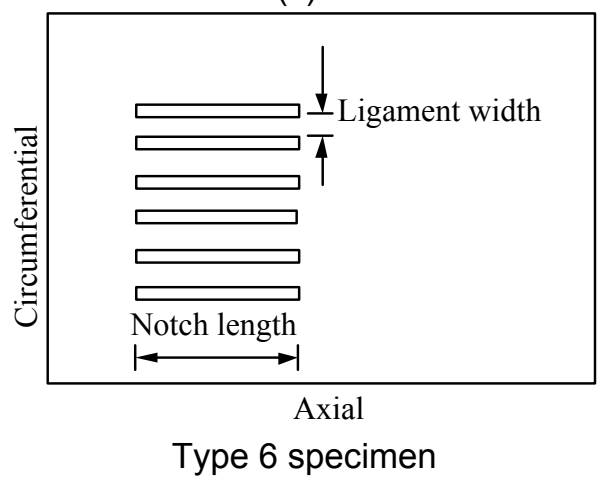

(e)

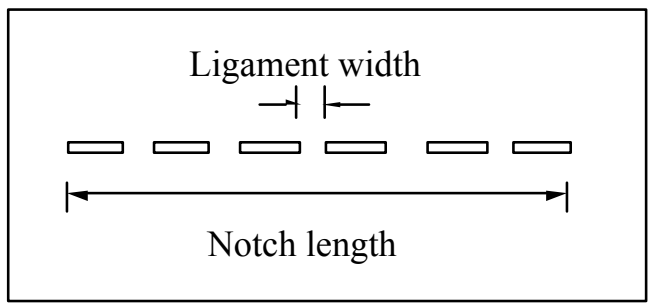

Type 3 specimen

(b)

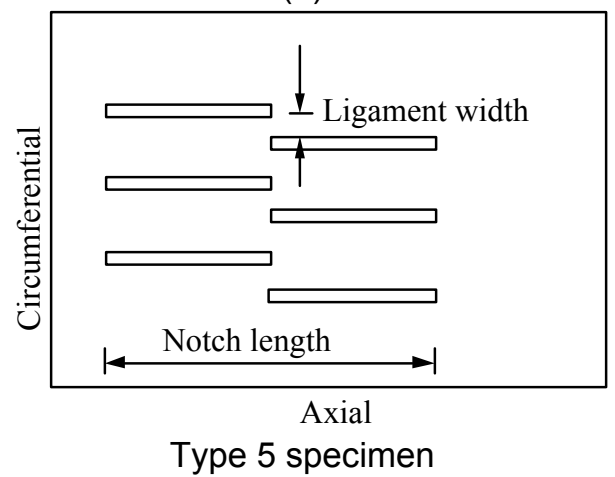

(d)

Figure 31. Geometries of multiple axial notch specimens.

\subsubsection{Specimens with Axial/Circumferential L- and T-Shaped Notches}

Tests were conducted with specimens having a $13-\mathrm{mm}(0.5-\mathrm{in}$.$) long, nominally 80 \%$ deep axial laser-cut notch and a $180^{\circ}$, nominally $80 \%$ deep circumferential laser-cut notch in an L-shaped (type 10) and T-shaped (type 9) configurations, as shown in Fig. 34. The measured depths of these notches are $69-71 \%$ by fractography and $69-72 \%$ by EC/NDE. There was no ligament separating the axial from the circumferential notch (i.e., zero ligament width). The T notch specimen failed at $31 \mathrm{MPa}$ (4.48 ksi), and the $L$ notch specimen failed at $31.3 \mathrm{MPa}(4.54 \mathrm{ksi})$. Figure $35 \mathrm{a}$ shows that the observed ligament rupture pressures for these two tests fall within the scatter bounds of a single (13-mm (0.5-in.) long axial notch of similar depth, thus indicating very little interaction effects. The axial notches in both these specimens were wide open after ligament rupture, and the through-thickness ligaments of the tip for the circumferential notches were ruptured to $123^{\circ}\left(65^{\circ}+58^{\circ}\right)$ from the point of intersection in the 
$\mathrm{T}$ notch and $90^{\circ}$ in the $\mathrm{L}$ notch. The unstable burst pressure plotted in Fig. 35b suggests that these specimens would have very likely burst unstably if the pump capacity was sufficient to keep up with the leak rate beyond $50 \mathrm{~L} / \mathrm{min}(12.8 \mathrm{gpm})$.
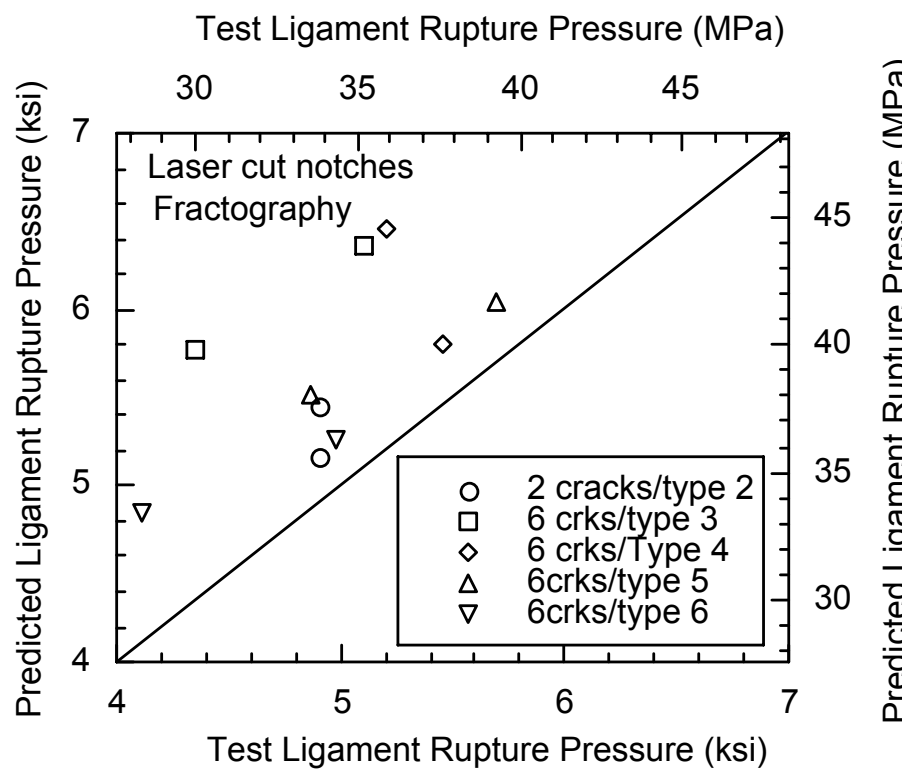

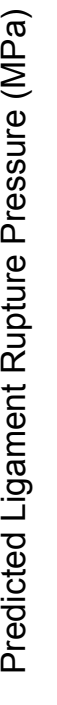

Figure 32.

Ligament rupture pressure vs. predicted ligament rupture pressure for multiple laser-cut notches.

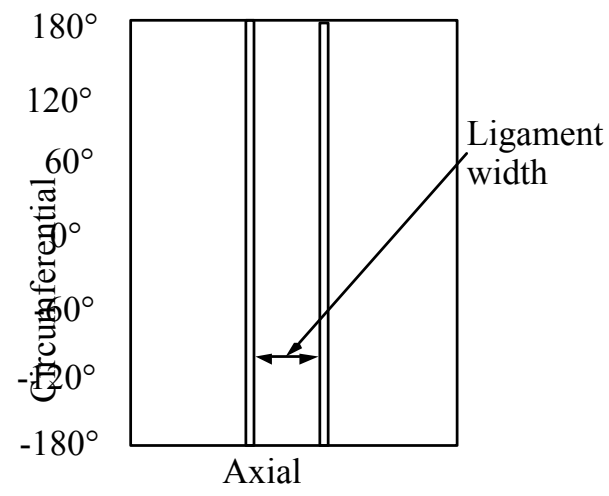

Type 7 Specimen

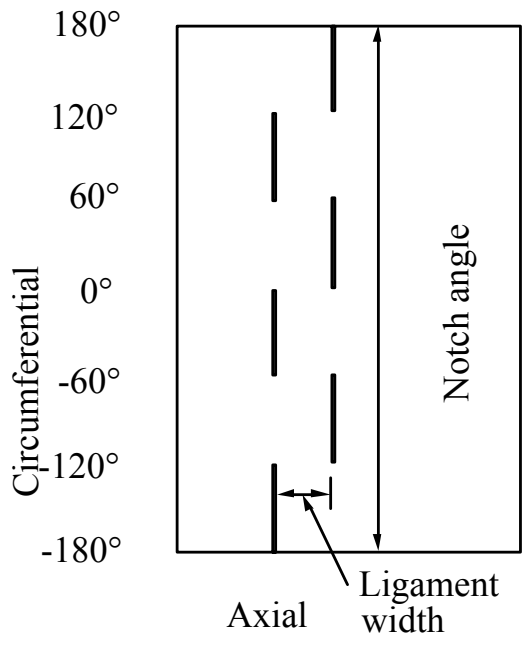

Type 8 specimen

Figure 33. Specimen with multiple circumferential laser-cut notches 


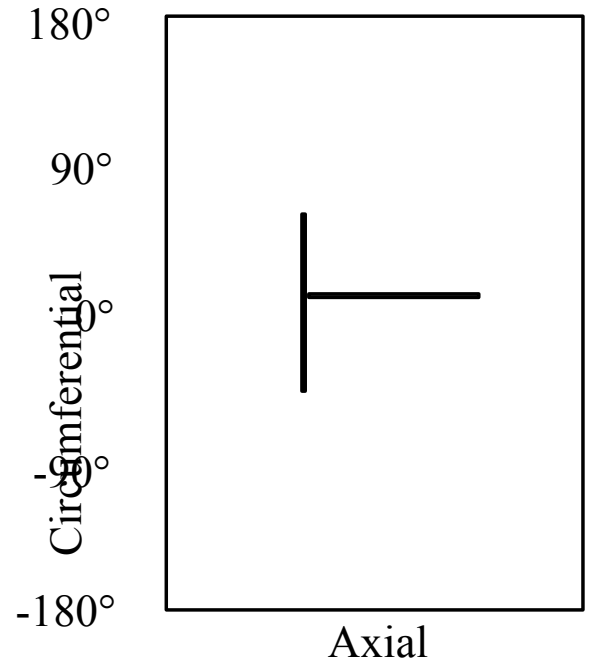

Type 9 specimen

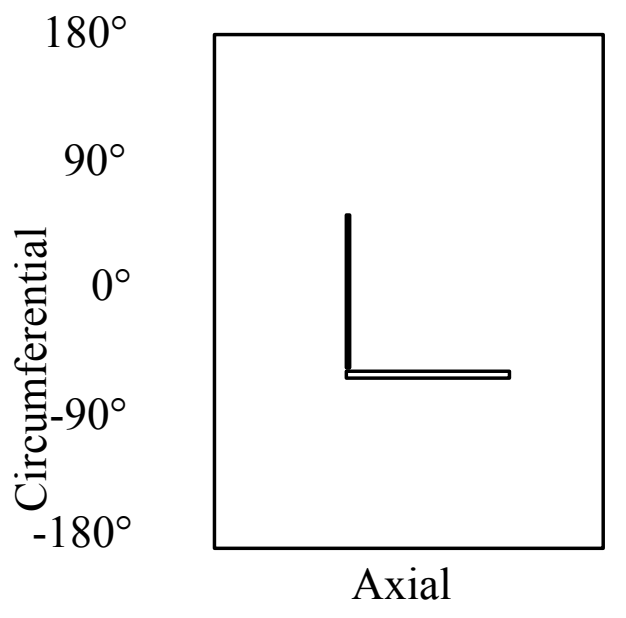

Type 10 specimen

Figure 34. Specimens with axial/circumferential laser-cut notches

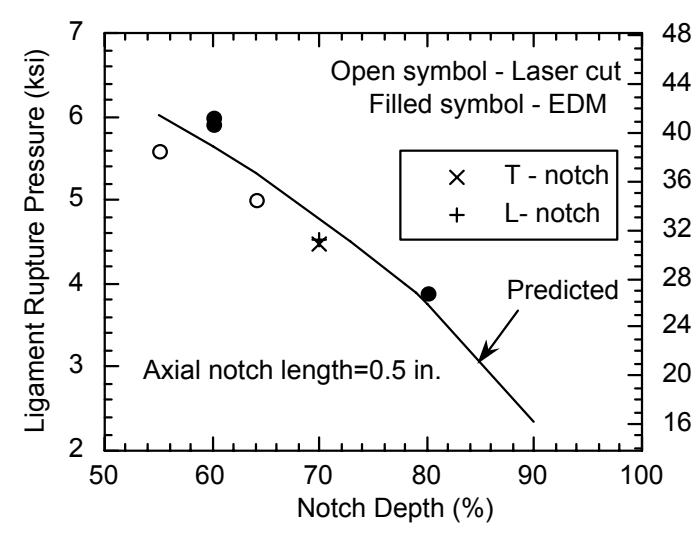

(a)

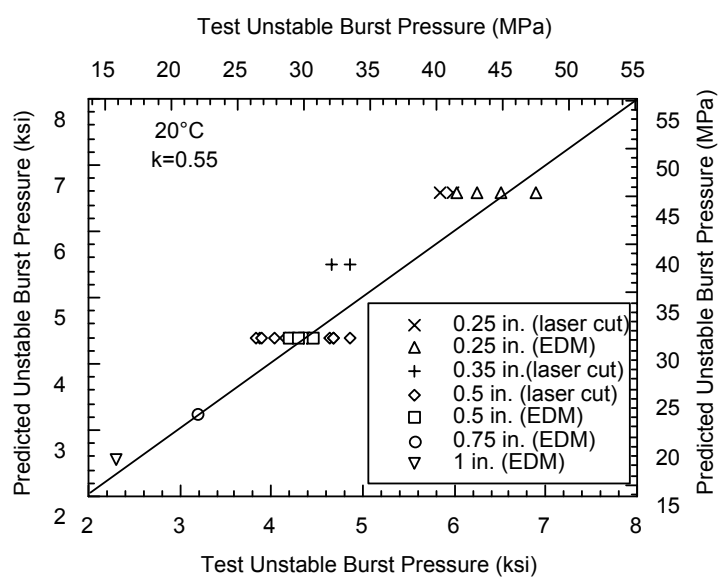

(b)

Figure 35. (a) Lgament rupture pressures of $T-$ and $L-$ notches with predicted and experimental ligament rupture pressures of a single $13-\mathrm{mm}(0.5-\mathrm{in}$.) long axial notch of various depths, and (b) predicted vs. observed unstable burst pressures for EDM and laser-cut notches of various lengths. 


\subsection{Leak Rate Model}

The volumetric leak rate $\mathrm{Q}$ at room temperature (RT) and $282^{\circ} \mathrm{C}$ is calculated using the smoothorifice, single-phase discharge equation.

$$
Q=0.6 \mathrm{~A} \sqrt{\frac{2 \Delta p}{\rho}},
$$

where $\mathrm{A}$ is crack opening area, $\Delta \mathrm{p}$ is pressure differential, and $\rho$ is mass density of water. Expressing $\mathrm{Q}$ in metric units $\left(\mathrm{L} / \mathrm{min}, \mathrm{A}\right.$ in $\mathrm{mm}^{2}, \Delta \mathrm{p}$ in $\mathrm{MPa}$, and $\rho$ in $\left.\mathrm{kg} / \mathrm{m}^{3}\right)$ gives

$$
Q=50.9 A \sqrt{\frac{\Delta p}{\rho}}
$$

or, using English units (i.e., $\mathrm{Q}$ in gpm, $\mathrm{A}$ in in ${ }^{2}, \Delta \mathrm{p}$ in $\mathrm{psi}$, and $\rho$ in $\mathrm{lb} / \mathrm{ft}^{3}$ ),

$$
\mathrm{Q}=180.2 \mathrm{~A} \sqrt{\frac{\Delta \mathrm{p}}{\rho}} .
$$

In leak rate calculations, we used the density of water as $997.5 \mathrm{~kg} / \mathrm{m}^{3}\left(62.27 \mathrm{lbs} / \mathrm{ft}^{3}\right)$ at RT and 735.3 $\mathrm{kg} / \mathrm{m}^{3}\left(45.9 \mathrm{lbs} / \mathrm{ft}^{3}\right)$ at $282^{\circ} \mathrm{C}$. We have previously used Eqs. $13 \mathrm{a}-\mathrm{C}$ to predict leak rates at $282^{\circ} \mathrm{C}$ with reasonable success down to a leak rate of $0.38 \mathrm{~L} / \mathrm{min}(0.1 \mathrm{gpm})$ without accounting for two-phase flow. ${ }^{2}$ We expect the above leak rate correlations to break down at or below an as-yet undetermined COD.

\subsection{Leak Rate Tests on EDM Notches}

\subsubsection{Rectangular Notches}

Leak rate tests on EDM notches validating Eq. 13a-c are reported in Ref. 2. Additional continuously measured leak rates in 100\% TW and 90\% TW rectangular EDM notches are compared with predicted leak rates in Figs. 36a and 36b, respectively. Note that both the ligament rupture pressure and subsequent leak rates are predicted well for the $90 \%$ part-TW notch (Fig. 36b). In both tests, the maximum pressure attained was limited by the maximum sustained flow capacity of $47 \mathrm{~L} / \mathrm{min}(12.5 \mathrm{gpm})$ in the High Pressure Test Facility.

\subsubsection{Trapezoidal Notches}

As mentioned in Section 2.1.3.2, TW crack lengths of some of the trapezoidal notches were measured after phase 1 testing at ANL. The TW crack length of the shallower notch (T-31) was close to the predicted equivalent rectangular crack length $(18 \mathrm{~mm}[0.7 \mathrm{in.}])$, and the TW crack length of the deeper notch (T-29) was less than predicted, $21 \mathrm{~mm}$ (0.83 in.) compared to the predicted $25 \mathrm{~mm}(1 \mathrm{in}$.). The leak rates for the two types of specimens were calculated by using the same correlation developed for rectangular cracks, assuming that the lengths are equal to the measured TW lengths. The results are compared with the measured leak rates for two similar specimens (OM-T32 and OM-T34) in Figs. 37a-b. Although the rupture pressures for the two tests are overestimated, the leak rate behavior during the depressurization phase is predicted quite accurately, suggesting that the TW COA of trapezoidal notches can be estimated from that of the equivalent rectangular crack. 


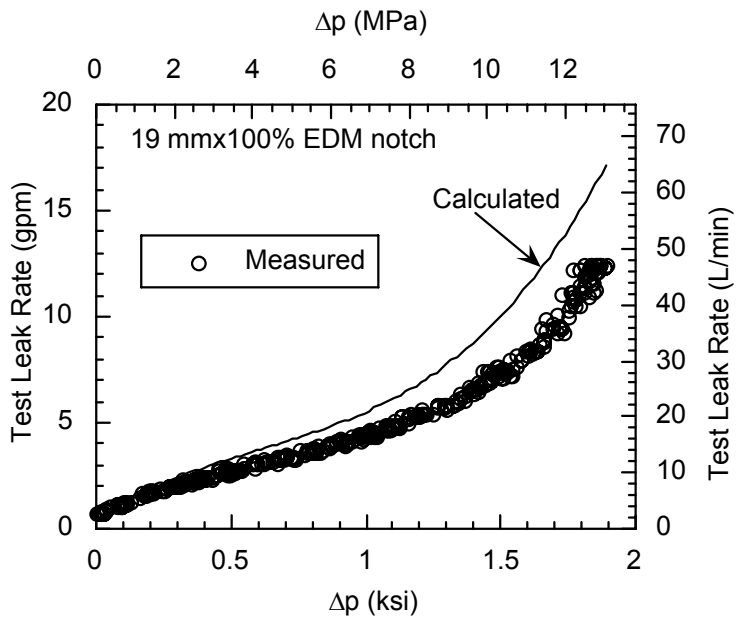

(a)

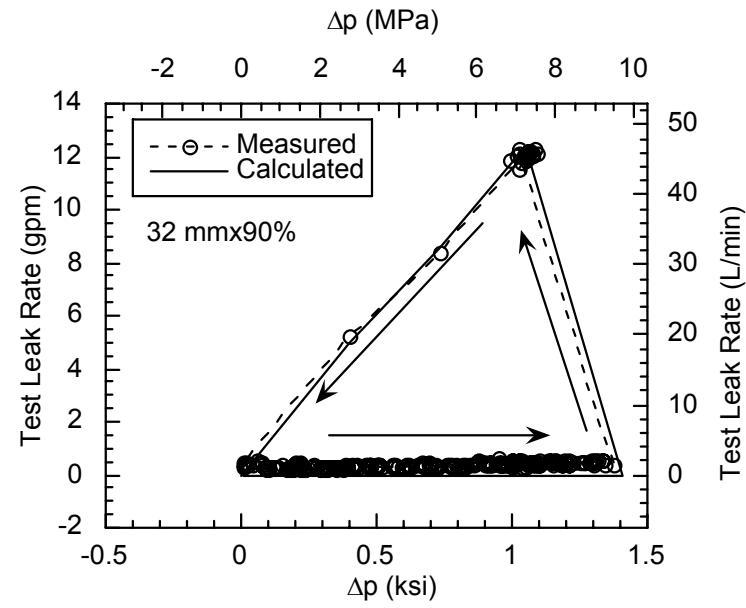

(b)

Figure 36. Calculated and measured pressure vs. leak rate plots of tests (a) OM-169 and (b) OM-171, both conducted on as-received tubes with rectangular notches at $20^{\circ} \mathrm{C}$.

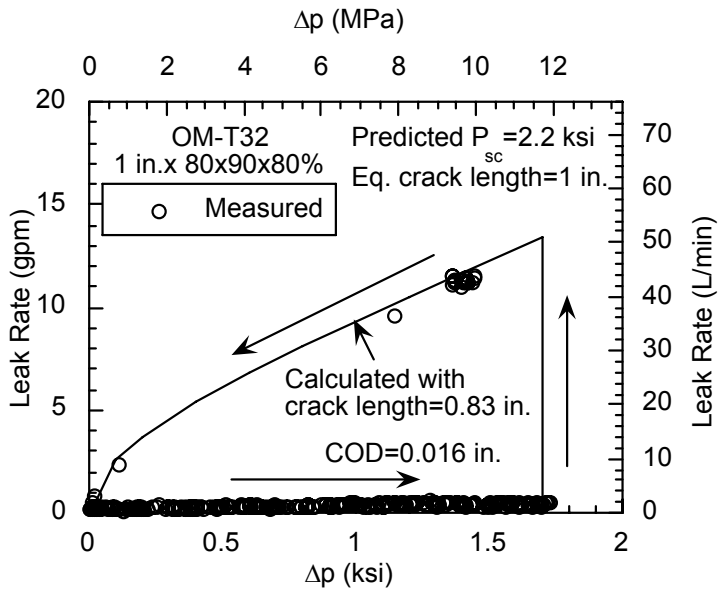

(a)

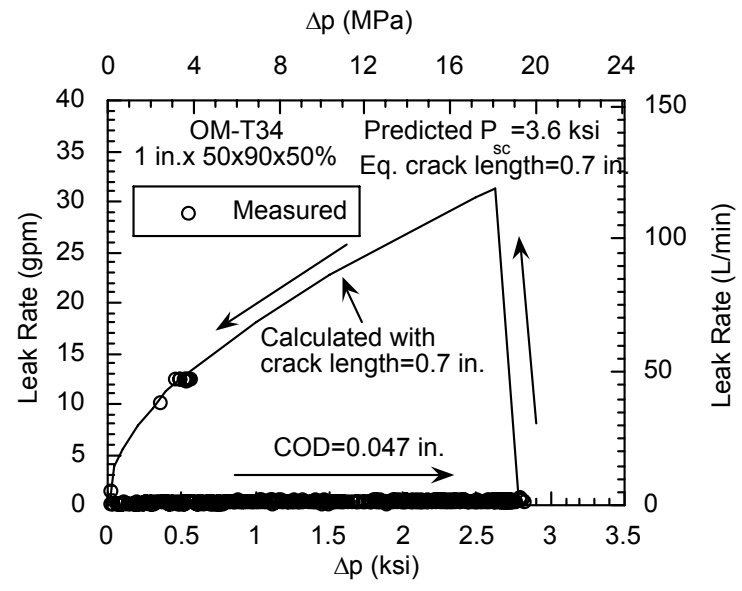

(b)

Figure 37. Calculated and measured pressure vs. leak rate plots of tests (a) OM-T32 and (b) OM-T34, both conducted on as-received tubes with trapezoidal notches at $20^{\circ} \mathrm{C}$.

\section{Pressure and Leak Rate Tests on Stress Corrosion Cracks}

The Pressure and Leak Rate Test Facility at ANL can be used to obtain data on failure pressures, failure modes, and leak rates of flawed SG tubes at temperatures up to $343^{\circ} \mathrm{C}\left(650^{\circ} \mathrm{F}\right)$, pressures of up to $21 \mathrm{MPa}(3.0 \mathrm{ksi})$, and pressurized-water flow rates of up to $1520 \mathrm{~L} / \mathrm{min}(400 \mathrm{gpm}) .^{2}$ A second HighPressure Test Facility (room-temperature water) with a working pressure of $52 \mathrm{MPa}(7.5 \mathrm{ksi})$ and a maximum sustainable flow rate of up to $47.5 \mathrm{~L} / \mathrm{min}(12.5 \mathrm{gpm})$ has also been constructed. Specimens with short notches and stress corrosion cracks that cannot be tested to unstable burst in the Pressure and Leak Rate Test Facility are tested to unstable burst in the High Pressure Test Facility using an internal bladder. Results from some preliminary laboratory-generated SCC tests are reported in Ref. 2.

Pressure and leak rate tests have been conducted mostly on specimens with laboratory-generated stress corrosion cracks, but a limited number of tests have also been conducted on tubes from a retired 
McGuire SG. Crack depth profiles for all the specimens were estimated by pretest advanced NDE and, in some cases, by posttest fractography. We used the equivalent rectangular crack length and depth to predict the ligament rupture pressure and leak rate, using crack depth profiles from both EC/NDE and fractography data. However, the full ligaments of stress corrosion cracks rarely rupture all at once during the initial rupture event, and specimens generally undergo incremental ligament rupture with increasing pressure before the cracks become unstable. We have tentatively generalized the equivalent crack approach for predicting incremental ligament rupture after the initial rupture event, as discussed in Section 2.1.3.1.

\subsection{Analysis of Tests on Laboratory-Generated SCC}

Two types of heat treatments were used for generating the stress corrosion cracks in the SG tubes. Early in the program, SG tubes were solution annealed at high temperature and sensitized before introducing the SCCs in the laboratory at ANL. The annealing treatment resulted in a loss of about $20 \%$ in flow stress. Later on, SCC specimens were not subjected to the high temperature annealing. As a result, the flow stresses of these specimens were virtually undiminished from those of the as-received tubes.

\subsubsection{Specimens with High Temperature Annealing}

Analyses of pressure and leak rate tests on several SCC specimens with high temperature annealing were presented in an earlier report. ${ }^{2}$ Analyses of several additional room-temperature pressure tests on specimens SGL 480, SGL 494, SGL 493, and SGL 413 of the 14-tube set with axial ODSCC are presented here. The tubes were tested without bladders under a quasi-static pressurization rate. Two types of leakage were observed during these tests. In SGL-413, SGL-480, and SGL-493, the first leak occurred in the form of one drop of water issuing from the flaw over a period of several minutes. The pressure at which this first leak occurred was reported as "ligament rupture pressure." The frequency of drop formation increased with increasing pressure. The leaks often passed through an atomized droplet spray stage, followed by a continuous leak stream stage. The tests were discontinued at a pressure when the leak rate exceeded the flow capacity of the system, $49 \mathrm{~L} / \mathrm{min}$ (12.8 gpm). Specimen SGL-494, on the other hand, experienced the usual ligament rupture event, i.e., it had no measurable leak rate prior to the pressure reaching a well-defined value, at which point rapid flaw opening accompanied by a high leak rate occurred. Crack depth profiles for all the specimens were estimated by pretest multiparameter analysis of EC RPC data and posttest fractography.

Analysis of SGL-480

Figure 39a shows the crack depth profiles of specimen SGL-480 measured by pretest NDE and posttest fractography. Figure 39b shows the variation of predicted crack length with pressure corresponding to the two profiles. The predicted ligament rupture pressures corresponding to the NDE and fractography profiles are 9.2 and $8.9 \mathrm{MPa}(1.34$ and $1.29 \mathrm{ksi})$, respectively, compared to the experimentally measured pressure of $6.2 \mathrm{MPa}(0.9 \mathrm{ksi})$ at the onset of first leakage. Following rupture, the crack length as a function of pressure was calculated using the proposed tentative procedure. The dashed line in Fig. 39b represents the unstable burst pressure. At the final pressure of $15 \mathrm{MPa}(2.2 \mathrm{ksi})$, the TW crack length is predicted to be 10.7 and $12.5 \mathrm{~mm}(0.42$ and $0.5 \mathrm{in}$.) by the NDE profile and fractography profile, respectively. The corresponding leak rates at the final pressure (Fig. 39a) are predicted to be 11 and $38 \mathrm{~L} / \mathrm{min}$ ( 3 and $10 \mathrm{gpm}$ ), respectively, compared to the $48 \mathrm{~L} / \mathrm{min}$ (12.5 gpm) measured experimentally. Overall, the predicted pressure vs. leak rate curve (based on fractography data) is close to the measured leak rate values. The posttest OD view of the crack (Fig. 39b) shows the 
open portion of the crack to be $\approx 13 \mathrm{~mm}(0.5 \mathrm{in}$.). Both the final crack length and the final leak rate are closer to the predictions based on fractography than NDE.

Analysis of SGL-494

The crack depth profiles of specimen SGL-494 measured by pretest NDE and posttest fractography are shown in Fig. 40a. The ligament rupture pressures corresponding to the NDE profile and fractography profile are 33 and $36 \mathrm{MPa}(4.8$ and $5.2 \mathrm{ksi}$ ), respectively. The predicted crack length vs. pressure plots (Fig. 40b) show that both profiles predict the crack to become unstable after some crack growth. The crack lengths at unstable burst are predicted to be 7.6 and $14 \mathrm{~mm}(0.3$ and $0.55 \mathrm{in}$.) by the NDE and fractography profile, respectively. The leak rates are also predicted to increase rapidly immediately after ligament rupture (Fig. 41a). The test showed the leak rate to increase from zero to almost $49 \mathrm{~L} / \mathrm{min}(12.5 \mathrm{gpm})$ abruptly at a pressure of 32-33 MPa (4.6-4.8 ksi). The posttest OD view of the crack (Fig. $41 \mathrm{~b}$ ) shows that the open is $\approx 16 \mathrm{~mm}(0.625 \mathrm{in}$.). The much larger opening of this crack compared to that of SGL-480 (Fig. 39b) and the evidence of tearing at the crack tip suggest that this specimen was close to burst, as predicted.

Analysis of SGL 493

The crack depth profiles of specimen SGL -493 measured by pretest NDE and posttest fractography are shown in Fig. 42a. The ligament rupture pressures corresponding to the NDE profile and fractography profile are 14 and $16 \mathrm{MPa}$ ( 2 and $2.3 \mathrm{ksi}$ ), respectively. The predicted crack length vs. pressure plots (Fig. 42b) show that both profiles predict the crack to remain stable at the final test pressure $(17.6 \mathrm{MPa}$ [2.55 ksi]) after some crack growth. The crack lengths at the final test pressure are predicted to be 15 and $10 \mathrm{~mm}$ ( 0.60 and $0.39 \mathrm{in}$.) by the NDE and fractography profile, respectively. The leak rates are also predicted to increase rapidly immediately after ligament rupture (Fig. 43a). The test showed the leak rate to increase from zero to a final $49 \mathrm{~L} / \mathrm{min}(12.5 \mathrm{gpm})$ gradually from a pressure of $0.6 \quad$ to $17.6 \mathrm{MPa}$ (0.08

to

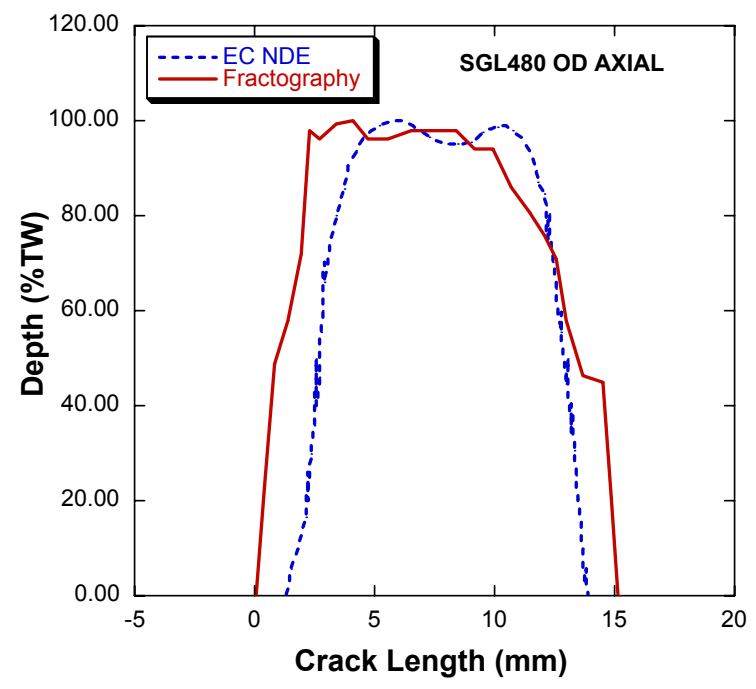

(a)

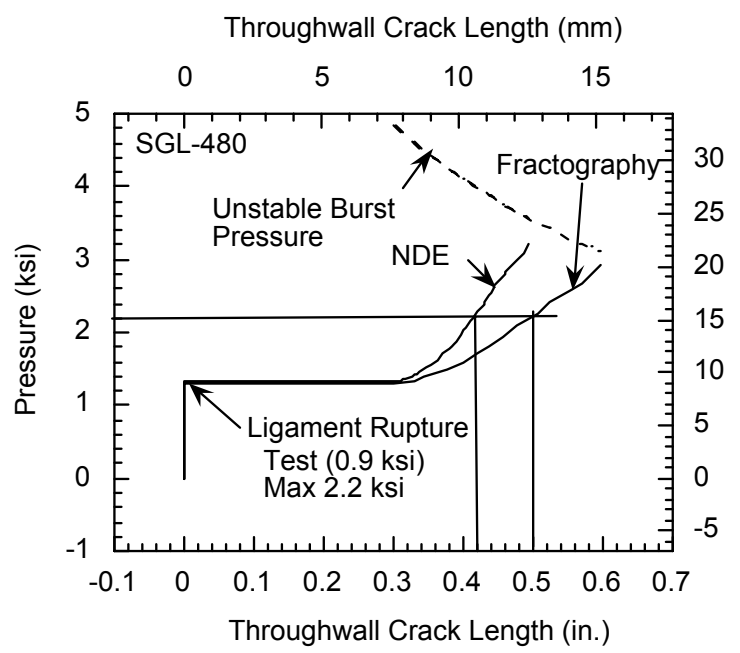

(b) 
Figure 38. (a) Crack depth profiles for specimen SGL-480 measured by pretest EC/NDE and posttest fractography and (b) variation of TW crack length with pressure calculated from crack depth profiles measured by EC/NDE and fractography.

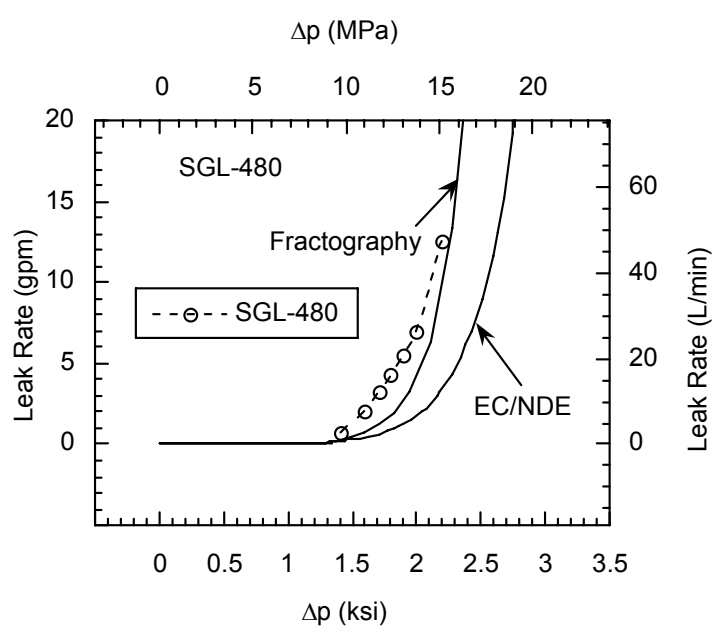

(a)

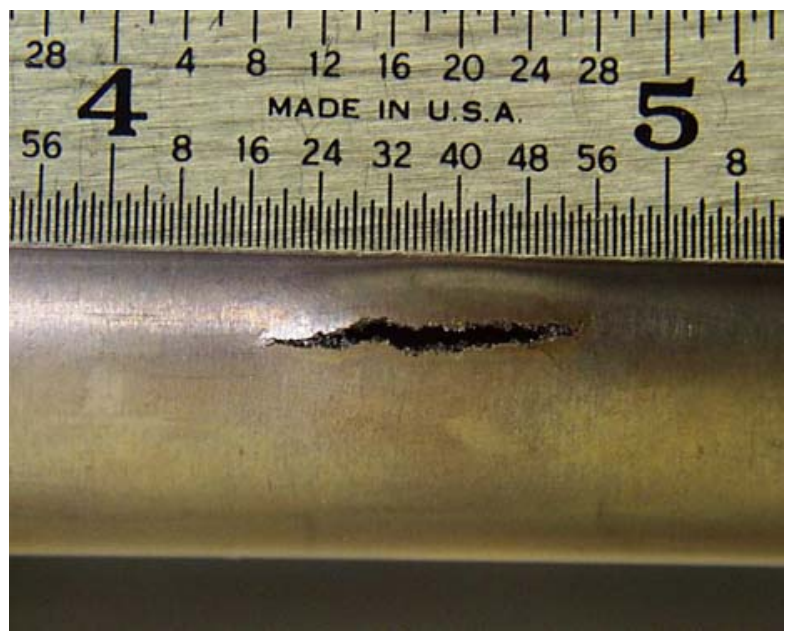

(b)

Figure 39. (a) Measured (symbols) and predicted (based on EC/NDE and fractography depth data) pressure vs. leak rate plots for Test SGL-480 and (b) posttest view of the OD surface of specimen SGL-480.

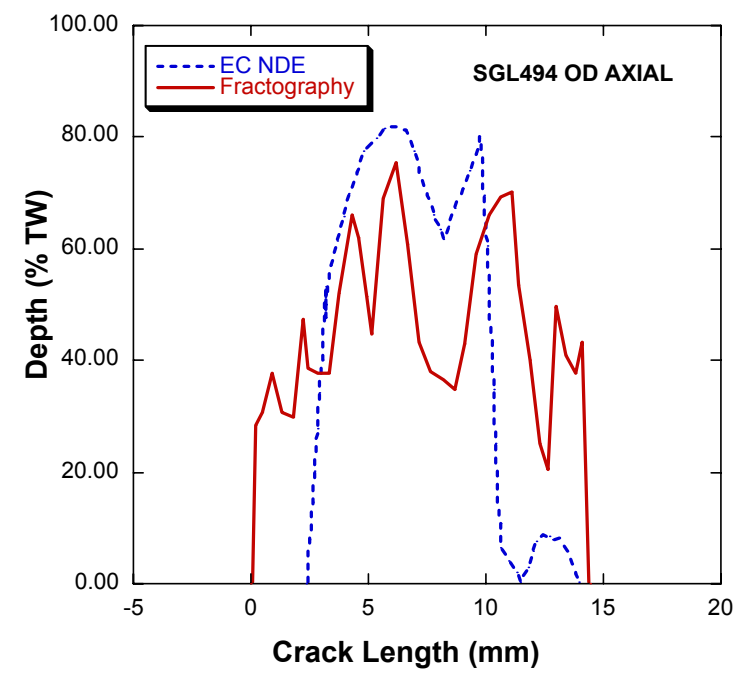

(a)

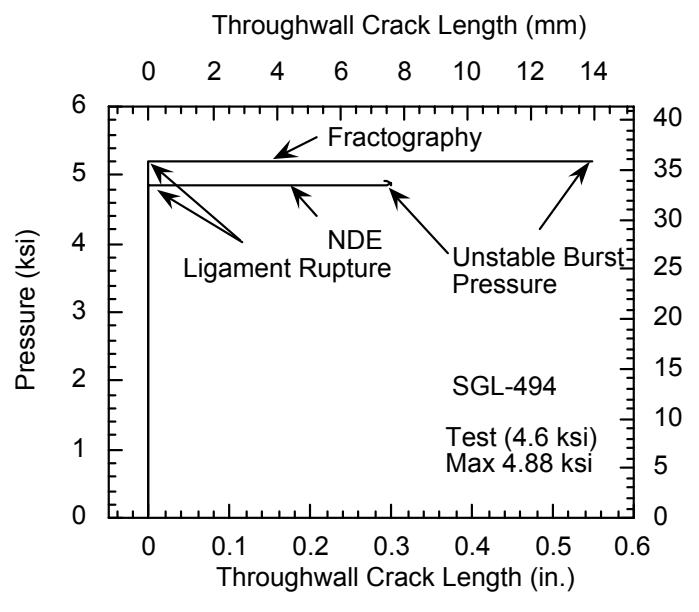

(b) 
Figure 40. (a) Crack depth profiles for specimen SGL-494 measured by pretest EC/NDE and posttest fractography and (b) variation of TW crack length with pressure calculated from crack depth profiles measured by EC/NDE and fractography.

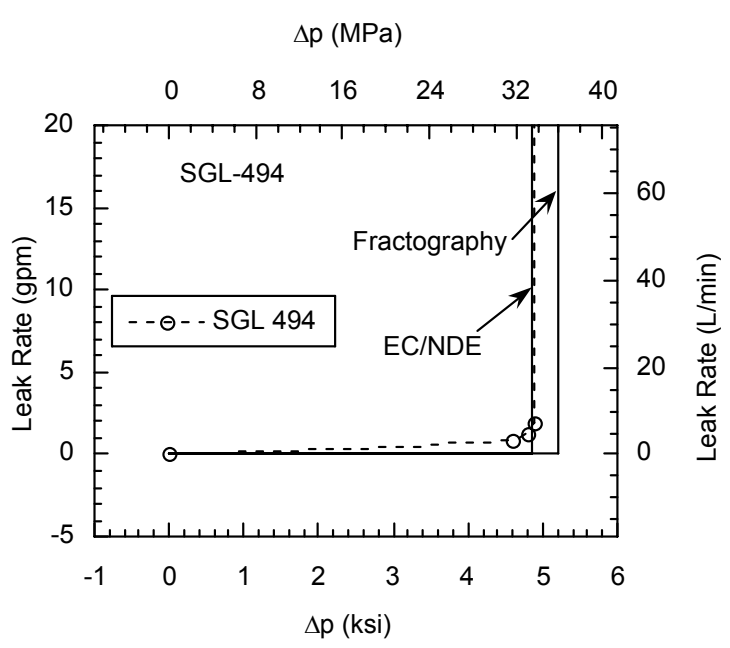

(a)

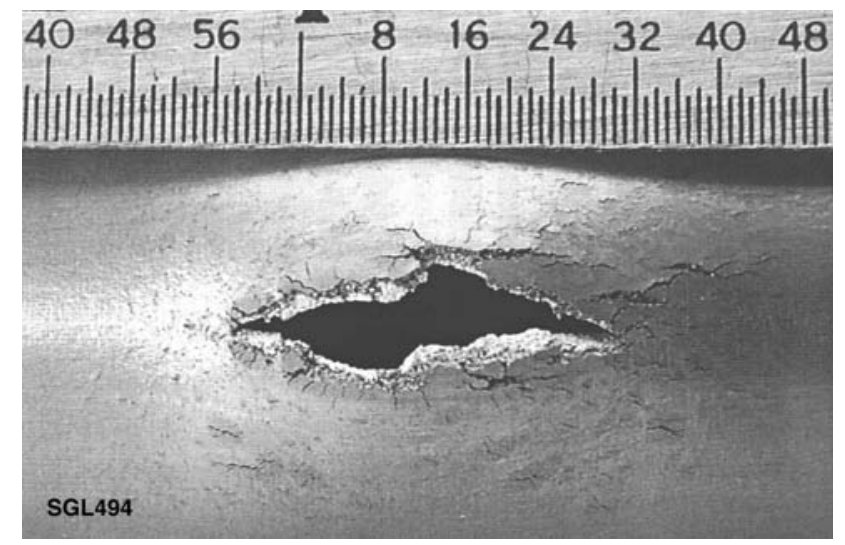

(b)

Figure 41. (a) Measured (symbols) and predicted (based on EC/NDE and fractography depth data) pressure vs. leak rate plots for Test SGL-494 and (b) posttest view of the OD surface of specimen SGL-494.
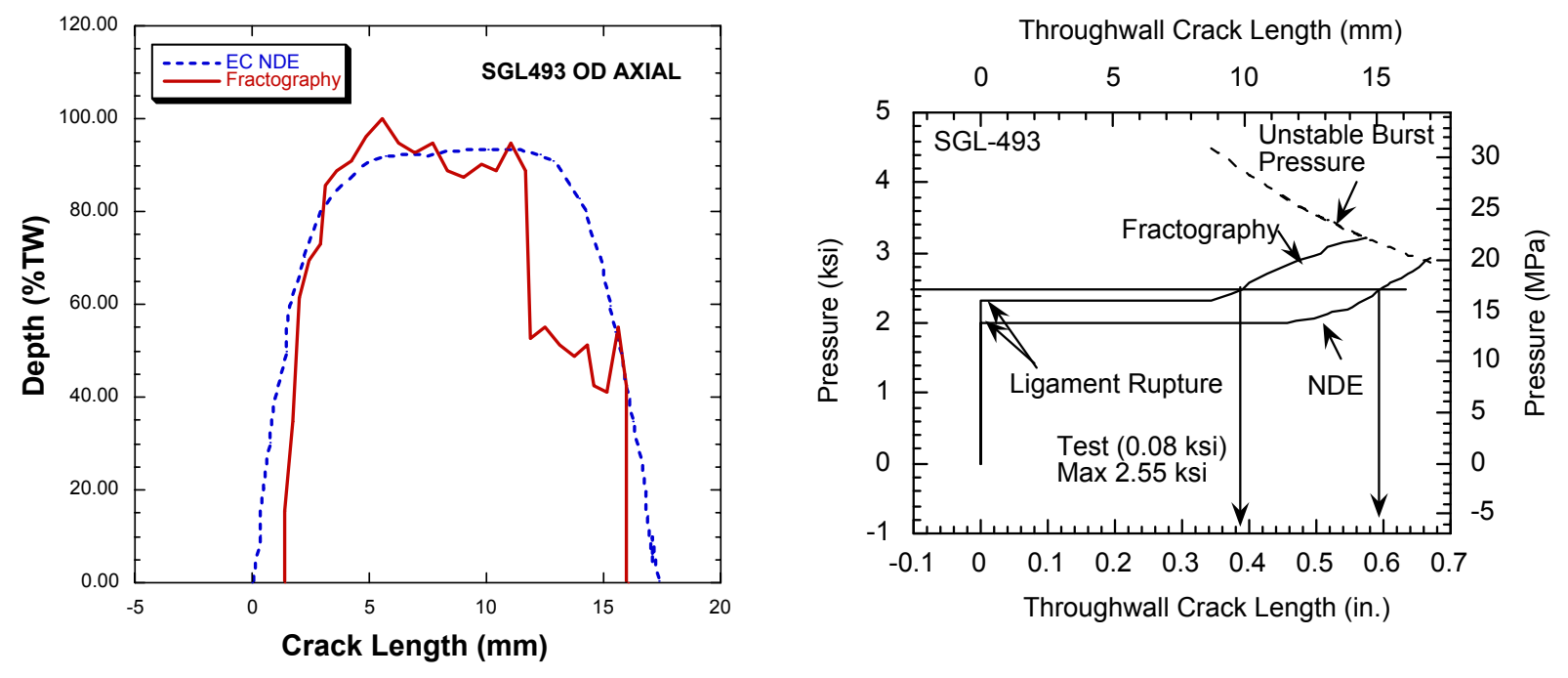
Figure 42. (a)Crack depth profiles for specimen SGL-493 measured by pretest EC/NDE and posttest fractography and (b) variation of TW crack length with pressure calculated from crack depth profiles measured by EC/NDE and fractography.

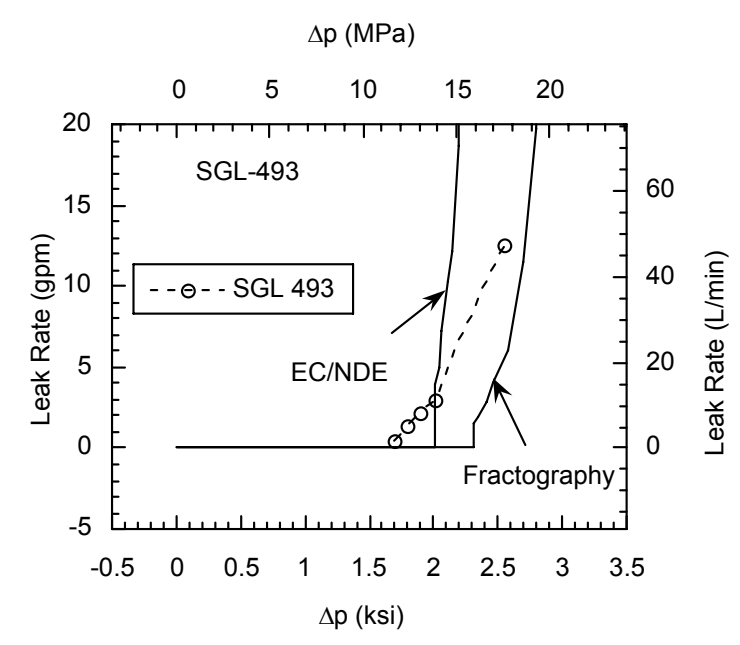

(a)

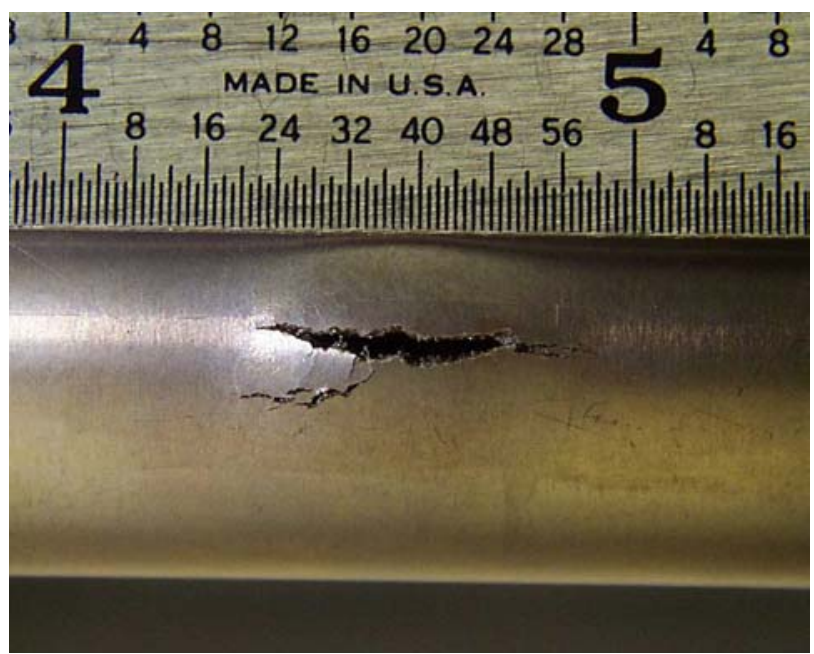

(b)

Figure 43. (a) Measured and predicted (based on EC/NDE and fractography depth data) pressure vs. leak rate plots for Test SGL-493 and (b) posttest view of the OD surface of specimen SGL493. 
$2.55 \mathrm{ksi})$. The final test leak rate is much closer to that predicted by the fractography profile $(23 \mathrm{~L} / \mathrm{m}$, $6 \mathrm{gpm}$ ) than the NDE profile. The posttest OD view of the crack (Fig. 43b) shows that the open portion is $\approx 12 \mathrm{~mm}(0.47 \mathrm{in}$.). Although there is no evidence of tearing at the crack tip (i.e., unstable burst), axial ligament rupture near the right crack tip is visible in Fig. 43b. The reason for the much greater discrepancy in the predicted leak rate by the NDE profile is evident in Fig. 42a, which shows that the advanced NDE method overestimated the depth near one end of the crack. Nonetheless, the difference in the predicted ligament rupture pressures is small.

Analysis of SGL-413

The crack depth profiles of specimen SGL -413 measured by pretest NDE and posttest fractography are shown in Fig. 44a. The ligament rupture pressures corresponding to the NDE profile and fractography profile are 29 and $24 \mathrm{MPa}(4.24$ and $3.53 \mathrm{ksi})$, respectively. The predicted crack length vs. pressure plots (Fig. 44b) show that both profiles predict the crack to remain stable at the final test pressure (25 MPa [3.57 ksi]). However, the NDE profile predicts that no ligament rupture occurred, whereas the fractography profile predicts a final crack length of $7.4 \mathrm{~mm}(0.29 \mathrm{in}$.), and the leak rate is predicted to increase rapidly immediately after ligament rupture (Fig. 45a). The test showed the leak rate to increase from zero to a final $49 \mathrm{~L} / \mathrm{min}(12.5 \mathrm{gpm})$ gradually from a pressure of 12 to $25 \mathrm{MPa}(1.8$ to $3.57 \mathrm{ksi}$ ). The final test leak rate is much closer to that predicted by the fractography profile $(19 \mathrm{~L} / \mathrm{min}[5 \mathrm{gpm}])$ than the NDE profile $(0 \mathrm{gpm})$. The posttest OD view of the crack (Fig. $45 \mathrm{~b})$ shows that the open portion is $\approx 6 \mathrm{~mm}(0.25 \mathrm{in}$.), which is close to that predicted by fractography. The reason for the much greater discrepancy in the predicted leak rate by the NDE profile is evident in Fig. 44a, which shows that the advanced NDE method underestimated the deepest portion of the crack. Nonetheless, the difference in the predicted ligament rupture pressures is small.

\subsubsection{Specimens without High Temperature Annealing}

We present leak rate analyses on three SCC specimens that were not subjected to the high temperature annealing. As a result, the flow stresses of these specimens were virtually undiminished from those of the as-received tubes. Specimen SGL-731 was tested at room temperature in the High Pressure Test Facility, and specimens SGL-822 and SGL-876 were tested at $282^{\circ} \mathrm{C}$ in the Pressure and Leak-Rate Test Facility.

Analysis of SGL-731

Figure 46a shows the depth profiles as measured by EC/NDE and fractography for SGL-731. The ligament rupture pressures corresponding to the NDE profile and fractography profile are 12 and $18 \mathrm{MPa}$ (1.8 and $2.6 \mathrm{ksi}$ ), respectively. The predicted crack length vs. pressure plots (Fig. 46b) show that both profiles predict the crack to remain stable at the final test pressure $(21.3 \mathrm{MPa}$ [3.1 ksi]) after some crack growth. The crack lengths at the final test pressure (21.4 MPa [3.1 ksi]) are predicted to be 15 and $13 \mathrm{~mm}(0.60$ and $0.53 \mathrm{in}$.) by the NDE and fractography profile, respectively. Figure 47 compares the predicted pressure vs. leak rates with experimental leak rates for test SGL-731, which was conducted at room temperature. Leakage started at a lower pressure than predicted based on fractography, but the measured leak rate approached the predicted leak rate at higher pressure. 


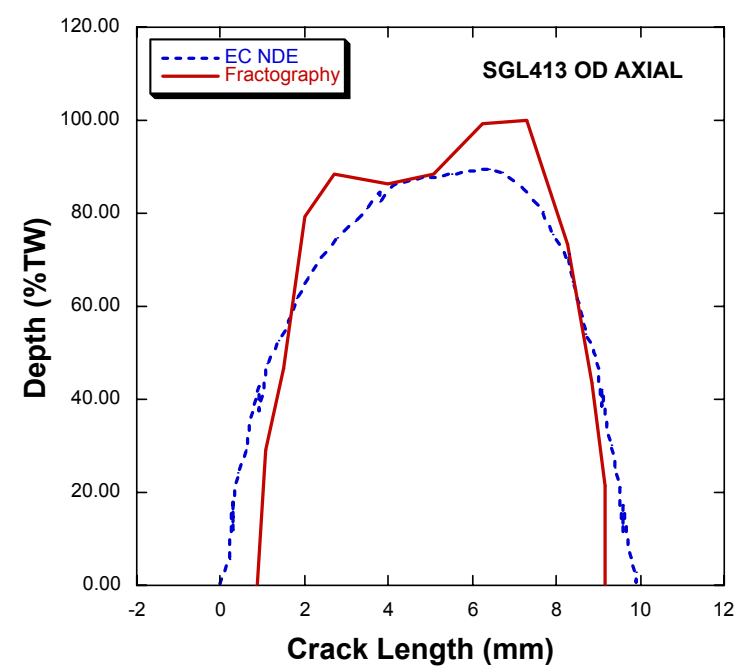

(a)

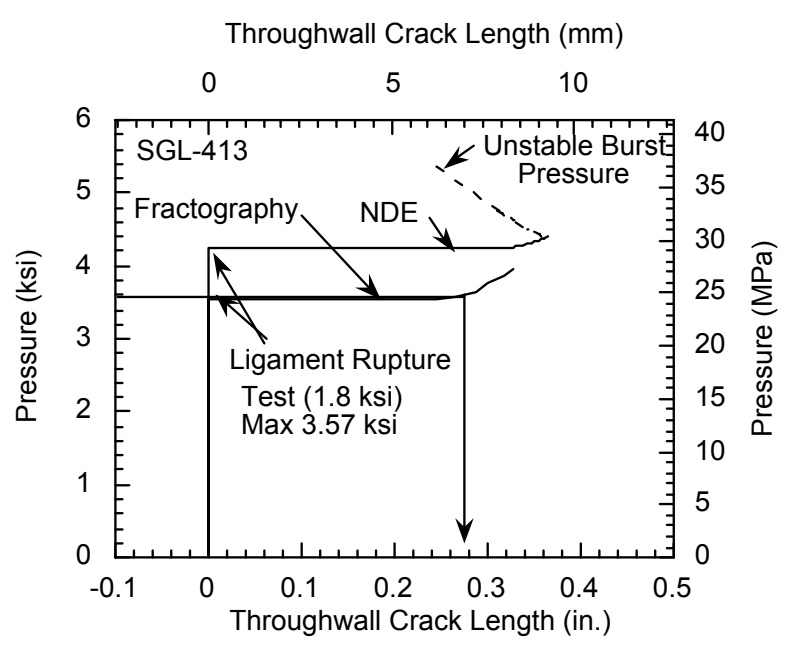

(b)

Figure 44. Crack depth profiles for specimen SGL-413 measured by pretest EC/NDE and posttest fractography and (b) variation of TW crack length with pressure calculated from crack depth profiles measured by EC/NDE and fractography.

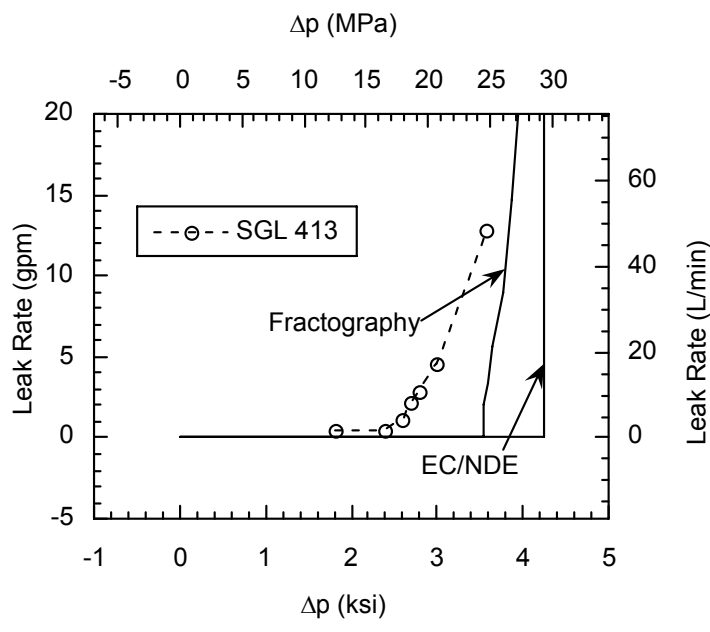

(a)

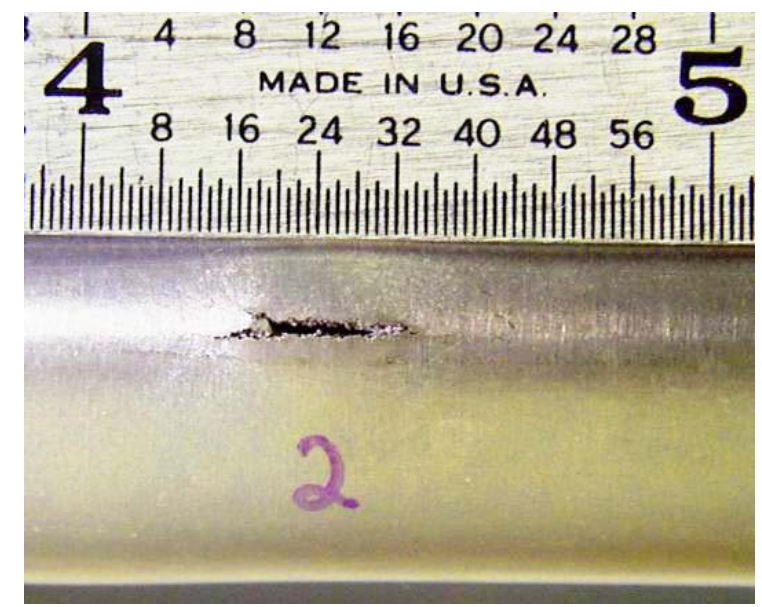

(b)

Figure 45. (a) Measured and predicted (based on NDE and fractography depth data) pressure vs. leak rate plots for Test SGL-413 and (b) post-test view of the OD surface of specimen SGL-413. 


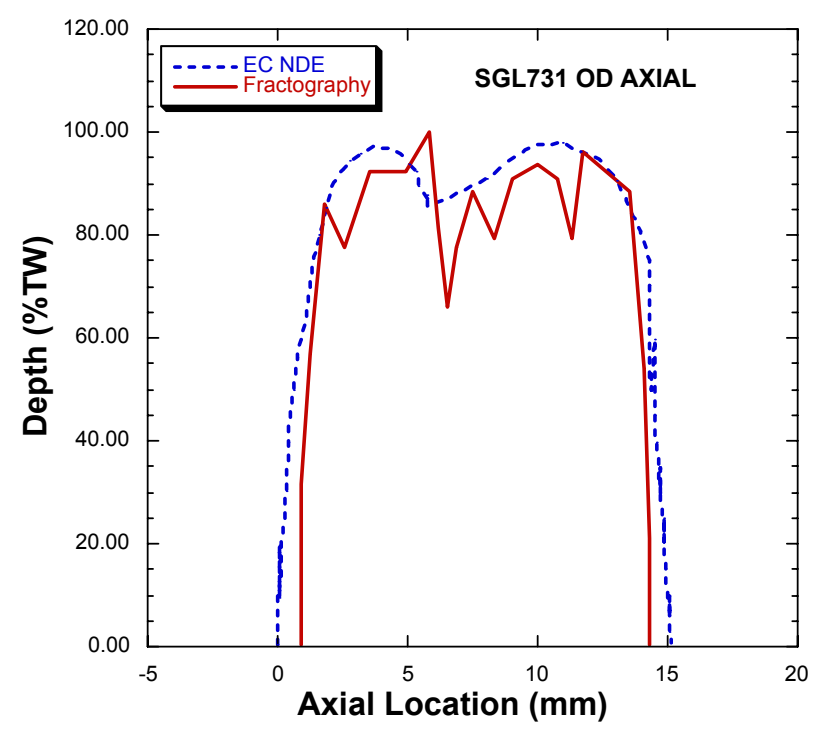

(a)

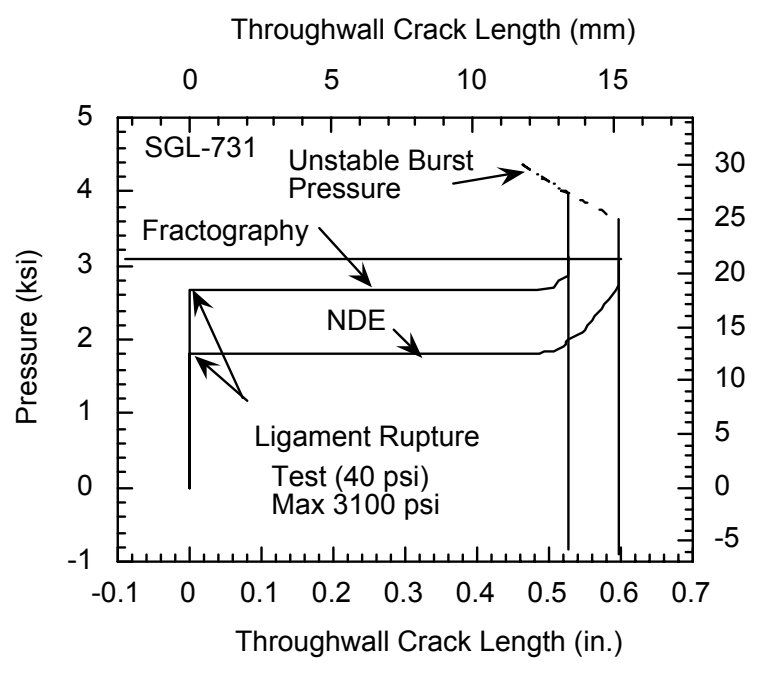

(b)

Figure 46. (a) Crack depth profiles by EC/NDE and fractography of test SGL-731 and (b) variation of TW crack length with pressure calculated from crack depth profiles measured by EC and fractography.

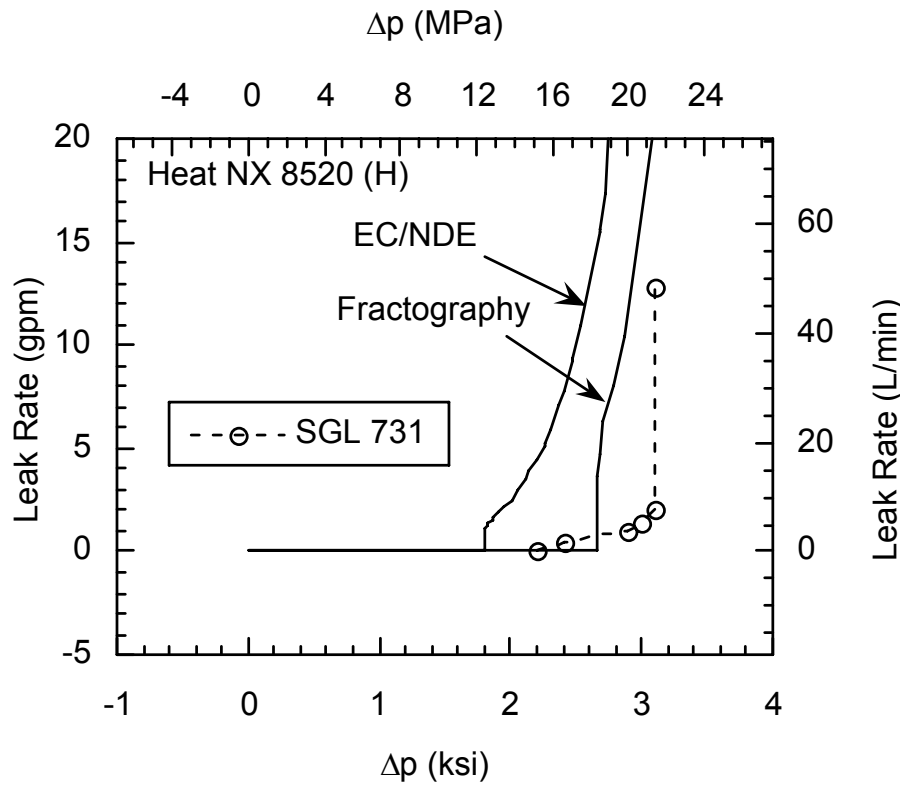

Figure 47.

Predicted and measured pressure vs. leak rate plots for SGL-731.

Analysis of SGL-822 
Figure 48 shows the depth profiles as measured by EC/NDE and fractography for specimen SGL822. Both fractography and EC/NDE indicated significant TW penetration of the crack for this specimen. As a result, the leak rates are predicted to start at very low pressures (Fig. 49a). In contrast, test SGL822 , which was conducted in the high temperature Pressure and Leak-Rate Test Facility at $282^{\circ} \mathrm{C}$, showed no sign of leakage before $14 \mathrm{MPa}(2 \mathrm{ksi})$ pressure. The predicted leak rates are significantly higher than measured, primarily because the rupture pressure was underestimated by both NDE and fractography data. This specimen showed a time-dependent leak rate (Fig. 49b). During a 30-min hold at $17 \mathrm{MPa}(2.5 \mathrm{ksi})$, the leak rate increased from 6 to $18 \mathrm{~L} / \mathrm{min}(1.6$ to $4.8 \mathrm{gpm})$. Currently, we do not have the ability to predict such a time-dependent increase of leak rate at constant pressure and $282^{\circ} \mathrm{C}$.

Analysis of SGL-876

This test was first conducted at room temperature in the High Pressure Test Facility. Leakage in the form of single drop first occurred at $0.14 \mathrm{MPa}(20 \mathrm{psi})$. This was followed by a constant spray of $2 \mathrm{~L} / \mathrm{min}(0.52 \mathrm{gpm})$ at $10 \mathrm{MPa}(1.4 \mathrm{ksi})$ and $5 \mathrm{~L} / \mathrm{min}(1.33 \mathrm{gpm})$ at $13 \mathrm{MPa}(1.9 \mathrm{ksi})$, then an increase of the leak rate under constant pressure hold at $15 \mathrm{MPa}(2.2 \mathrm{ksi})$ from 17 to $35 \mathrm{~L} / \mathrm{min}$ ( $4.45 \mathrm{gpm}$ to $9.25 \mathrm{gpm}$ ) in $30 \mathrm{~s}$, after which the test was stopped. The TW crack length calculated by matching these leak rate data increased from 12 to $16 \mathrm{~mm}$ ( 0.47 to $0.63 \mathrm{in}$.) during the test. Based on the pretest NDE profile (Fig. 50a), the ligament rupture pressure is predicted to be $21 \mathrm{MPa}$ (3 ksi) with an equivalent rectangular crack length $=7 \mathrm{~mm}(0.27 \mathrm{in}$.). The predicted pressure vs. leak rate (predicted crack length increases from $7 \mathrm{~mm}$ [0.27 in.] to $11 \mathrm{~mm}$ [0.43 in.] during pressurization) is compared with the test data in Fig. 50b. Clearly in this case the EC/NDE data failed to detect the highly damaged state of the crack. The posttest EC/NDE depth profile (Fig. 50a) showed that during pressure testing the TW crack length had grown to almost $22 \mathrm{~mm}(0.86 \mathrm{in}$.). The same specimen was then pressurized in the high temperature Pressure and Leak Rate Test Facility at $282^{\circ} \mathrm{C}$, where it suddenly burst (fishmouth) and developed a leak rate of $1330 \mathrm{~L} / \mathrm{min}(350 \mathrm{gpm})$ at a pressure of $16 \mathrm{MPa}(2.27 \mathrm{ksi})$. The crack had undergone extensive tearing and extended to approximately $64 \mathrm{~mm}$ (2.5 in.) in length and $32 \mathrm{~mm}$ (1.25 in.) in width (Fig. 51). Although similar catastrophic burst had occurred with EDM notches in the past, this was the first time that we observed a similar failure with SCC. The predicted unstable burst pressure at $282^{\circ} \mathrm{C}$, based on the posttest NDE depth profile, is $17 \mathrm{MPa}(2.52 \mathrm{ksi})$.

\subsection{Analysis of Tests on McGuire Steam Generator Tubes}

Six McGuire tubes were inspected by EC/NDE prior to pressure and leak rate testing, and the depth profiles of four of these were determined by posttest fractography. Table 2 reports the pressure and leak rate results. The depth profiles are shown in Figs. 52a-b, 53a-b, and 54a-b. Flow stress data of the McGuire tubes tested were obtained from the mill certificates ${ }^{*}$ and are plotted in Figs 55a-b. Mean values of the yield and ultimate tensile strengths at locations from where the test specimens were obtained are also shown in the figures. As expected, the mean values of the flow stress of the 19-mm (0.75-in.)

diameter

\footnotetext{
* Private Communication, R. Keating, Westinghouse Electric Company, to S. Majumdar, Argonne National Laboratory, January 25, 2002.
} 


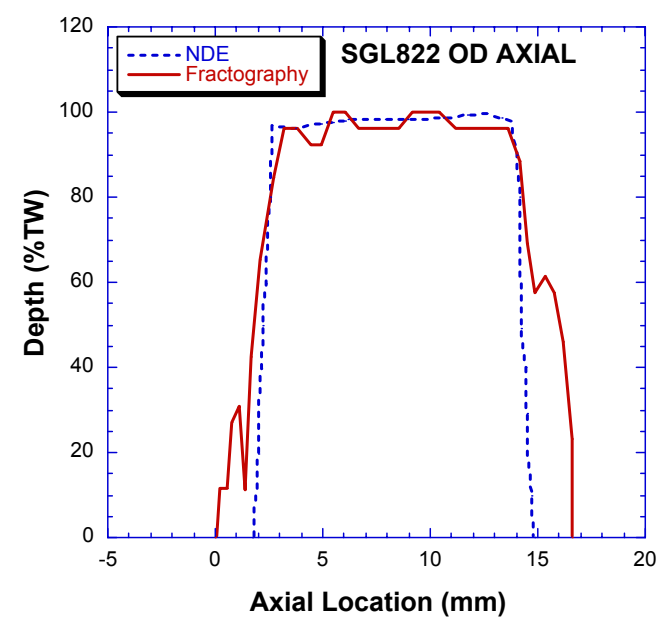

$\Delta \mathrm{p}(\mathrm{MPa})$

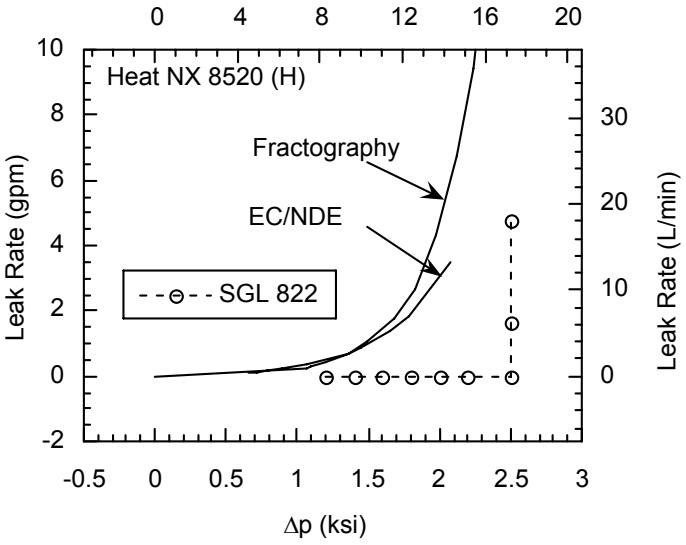

(a)
Figure 48.

Crack depth profiles by EC/NDE and fractography of test SGL-822.

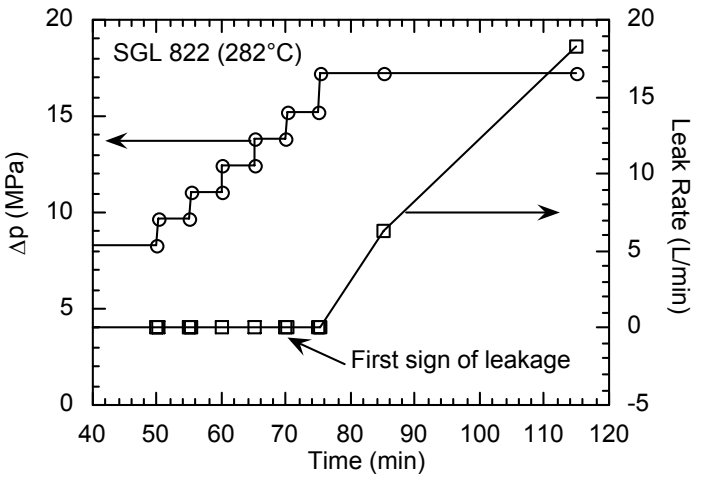

(b)

Figure 49. (a) Predicted and measured pressure vs. leak rate plots for specimen SGL-822 conducted at $282^{\circ} \mathrm{C}$ and (b) pressure and leak rate variation observed during test SGL-822.

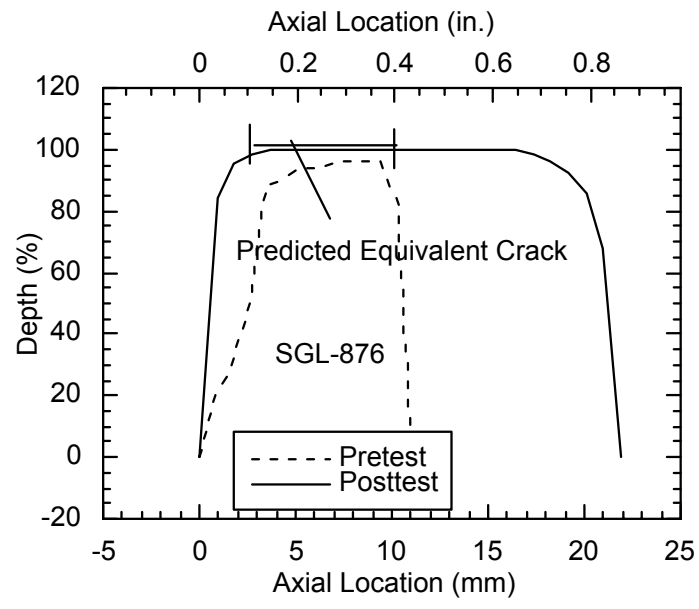

(a)

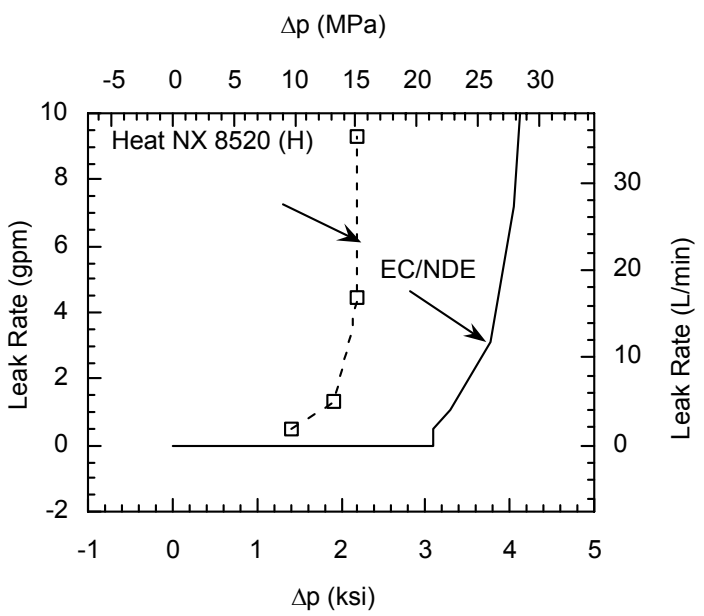

(b)

Figure 50. (a) Pretest and posttest (after room-temperature testing) EC/NDE profile of SCC flaw in specimen SGL-876 and (b) observed vs. predicted leak rate curve based on EC/NDE depth profile. 


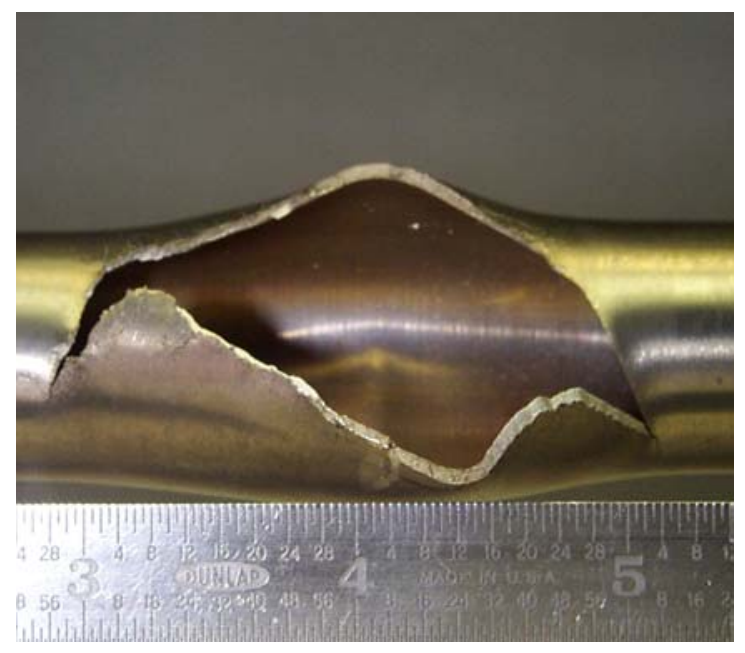

Figure 51.

Fishmouth burst of specimen SGL-876 during pressurization at $282^{\circ} \mathrm{C}$.

Table 2. Results from pressure and leak rate tests on tubes from McGuire SG. All flaws were in the TSP region.

\begin{tabular}{|c|c|c|c|c|}
\hline $\begin{array}{l}\text { Tube } \\
\text { ID }\end{array}$ & $\begin{array}{c}\text { Pressure at First } \\
\text { Leak, } \\
\text { MPa (psi) }\end{array}$ & $\begin{array}{l}\text { Leak Rate at Max. } \\
\text { Pressure, } \\
\text { L/min @ MPa } \\
\text { (gpm @ psi) }\end{array}$ & $\begin{array}{c}\text { Predicted } \\
\text { Opening } \\
\text { Pressure, MP } \\
\text { a (psi) }\end{array}$ & $\begin{array}{c}\text { Visual Flaw } \\
\text { Characteristics }\end{array}$ \\
\hline $7-24-3$ & (no leak) & $\begin{array}{c}0.0 @ 51.6 \\
(0.0 @ 7490)\end{array}$ & $\begin{array}{c}62.0 \\
(9000)\end{array}$ & $\begin{array}{l}\text { Bulge; hairline circ. } \\
\text { crack 6.35-mm (0.25- } \\
\text { in,) long; secondary } \\
\text { cracks. }\end{array}$ \\
\hline $5-51-2$ & (no leak) & $\begin{array}{c}0.0 @ 51.0 \\
(0.0 @ 7400)\end{array}$ & $\begin{array}{c}66.2 \\
(9600)\end{array}$ & $\begin{array}{l}\text { Bulge; hairline axial } \\
\text { crack 6.35-mm ( } 0.25- \\
\text { in,) long; secondary } \\
\text { cracks. }\end{array}$ \\
\hline $4-43-2$ & $49.0(7100)$ & $\begin{array}{c}32.2 @ 49.0 \\
(8.5 @ 7100)\end{array}$ & $\begin{array}{c}54.5 \\
(7900)\end{array}$ & $\begin{array}{l}\text { Bulge, } 2 \text { axial cracks } \\
\text { with ligament between; } \\
\text { total length } 10 \mathrm{~mm} \\
(3 / 8 \text { in.). }\end{array}$ \\
\hline $14-55-3$ & (no leak) & $\begin{array}{c}0.0 @ 51.2 \\
(0.0 @ 7425)\end{array}$ & $\begin{array}{c}64.8 \\
(9400)\end{array}$ & $\begin{array}{l}\text { No bulge; hairline axial } \\
\text { crack } 5-\text { mm } 3 / 16 \text {-in.) } \\
\text { long; secondary cracks. }\end{array}$ \\
\hline $14-55-5$ & (no leak) & $\begin{array}{c}0.0 @ 50.9 \\
(0.0 @ 7380)\end{array}$ & $\begin{array}{c}72.4 \\
(10,500)\end{array}$ & $\begin{array}{l}\text { No bulge; axial crack } \\
6.35-\mathrm{mm}(0.25-\text { in. }) \\
\text { long. }\end{array}$ \\
\hline 39-57-2 & $36.2(5250)$ & $\begin{array}{c}28.0 @ 36.2 \\
(7.4 @ 5250)\end{array}$ & $\begin{array}{c}61.4 \\
(8900)\end{array}$ & $\begin{array}{l}\text { Bulge; hairline axial } \\
\text { crack } 10 \mathrm{~mm}(3 / 8-i n .) \\
\text { long; secondary cracks. }\end{array}$ \\
\hline
\end{tabular}




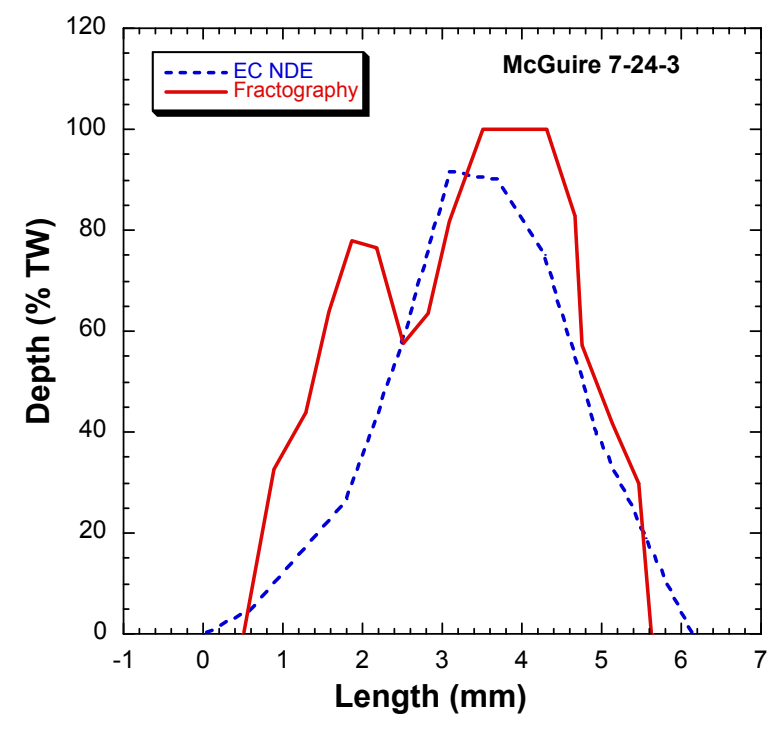

(a)

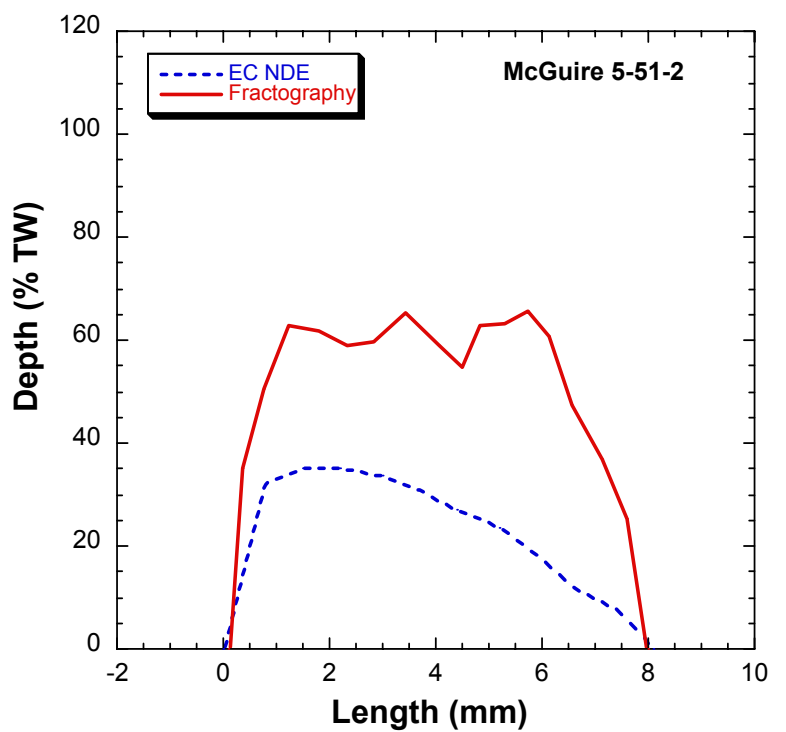

(b)

Figure 52. Crack depth profiles by EC/NDE and fractography of McGuire tube (a) 7-24-3 and (b) 5-512

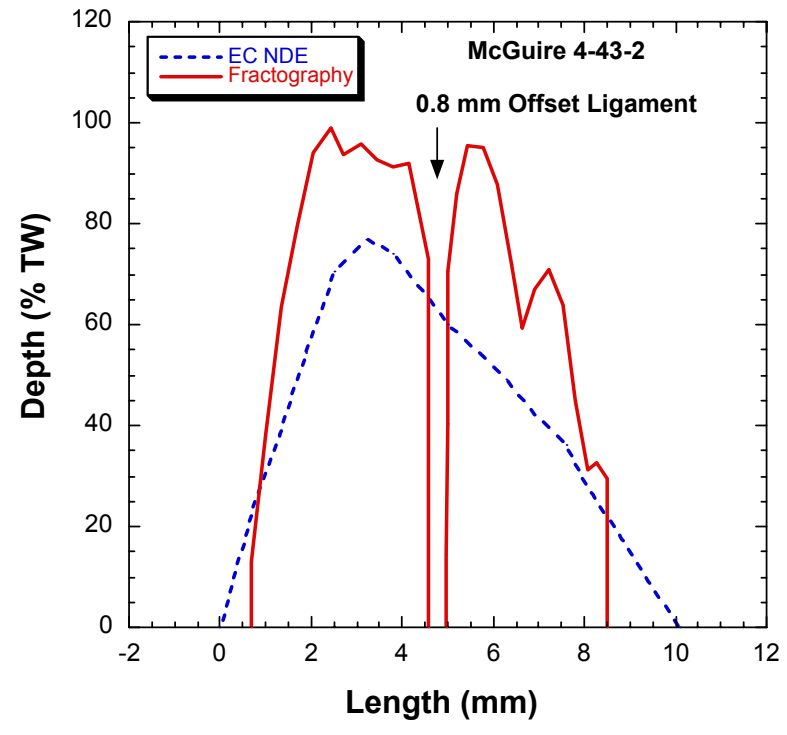

(a)

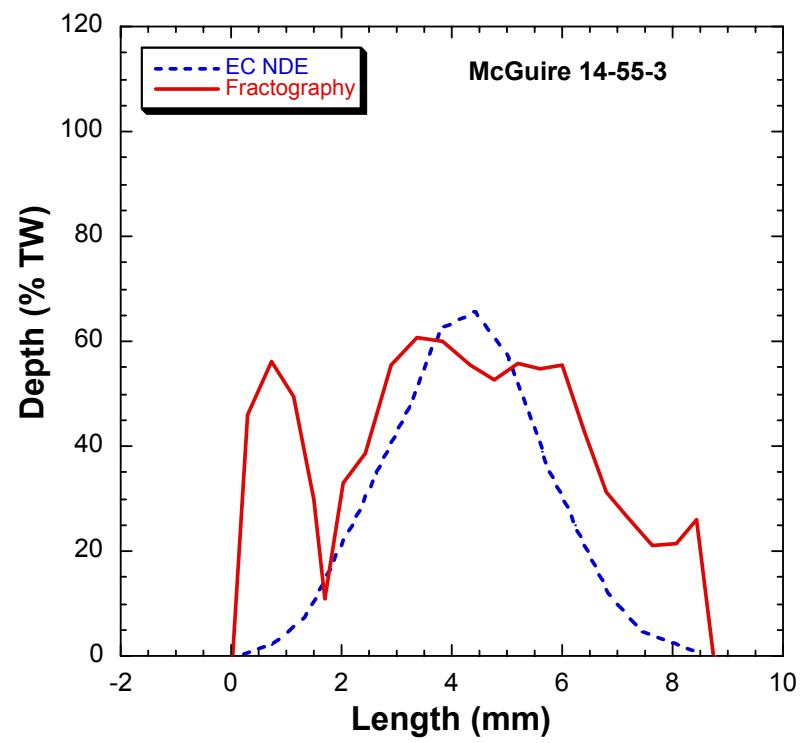

(b)

Figure 53. Crack depth profiles by EC/NDE and fractography of McGuire tube (a) 4-43-2 and (b) 1455-3. 


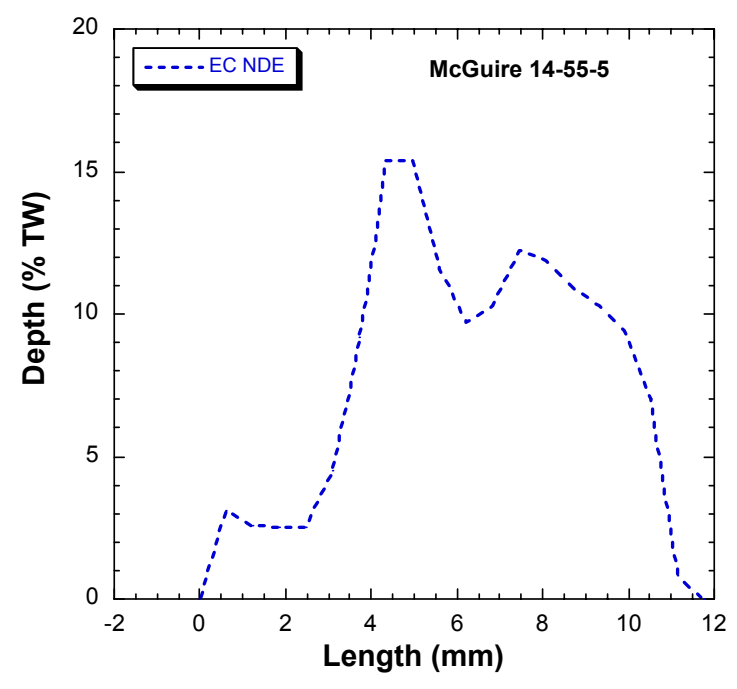

(a)

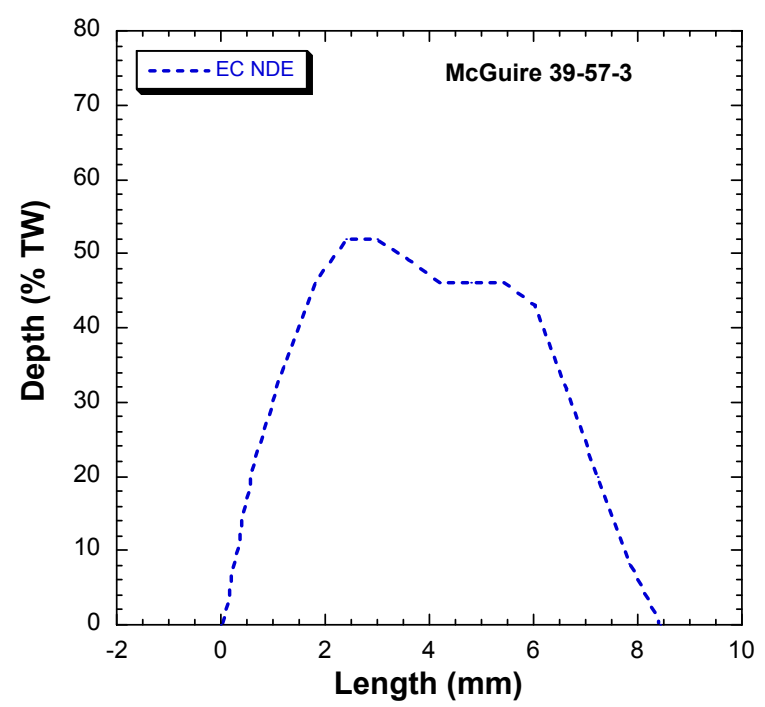

(b)

Figure 54. Crack depth profiles by EC/NDE and fractography of McGuire tube (a) 14-55-5 and (b) 3957-3.

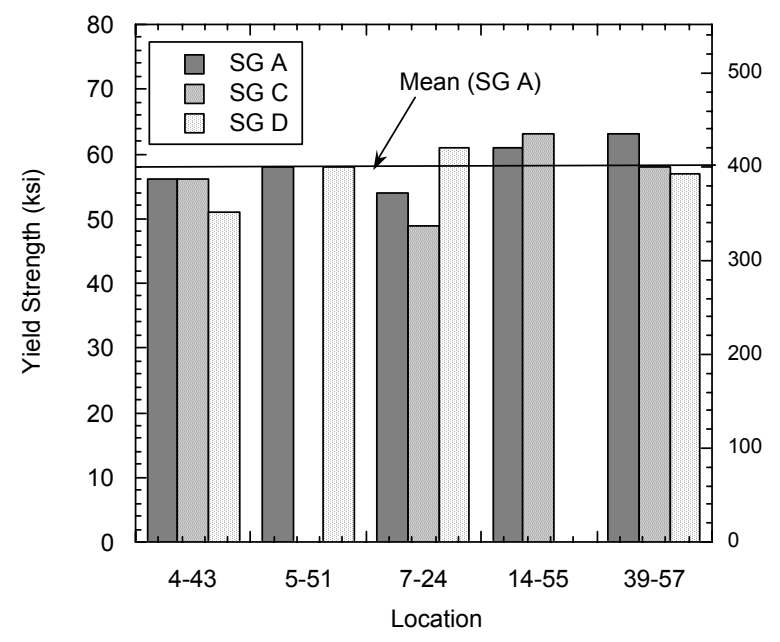

(a)

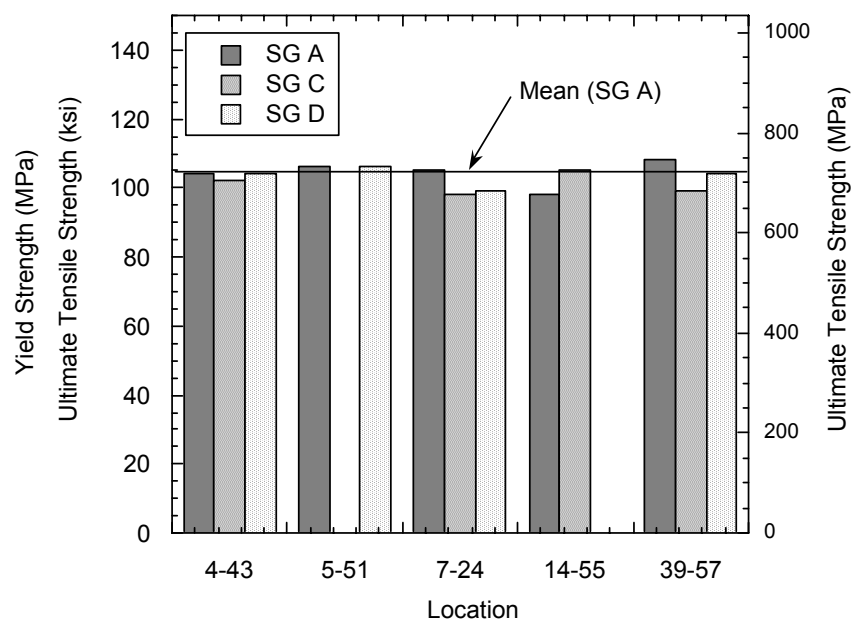

(b)

Figure 55. Reported (a) yield and (b) ultimate tensile strengths of tubes in McGuire Unit 1 SGs A, B, and C. Test specimens were obtained from SG $A$ at the row-column locations shown.

Alloy 600 tubes were at the high end, i.e., $S_{y}=400 \mathrm{MPa}(58.1 \mathrm{ksi})$ and $\mathrm{S}_{\mathrm{u}} 730 \mathrm{MPa}(105.8 \mathrm{ksi})$. Observed rupture pressures are plotted against predicted rupture pressures in Fig. 56 using high and average values of flow stress, respectively. The observed leak rates for test 4-43 are compared with predicted leak rates in Fig. 57 . The comparisons in Figs. 56 and 57 suggest that the observed results are consistent with the predicted results based on fractography data. Both the test and the predictions show a rapid increase of leak rate with pressure immediately after ligament rupture. Note that this specimen had an offset ligament (Type 4), as shown by 

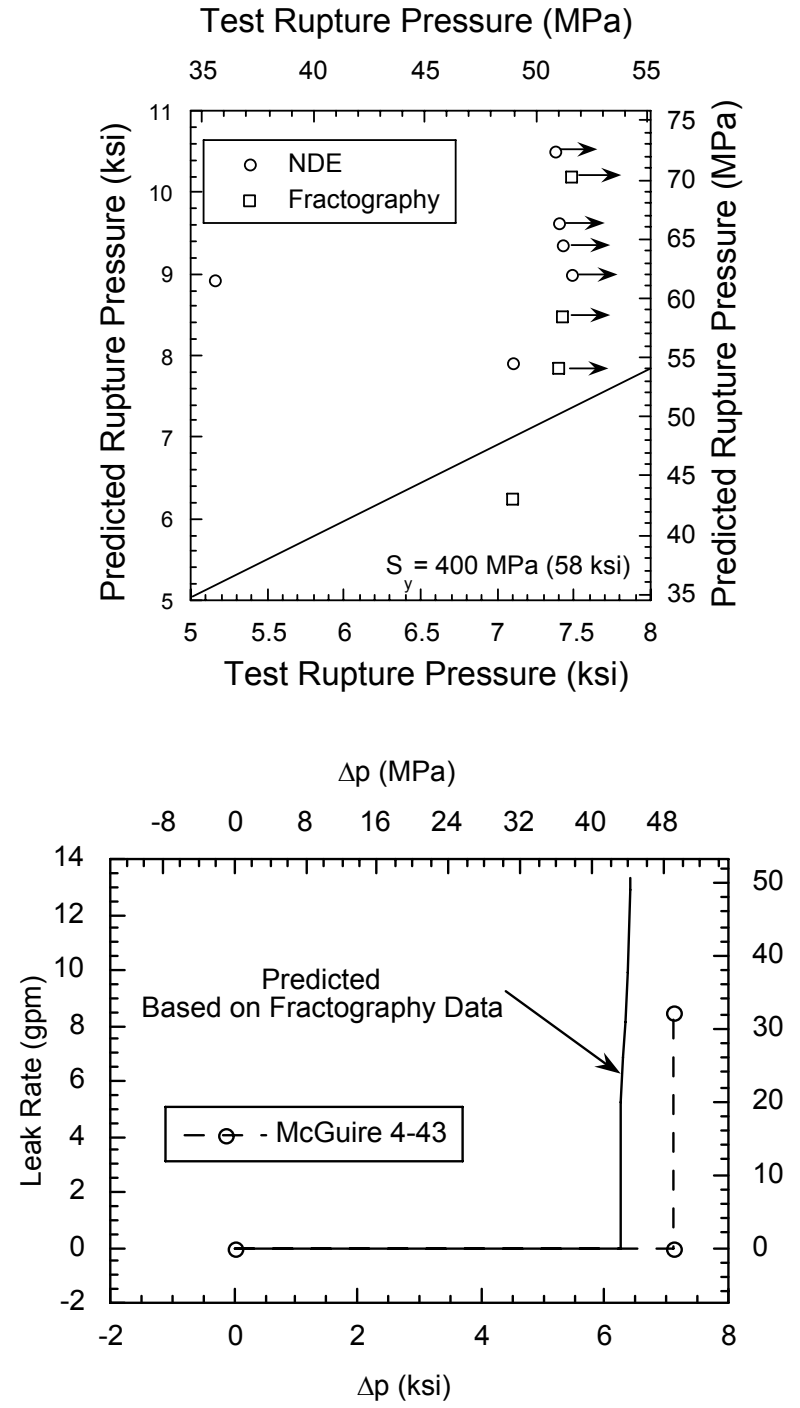

Figure 56.

Observed vs. predicted rupture pressures for McGuire SG tubes using reported value of flow stress. Right arrows indicate no rupture in the tests.
Figure 57. Observed and predicted pressure vs. leak rates for McGuire test 4-43.

the fractography depth data in Fig. 53a. Most of the SCCs were shallow and, consequently, did not rupture during the tests, in agreement with predictions using the higher flow stress. The only exception was test 59-17-2, which experienced ligament rupture at $36 \mathrm{MPa}(5.16 \mathrm{ksi})$ and was predicted to fail at $61 \mathrm{MPa}(8.9 \mathrm{ksi}$ ) based on the EC/NDE profile. The depth profile for the flaw in this specimen will be determined by fractography in the future. 


\section{Jet Erosion under Design Basis Accident Conditions}

Two basic mechanisms of erosion damage, droplet impact and cavitation, are believed to be associated with fluid jets. In the case of the former, the impact of water droplets give rise to fluctuating stresses in the target, which produce fatigue damage. In the case of the latter, bubbles form in the liquid stream and then collapse on impact, again producing fluctuating stresses and fatigue in the target.

Tests have been conduced to determine the susceptibility of steam generator tubes to erosive damage from impacting jets of superheated water or steam leaking from adjacent tubes. Most of the tests were performed using jets leaking from circular holes, though a few tests also used leaking tubes with laboratory-produced SCC flaws. In all cases, the distance between the leaking tube and the target tube was $6.35 \mathrm{~mm}\left(0.25 \mathrm{in}\right.$.), and the tubes were oriented to produce an impact angle of $90^{\circ}$ on the target tube. All tests were conducted in the high-temperature Pressure and Leak Rate Test Facility. The test duration was generally based on the hole leak rate, which is a function of the hole area and the pressure. Test times are constrained by the blowdown vessel capacity of $760 \mathrm{~L}$ ( $200 \mathrm{gal})$, though longer test times can be achieved by shutting down the facility, refilling the blowdown vessel, and restarting.

The target specimens were fabricated from 22.2-mm (7/8-in.)-diameter Alloy 600 tubing with a nominal wall thickness of $1.27 \mathrm{~mm}$ (0.050 in.). A cold-discharge machining method was used to avoid any mechanical or thermal working of the material. The target specimens were $6.35-\mathrm{mm}(0.25-\mathrm{in}$.) wide and 38.1-mm (1.5-in.) long, with four legs that attach to the leaking flawed tube to hold the target at a distance of $6.35 \mathrm{~mm}(0.25 \mathrm{in}$.) from the jet exit. Each leg is fastened to the flawed tube by four spotwelded fastening straps, and the escaping jet strikes the concave surface of the target specimen (Fig. 58 ).

Erosion tests were performed using jets from 1.59-, 0.79-, and $0.40-\mathrm{mm}(1 / 16,1 / 32$, and $1 / 64-\mathrm{in}$.)diameter EDM circular holes. The jets were produced using a tube internal pressure of $17.2 \mathrm{MPa}$ (2500 psi). The external pressure for most of the tests was zero, approximating MSLB conditions, but a few tests were performed with other external pressures. The test duration was typically $\approx 2 \mathrm{~h}$. A range of water temperatures was used to assess the influence of degree of subcooling on erosion behavior.

Figure 59 shows a close-up view of the jet impact zone for a test with a $0.79-\mathrm{mm}(1 / 32-\mathrm{in}$.)diameter hole, a temperature of $282^{\circ} \mathrm{C}\left(540^{\circ} \mathrm{F}\right)$, an internal pressure of $16.7 \mathrm{MPa}(2428 \mathrm{psi})$, and a back pressure of $3.7 \mathrm{MPa}(530 \mathrm{psig})$. Perceptible erosion of the $0.79-\mathrm{mm}(1 / 32-\mathrm{in}$.)-diameter hole occurred in the leaking tube. Higher-magnification SEM examinations of the edges of the hole verified the presence of erosion suggested in this optical photograph. The depth of material removed was estimated by using a scanning electron microscope with a phase-shift three-dimensional surface profiler. This instrument produces an image in which color or shading represents height or depth relative to a reference location. Figure 60 shows the phase-shift image of the jet impact zone shown in Fig. 59. The depths of various features for each scan, referenced relative to the uneroded surface of the specimen, are rendered in a different shade in the photograph. The deepest erosion penetration is $260 \mu \mathrm{m}$, or $\approx 21 \%$ of the tube wall thickness. 

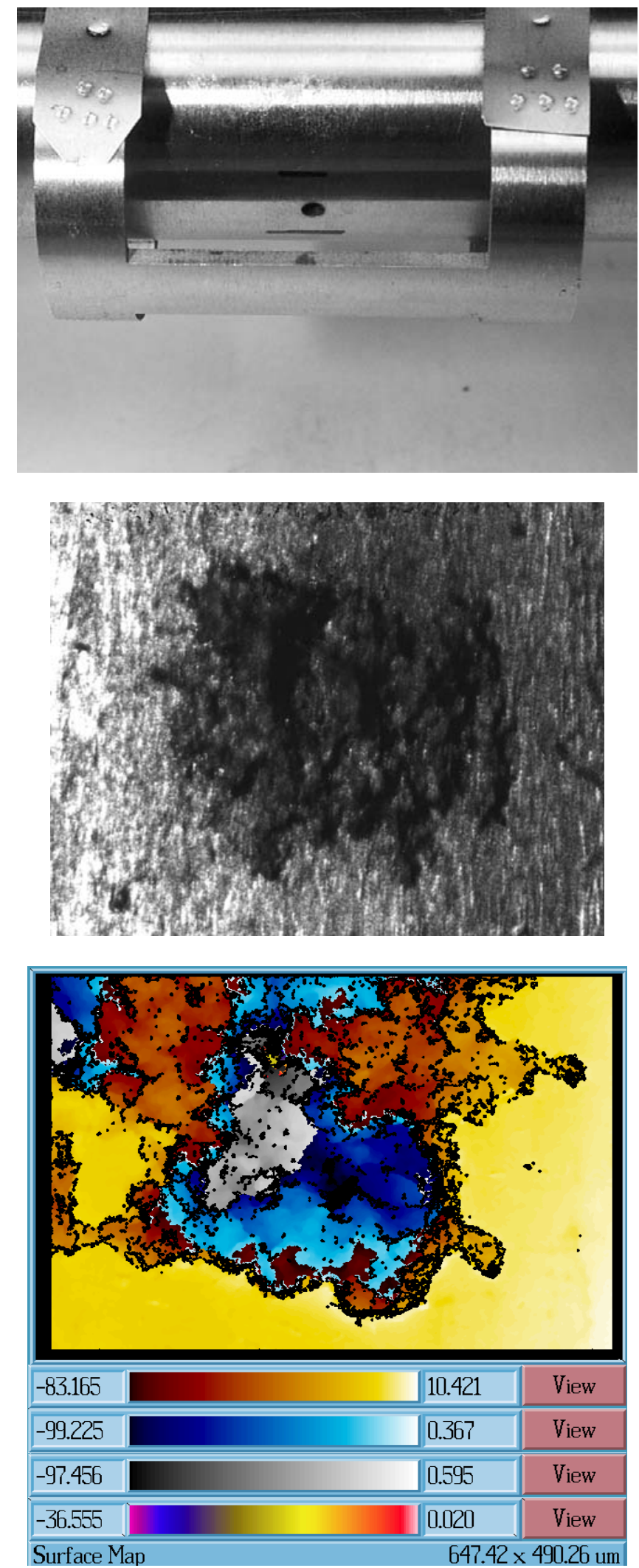

Figure 58.

Jet-impact erosion test setup showing circular EDM hole in Alloy 600 tube and Alloy 600 impact specimen fastened by spot-welded straps to the tube with a $6.35-\mathrm{mm}(0.25-\mathrm{in}$.) gap between the jet exit and the impact specimen.

Figure 59.

Close-up view of $0.79-\mathrm{mm}$ (1/32-in.) hole from jet-impact specimen after 265 min of testing at $282^{\circ} \mathrm{C}\left(540^{\circ} \mathrm{F}\right)$ and 17.2 $\mathrm{MPa}(2500 \mathrm{psig}$ ) with $3.7 \mathrm{MPa}$ (530 psig) back pressure.

Figure 60.

Depth of the erosion zone shown in Fig. 59, as determined using interferometric techniques. 
The test results for the erosion tests on circular orifices are summarized in Tables 3-5, The tests in Table 3 involved a significant amount of subcooling. An additional 16 erosion tests were conducted with 0.40 - and $0.79-\mathrm{mm}$ ( $1 / 64^{-}$and 1/32-in.)-diameter holes (Tables 4 and 5, respectively) to more thoroughly explore the parameters influencing jet-impingement erosion under prototypical conditions. The tests featured reduced levels of subcooling over a broader range of water temperature, $135-308^{\circ} \mathrm{C}$ $\left(275-587^{\circ} \mathrm{F}\right)$. Most of the tests were of $2-\mathrm{h}$ duration, but two of the tests with $0.79-\mathrm{mm}(1 / 32-\mathrm{in}$.)diameter holes lasted 4 and $6 \mathrm{~h}$ (see Table 5).

Figure 61 shows a plot of jet-induced erosion depth as a percent of specimen wall thickness as a function of temperature for both hole sizes. For the sake of completeness, also included are data from testing a $1.59-\mathrm{mm}\left(1 / 16^{-i n}\right.$. $)$-diameter hole with $282^{\circ} \mathrm{C}\left(550^{\circ} \mathrm{F}\right)$ water, which yielded $3.2 \%$ coupon penetration depth. This plot indicates that impact erosion depth varies with water temperature, and erosion rate is substantially reduced with decreasing and increasing subcooling on either side of the peak damage temperature range. Examination of the jet impact zones revealed that, as expected, for large amounts of subcooling, the impact zone is about the same diameter as the jet. For very small amounts of subcooling, the size of the impact zone is substantially larger than the initial jet diameter, indicating that flashing has occurred. The zone of peak erosion corresponds to a situation in which the impact zone is the same diameter as the jet. This suggests that the primary mechanism for erosion is cavitation due to bubble formation at the onset of two-phase conditions. Erosion rates are low in the purely singlephase regime (large subcooling) while in the two-phase region flashing occurs either in the tube wall or in the region between the tube and the target (small subcooling).

The temperature at which the peak erosion rate occurs varies with hole size, The peak erosion rate for the $0.40-\mathrm{mm}(1 / 64-$ in. $)$-diameter hole occurs in the range $182-210^{\circ} \mathrm{C}\left(360-410^{\circ} \mathrm{F}\right)$, while that for the $0.79-\mathrm{mm}\left(1 / 32-\mathrm{in}\right.$.)-diameter hole occurs in the range $271-288^{\circ} \mathrm{C}\left(520-550^{\circ} \mathrm{F}\right)$. This behavior is consistent with the primary damage mechanism being cavitation and reflects the degree of flashing of water to steam in the hole, with the smaller-diameter hole producing more flashing at a given temperature and consequently lower erosion. In addition, the temperature at which flashing becomes significant is lower for the smaller-diameter hole.

For the orifice flows considered here, the peak erosion rates occur for degrees of subcooling typical of the cold leg, where cracking is much less likely to occur. Erosion rates are much lower for conditions more typical of the hot leg. The trends observed with decreasing orifice size also suggest that the margin is even larger for actual stress corrosion cracks, since they typically would be even tighter than the $0.40-\mathrm{mm}(1 / 64-$ in. $)$-diameter hole.

Tests were planned to validate these results on more prototypical flaws, but to date only one test has been performed with a laboratory-produced ODSCC axial flaw. The nature of the flaws and the associated jets at $17.2 \mathrm{MPa}$ (2500 psi) is first evaluated in the room-temperature High-Pressure Test Facility, where visual observation of the flaw jet behavior and very accurate determination of flow rate are possible.

Specimen SGL818 was identified by NDE to be axial OD and nominally $10-\mathrm{mm}(0.4-$ in.) long, with greater than $95 \%$ penetration. At $17.2 \mathrm{MPa}$ ( $2500 \mathrm{psi})$ at room temperature, the leaking jet was fanshaped and somewhat rotated out of axial alignment, with a base length at the tube of $3.2 \mathrm{~mm} \mathrm{(1/8} \mathrm{in.);}$ at $6.35 \mathrm{~mm} \quad(1 / 4 \mathrm{in}$.) above the tube surface (where the coupon 
Table 3. Erosion data from jet-impact erosion tests utilizing jets from 1.59-, 0.79-, and $0.40-$ $\mathrm{mm}\left(1 / 16^{-}, 1 / 32-\right.$, and 1/64-in.)-diameter circular EDM holes impacting Alloy 600 erosion coupons positioned $6.35-\mathrm{mm}(0.25-\mathrm{in}$.) from the hole exit.

\begin{tabular}{ccccccc}
\hline $\begin{array}{c}\text { Jet Hole Diameter } \\
\text { mm (in.) }\end{array}$ & $\begin{array}{c}\text { Water } \\
\text { Temperature, } \\
{ }^{\circ} \mathrm{C}\left({ }^{\circ} \mathrm{F}\right)\end{array}$ & $\begin{array}{c}\text { Tube } \\
\text { Internal/External } \\
\text { Pressure, } \\
\text { MPa (psig) }\end{array}$ & $\begin{array}{c}\text { Test } \\
\text { Duration, } \\
\text { min }\end{array}$ & $\begin{array}{c}\text { Erosion Depth, \% } \\
\text { Wall Thickness }\end{array}$ \\
\hline 1.59 & $(1 / 16)$ & 282 & $(540)$ & $\begin{array}{c}16.7 / 0.04 \\
(2428 / 6)\end{array}$ & 34.1 & $\begin{array}{c}\text { (slight surface } \\
\text { burnishing) } \\
\text { (slight surface } \\
\text { burnishing) }\end{array}$ \\
0.79 & $(1 / 32)$ & 21 & $(70)$ & $\begin{array}{c}17.2 / 0 \\
(2500 / 0)\end{array}$ & 240 & 21 \\
0.79 & $(1 / 32)$ & 282 & $(540)$ & $\begin{array}{c}16.7 / 3.7 \\
(2428 / 530)\end{array}$ & 265 & 9 \\
0.40 & $(1 / 64)$ & 282 & $(540)$ & $\begin{array}{c}17.3 / 0 \\
(2502 / 0)\end{array}$ & 198 & 9 \\
\hline
\end{tabular}

Table 4. Erosion data from jet-impact erosion tests utilizing jets from $0.40-\mathrm{mm}(1 / 64$-in.)-diameter circular EDM holes striking Alloy 600 erosion coupons positioned $6.35 \mathrm{~mm}(0.25 \mathrm{in}$.) from the hole exit for various water temperatures. For all tests, the tube internal pressure was 16.8 MPa (2432 psig) with zero back pressure.

\begin{tabular}{ccccc}
\hline $\begin{array}{c}\text { Coupon } \\
\text { No. }\end{array}$ & $\begin{array}{c}\text { Water Temp., } \\
{ }^{\circ} \mathrm{C}\left({ }^{\circ} \mathrm{F}\right)\end{array}$ & $\begin{array}{c}\text { Test Duration, } \\
\text { min }\end{array}$ & $\begin{array}{c}\text { Erosion Depth, } \\
\text { \%wall thickness }\end{array}$ \\
\hline 21 & 289 & $(553)$ & 123 & 1.8 \\
24 & 239 & $(463)$ & 123 & 11.9 \\
26 & 209 & $(408)$ & 123 & 18.6 \\
28 & 182 & $(360)$ & 123 & 18.6 \\
29 & 135 & $(275)$ & 123 & 5.9 \\
\hline
\end{tabular}

would be located in the erosion test), its length had spread to $6.3-\mathrm{mm}(1 / 4-\mathrm{in}$.). The jet was nonuniform over its breadth. The measured leak rate for the flaw was $1.1 \mathrm{~kg} / \mathrm{min}(2.5 \mathrm{lb} / \mathrm{min})$ or $1.1 \mathrm{~L} / \mathrm{min}$ (0.3 gpm).

An erosion test at $288^{\circ} \mathrm{C}\left(550^{\circ} \mathrm{F}\right)$ and an internal pressure of $17.2 \mathrm{MPa}$ ( $2500 \mathrm{psi}$ ) was then performed with this flaw. After 123 min. of testing, no significant erosion of the target specimen was detected, with only very slight burnishing observed. Because this flaw was much tighter than the EDM holes, it would likely have higher frictional losses and hence a greater tendency for flashing under the same pressure and temperature conditions. Based on the orifice results, flashing results in a decreased erosion rate.

The SCC flaw in Specimen SGL 818 was opened in the High-pressure Test Facility by subjecting it to a pressure of $21.7 \mathrm{MPa}$ (3150 psi) to achieve a higher flow rate. It was then again used in an jetimpact erosion test under the same conditions as previously. The erosion coupon showed more burnishing than in the first test, but the erosion depth was still $<1 \%$. It appears that the flaw was still tight enough that flashing is still occurring either in the tube wall or in the gap between tube and coupon or both. 
Table 5. Erosion data from jet-impact erosion tests utilizing jets from $0.79 \mathrm{~mm}(1 / 32 \mathrm{in}$.)-diameter circular EDM holes striking Alloy 600 erosion coupons positioned $6.35 \mathrm{~mm}(0.25 \mathrm{in}$.) from the hole exit for various water temperatures. For all tests, the tube internal pressure was 16.8 MPa (2432 psig) with zero back pressure.

\begin{tabular}{ccccc}
$\begin{array}{c}\text { Coupon } \\
\text { No. }\end{array}$ & $\begin{array}{c}\text { Water Temp., } \\
{ }^{\circ} \mathrm{C}\left({ }^{\circ} \mathrm{F}\right)\end{array}$ & $\begin{array}{c}\text { Test Duration, } \\
\text { min }\end{array}$ & $\begin{array}{c}\text { Erosion Depth, } \\
\text { \%wall thickness }\end{array}$ \\
\hline 8 & 278 & $(532)$ & 123 & 28.0 \\
9 & 307 & $(586)$ & 123 & 4.6 \\
10 & 281 & $(537)$ & 369 & 28.1 \\
11 & 308 & $(587)$ & 246 & 7.9 \\
12 & 292 & $(558)$ & 124 & 14.0 \\
13 & 271 & $(519)$ & 123 & 27.8 \\
14 & 287 & $(548)$ & 127 & 13.0 \\
15 & 259 & $(499)$ & 123 & 14.0 \\
17 & 288 & $(550)$ & 123 & 15.2 \\
18 & 233 & $(451)$ & 124 & 17.0 \\
19 & 180 & $(356)$ & 123 & 15.6 \\
\hline
\end{tabular}

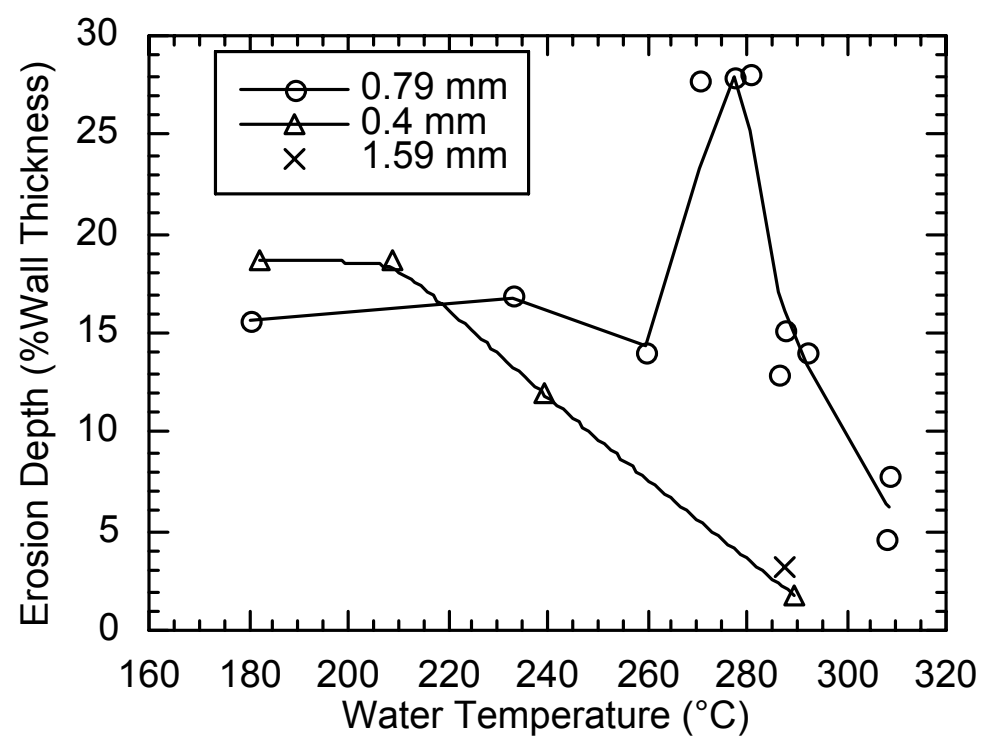

Figure 61.

Jet erosion penetration depth as a function of water temperature for circular EDM holes with 0.40 (triangles), 0.79-(circles), and 1.59-mm (cross) $(1 / 64,1 / 32$, and $1 / 16$-in.) diameter. For all tests, the tube internal pressure was $16.8 \mathrm{MPa}$ (2432 psig) with zero back pressure. Most tests were 123min duration. 


\section{Discussion and Conclusions}

Failure and leak rate tests at room temperature and $282^{\circ} \mathrm{C}$ have been conducted on SG tubes with OD PTW EDM notches. Notch length in these tests ranged from $6 \mathrm{~mm}(0.25 \mathrm{in}$.) to $38 \mathrm{~mm}$ (1.5 in.), and notch depths were 60,80 , and $90 \%$ (in addition to $100 \%$ TW. Based on a large body of data on Alloy 600 and other materials, the critical pressures and crack sizes for the unstable rupture (burst) of a thin-wall, internally pressurized-cylindrical shell with a single TW axial crack can be estimated from Eq. 1a):

$$
\mathrm{p}_{\mathrm{cr}}=\frac{\bar{\sigma} \mathrm{h}}{\mathrm{mR}}=\frac{\mathrm{p}_{\mathrm{b}}}{\mathrm{m}} \text {, }
$$

Extensive tests have shown that the following correlation for predicting ligament rupture pressure of rectangular as well as trapezoidal and triangular PTW flaws gives reasonable predictions for tests on tubes with axial notches, either shallow or deep (Eqs. 4a and 4b):

$$
\begin{aligned}
& \mathrm{m}_{\mathrm{p}}(\mathrm{ANL})=\frac{1-\alpha \frac{\mathrm{a}}{\mathrm{mh}}}{1-\frac{\mathrm{a}}{\mathrm{h}}} . \\
& \alpha=1+\beta\left(\frac{\mathrm{a}}{\mathrm{h}}\right)^{2}\left(1-\frac{1}{\mathrm{~m}}\right),
\end{aligned}
$$

where $\beta=1$.

A procedure has been developed for defining an equivalent rectangular crack for an arbitrarily shaped notch or (e.g., ODSCC) crack, based on EC/NDE data. Structural and leak rate analyses of the flaws and comparisons with experimental data show that the ligament failure pressure in nonrectangular notches or SCCs can be predicted reasonably well by a flow stress model for rectangular PTW cracks, when the actual crack profile is replaced by an equivalent rectangular crack.

Interaction effects between two or more TW notches, as influenced by ligaments separating the notches, were determined by finite element analyses. For type 4 (staggered) axial notches with two 6or $13-\mathrm{mm}$ cracks, the ligament width has to be $\geq 0.8$ to $1.1 \mathrm{~mm}$ in order for the notch strength (i.e., unstable burst pressure) to exceed that of the notches without the ligament. For type 2 (colinear) notches of similar size, the equivalent ligament width has to be greater than 1.8 to $2.5 \mathrm{~mm}$.

Interaction effects between two or more PTW notches were estimated by the equivalent rectangular crack approach. The inter-notch ligament width beyond which the two notches do not interact (from the viewpoint of through-thickness ligament rupture pressure) depends on the notch depth and length. A 3-mm (0.1-in.) wide ligament increases the through-thickness ligament rupture pressure by $\approx 30 \%$, with the axial ligament (type 2 ) having a slightly higher strengthening effect than the circumferential ligament (type 4). For smaller ligament widths, both types of ligaments have comparable strengthening effect. 
An empirical approach for calculating crack growth by stable ligament rupture has been developed by an extension of the equivalent rectangular crack method. This approach has been used to calculate the incremental ligament rupture of nonrectangular notches and stress corrosion cracks.

Leak rates (Q) for tests on specimens with EDM notches were predicted reasonably well by using Eq. 13a for single-phase flow through smooth circular orifices by replacing the orifice area by the crack opening:

$$
\mathrm{Q}=0.6 \mathrm{~A} \sqrt{\frac{2 \Delta \mathrm{p}}{\rho}}
$$

where for axial cracks, the crack opening area is given by Eq. 2:

$$
\mathrm{A}=2 \pi \mathrm{c}_{\mathrm{e}}^{2} \mathrm{~V}_{\mathrm{o}} \sigma / \mathrm{E}
$$

and for circumferential cracks, $\mathrm{A}$ is given by Eq. 7a:

$$
\mathrm{A}=\frac{\pi \mathrm{pR}^{2}}{\mathrm{E}} \mathrm{B}
$$

The calculated crack opening displacements (areas) for rectangular and trapezoidal TW notches are in reasonable agreement with measured values. The above set of equations can predict the ligament rupture pressures and leak rates for rectangular and trapezoidal EDM notches at both room temperature and $282^{\circ} \mathrm{C}$ if the appropriate densities of water are used.

The potential for flashing and two-phase flow at elevated temperatures suggests that the single-phase leak rate from Eq. 13a must have limits of applicability at elevated temperature. Amos and Schrock ${ }^{17}$ conducted a series of tests on two-phase critical flow. These tests were conducted not on flawed pipes but on rectangular slits in a plate of thickness $63.5 \mathrm{~mm}(2.5 \mathrm{in}$.) with the height of the slits varying between 1.27 and $3.81 \mathrm{~mm}$ (0.005 and $0.015 \mathrm{in}$.). Their results on flashing are plotted in Figs. 62a-b. In this figure, the dashed lines indicate the minimum subcooling necessary for flashing to occur at the exit plane as a function of stagnation pressure. Results are shown for two values of $L / D$, where $L$ is the flow path length (wall thickness) and $D$ is hydraulic diameter (defined by Amos and Schrock ${ }^{17}$ as $4 A / P$, where $A$ is the area and $P$ the perimeter of the channel). The test data appear to show that the minimum subcooling initially increases with stagnation pressure but reaches a peak beyond which it either drops slightly $(L / D=85)$ or drops substantially $(L / D=135)$. Note that the peak value of subcooling increases from $20^{\circ} \mathrm{C}$ (stagnation pressure $=7 \mathrm{MPa}\left[1 \mathrm{ksi}\right.$ ) to $26^{\circ} \mathrm{C}$ (stagnation pressure $=12 \mathrm{MPa}$ [1.7 ksi]). Leak rate tests have been conducted at ANL on Alloy 600 tube specimens with EDM notches and stress corrosion cracks using a stagnation pressure of $18 \mathrm{MPa}(2.56 \mathrm{ksi})$, stagnation temperature of $282^{\circ} \mathrm{C}$ (subcooling of $\sim 72^{\circ} \mathrm{C}$ ) and ambient downstream pressure. At full pressure, the L/D value for EDM notches tested is about 1 ( 3 at zero pressure), and that for the $13-\mathrm{mm}(0.5-\mathrm{in}$.) long SCC flaws is about 2. Comparing these numbers with Figs. $62 a-b$, we concluded that the flow in all the tests conducted to date was single phase, and flashing would not be expected to occur within the tube wall. Even for a tight stress corrosion crack of $1.3 \mathrm{~mm}(0.05 \mathrm{in}$.), L/D is $\sim 250$. Thus according to the data generated by Amos and Schrock. ${ }^{17}$ two-phase flow should not occur in EDM slots and may not occur even in stress corrosion cracks in steam generator tubes at the temperature and pressure used for the ANL tests. However, the flow rate would be reduced with increasing L/D ratio (because of friction) and increasing back pressure. 


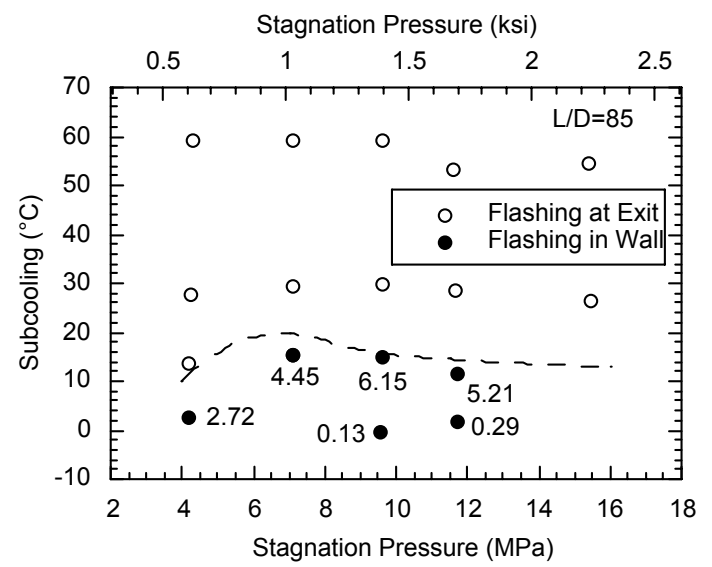

(a)

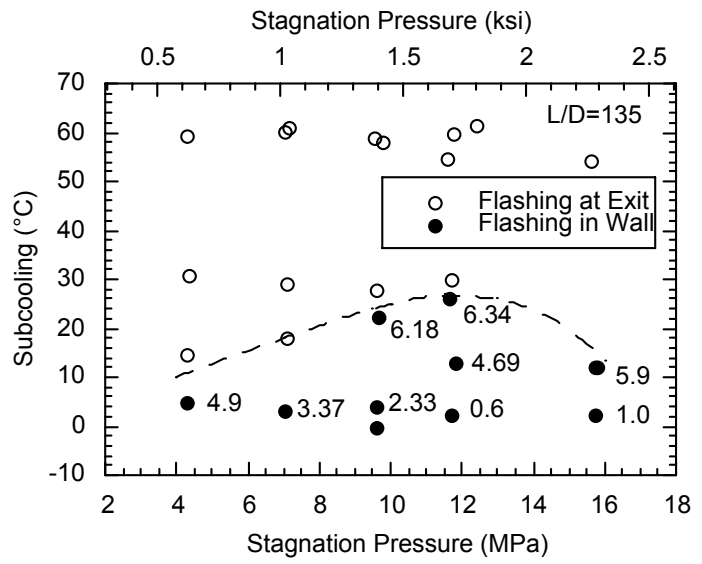

(b)

Figure 62. Test results from Amos and Schrock ${ }^{17}$ on flashing as a function of stagnation pressure and subcooling for $(a) L / D=85$ and $(b) L / D=135$. Numbers next to symbols denote location of flashing in $\mathrm{cm}$ from entrance (wall thickness $=6.35 \mathrm{~cm}$ ).

Tests have been performed on laboratory-degraded tubes containing $10-15 \mathrm{~mm}(0.39-0.55 \mathrm{in}$.)long axial ODSCC in 22-mm (7/8-in.)-diameter Alloy 600 tubing. Some of the tubes had lower flow stress because they had received a high-temperature anneal. The predicted ligament rupture pressures and leak rates for these specimens, based on depth profile by fractography, are in reasonable agreement with test results. Predictions based on EC/NDE profiles are less accurate than those based on fractography. Prediction of rupture pressure and leak rate for specimens without the high temperature anneal has been less successful for the tests at $282^{\circ} \mathrm{C}$, because such specimens start leaking at very low pressures and experience a time-dependent increase of leak rate under constant pressure hold. Currently, we do not have analytical or empirical methods for predicting such crack growth at low temperature.

Six pressure tests have been conducted on tubes with field-induced ODSCC from a retired McGuire SG in the High Pressure Test Facility at room temperature. Due to the shallow nature of these flaws, four of them did not show any leakage up to a pressure of $52 \mathrm{MPa}(7.5 \mathrm{ksi})$. The predicted rupture pressures and leak rates for these tubes are consistent with the observed behavior.

Tests have been conduced to determine the susceptibility of steam generator tubes to erosive damage from impacting jets of superheated water or steam leaking from adjacent tubes. The tests show that erosion depth varies with water temperature and there is a substantial reduction in erosion rate with decreasing and increasing subcooling on either side of the peak damage temperature range. The peak erosion rates occur for subcooling typical of the cold leg, where, however, cracking is much less likely to occur. Erosion rates are much lower for conditions more typical of the hot leg. Even in the case of the cold leg where the erosion rates are higher, the likelihood of failure propagation by jet erosion appears to be very low.

\section{References}

1. S. Majumdar, W. J. Shack, D.R. Diercks, K. Mruk, J. Franklin, and L. Knoblich, "Failure behavior of internally pressurized flawed and unflawed steam generator tubing at high temperatures Experiments and comparison with model predictions," NUREG/CR-6575, ANL-97/17, Argonne, IL, 1998. 
2. S. Majumdar, K. Kasza, and J. Franklin, "Pressure and leak-rate tests and models for predicting failure of flawed steam generator tubes," NUREG/CR-6664, ANL-99/23, Argonne, IL, 2000.

3. G. T. Hahn, M. Sarrate, and A. R. Rosenfield, "Criteria for crack extension in cylindrical pressure vessels," Int. J. Fracture Mech. 5, No. 3, pp. 187-210, 1969.

4. F. Erdogan, "Ductile failure theories for pressurized pipes and containers," Int. J. of Pres. Ves. \& Piping, 4, pp. 253-283, 1976.

5. A. Zahoor, "Ductile Fracture Handbook, "Electric Power Research Institute, Palo Alto, CA, 1989.

6. J. M. Alzheimer, R. A. Clark, C. J. Morris, and M. Vagins, "Steam Generator Tube Integrity Program, Phase I Report," NUREG/CR-0718, PNL-2937, Richland, WA, 1979.

7. M. F. Kanninen, A. Zahoor, G. M. Wilkowski, I. Abou-Sayed, C. Marschall, D. Broek, S. Sampath, C. Rhee, and J. Ahmad, "Instability predictions for circumferentially cracked Type 304 stainless steel pipes under dynamic loading," EPRI NP-2347 (Vol. 1: Summary; Vol. 2: Appendices), Electric Power Research Institute, Palo Alto, CA,1982.

8. S. Ranganath and H. S. Mehta, "Engineering methods for the assessment of ductile fracture margin in nuclear power plant piping," in Fracture Resistance Curves and Engineering Applications, ASTM STP 803, Philadelphia, 1983.

9. B. Cochet, J. Engstrom, and B. Flesch, "PWR Steam generator tube and tube support plate plugging criteria," Paper 4.1, Steam Generator Tubes Mechanical, LBRB, and Probabilistic Studies, EDF, France, 1990.

10. S. Majumdar, "Failure and leakage through circumferential cracks in a steam generator tubing during accident conditions," Int. J. of Pres. Ves. \& Piping, 76, pp. 839-847, 1999.

11. P. C. Paris and H. Tada, "The application of fracture proof design methods using tearing instability theory to nuclear piping postulating circumferential TW cracks," NUREG/CR-3464, Washington, DC, 1983.

12. R. Kurihara, S. Ueda, and D. Sturm, "Estimation of the ductile unstable fracture of pipe with a circumferential surface crack subjected to bending," Nucl. Eng. Design, 106, 1988.

13. E. Smith, "Factors influencing the crack-system compliance of a piping system," Int. J. Pres. Ves. \& Piping, 75, pp. 125-129, 1998.

14. G. M. Wilkowski, Nucl. Eng. and Des. 98, p. 195, 1987.

15. P. Hernalsteen, "Structural and Leakage Integrity of Tubes Affected by Circumferential Cracking," NUREG/CP-0154, Proc. CNRA/CSNI Workshop on Steam Generator Tube Integrity in Nuclear Power Plants, Oak Brook, IL, Oct. 30-Nov. 2, 1995.

16. K. E. Kasza, S. Majumdar, and J. Muscara, "Steam generator tube integrity testing/analysis," Proc. SmiRT-15 Conference, Seoul, Korea, 1999. 
17. C. N. Amos and V. E. Schrock, "Two-phase critical flow in slits," Nucl. Sci. Eng., 88, No. 26, pp. 1-274, 1984. 
C FORM 335

89)

CM 1102,

1,3202
U. S. NUCLEAR REGULATORY COMMISSION

\section{BIBLIOGRAPHIC DATA SHEET}

(See instructions on the reverse)
1. REPORT NUMBER

(Assigned by NRC. Add Vol., Supp., Re and Addendum Numbers, if any.)

NUREG/CR-XXXX

ANL-01/34

3. DATE REPORT PUBLISHED

MONTH

4. FIN OR GRANT NUMBER

W6487

6. TYPE OF REPORT

Technical; Topical

7. PERIOD COVERED (Inclusive Dates)

S. Majumdar, S. Bakhtiari, K. Kasza, and J. Y. Park

DERFORMING ORGANIZATION - NAME AND ADDRESS (If NRC, provide Division, Office or Region, U.S. Nuclear Regulatory Commission, and mailing address; if contractc rovide name and mailing address.)

Argonne National Laboratory

9700 South Cass Avenue

Argonne, IL 60439

PONSORING ORGANIZATION - NAME AND ADDRESS (If NRC, type "Same as above": if contractor, provide NRC Division, Office or Region, U.S. Nuclear Regulatory Commission, and mailing address.)

Division of Engineering

Office of Nuclear Regulatory Research

U. S. Nuclear Regulatory Commission

Washington, DC 20555

SUPPLEMENTARY NOTES

ABSTRACT (200 words or less)

This report summarizes models for the prediction of failure pressures and leak rates under normal operation and design-basis accic conditions in steam generator tubes with axial and circumferential cracks. These models were first validated through failure and leak tests at room temperature and at $282^{\circ} \mathrm{C}$ on tubes with rectangular, triangular, and trapezoidal notches fabricated by electrodische machining. They were then compared with failure and leak rate tests conducted on tubes with laboratory-generated outer-diam stress corrosion cracks and steam generator tubes with field-induced stress corrosion cracks, which have highly complex morphol Complex crack profiles are addressed using a model based on the concept of equivalent rectangular cracks. The predictions of the mo are in reasonable agreement with test results, the time-dependent initiation and increase of leak rates observed in some tests canno predicted by the model. 
